\title{
WestVirginiaUniversity
}

THE RESEARCH REPOSITORY @ WVU

Graduate Theses, Dissertations, and Problem Reports

2009

\section{Success from the voices of educators}

\author{
Katherine Eddy Cox \\ West Virginia University
}

Follow this and additional works at: https://researchrepository.wvu.edu/etd

\section{Recommended Citation}

Cox, Katherine Eddy, "Success from the voices of educators" (2009). Graduate Theses, Dissertations, and Problem Reports. 2892.

https://researchrepository.wvu.edu/etd/2892

This Dissertation is protected by copyright and/or related rights. It has been brought to you by the The Research Repository @ WVU with permission from the rights-holder(s). You are free to use this Dissertation in any way that is permitted by the copyright and related rights legislation that applies to your use. For other uses you must obtain permission from the rights-holder(s) directly, unless additional rights are indicated by a Creative Commons license in the record and/ or on the work itself. This Dissertation has been accepted for inclusion in WVU Graduate Theses, Dissertations, and Problem Reports collection by an authorized administrator of The Research Repository @ WVU.

For more information, please contact researchrepository@mail.wvu.edu. 
Success from the Voices of Educators

Katherine Eddy Cox

Dissertation submitted to the

College of Human Resources and Education

at West Virginia University

in partial fulfillment of the requirements

for the degree of

Doctor of Education

in

Curriculum and Instruction

Ardeth Deay, Ph.D., Chair

Elizabeth Juckett, Ph.D.

Patricia Obenauf, Ed.D.

Steven Rinehart, Ed.D.

Samuel Stack, Ph.D.

Jacqueline Webb-Dempsey, Ph.D.

Department of Curriculum and Instruction

Morgantown, West Virginia

2009

Keywords: Teacher Success, Teacher Voice

Copyright 2009 Katherine Eddy Cox 


\section{ABSTRACT \\ Success from the Voices of Educators}

\section{Katherine Eddy Cox}

This study examines teachers' conceptions of success through interviews of fourteen educators from a rural county in a Mid-Atlantic state. The results find that the critical elements of success are student-oriented, practice-oriented, and policy-oriented; the consensus definition of success is caring for individual students; and the beliefs and values of educators are in making a difference for every student. Relationships, joy in learning, and fair testing are enabling of success within the community and culture studied. In terms of challenges and needs-parents are often named as the biggest barrier to success; secondly, having time to teach as well as possible; and, lastly, being able to teach well given the vast number of content standards the teachers are expected to cover. In all interviews, hope about education outweighs frustrations in the voices of successful educators.

The study includes triangulation through multiple participants, multiple data sources (interviews and documents), multiple perspectives (teachers and administrators), and member checking. From the pooled participants' definition of success to the emergent themes of each type of perspective, patterns emerge to address the research questions and the literature review. The most central conceptualization of success is individual student learning through the engaging moment, the steady relationships, and the supportive community that occur in successful schools. 


\section{DEDICATION}

To the many successful educators in my life who have inspired me through their enthusiasm, their mentoring, their talents, and their hard work, beginning with the first, best educator in my life who raised me with love that has sustained me throughout my lifetime, my mother McKee. 


\section{ACKNOWLEDGEMENTS}

I would like to acknowledge all the people who have made this dissertation possible, from my entire dissertation committee and especially its dedicated chair, Dr.

Ardeth Deay, to the fourteen gracious participants who were truly inspirational to interview. I would also like to acknowledge my doctoral cohort who helped support me through the writing process. My friends and family have also been patient and supportive as I worked on the several drafts that became this final version of my dissertation. 


\section{TABLE OF CONTENTS}

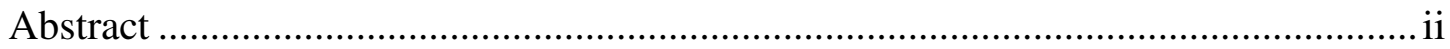

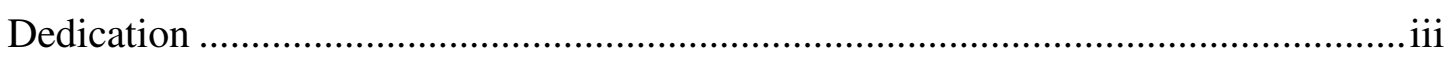

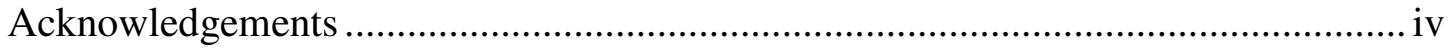

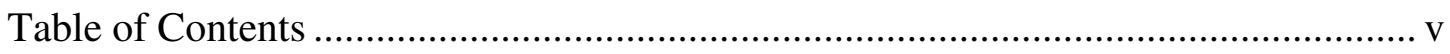

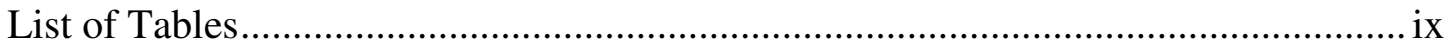

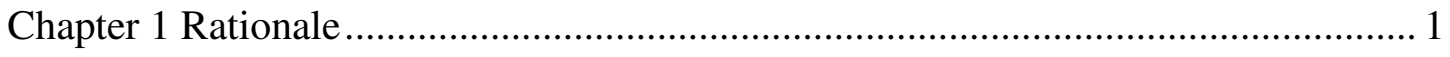

Introduction to the Topic ..................................................................... 1

Statement of the Problem ................................................................. 2

Purpose of the Study ......................................................................... 4

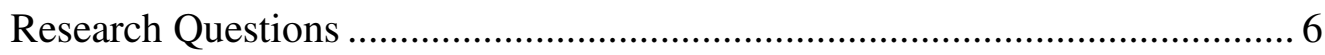

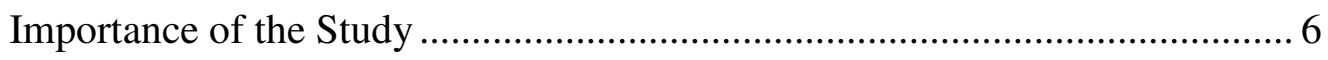

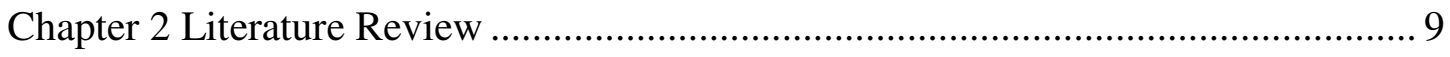

1. Section 1 Quality of Life-Affect and Core Beliefs............................... 10

2. Section 2 Quality of Teaching-Teacher Education and Teaching

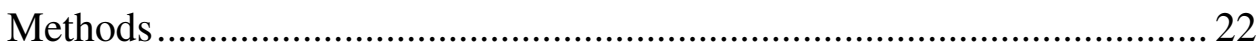

3. Section 3 Quality of Educational Reform — Community and Culture ....... 32

4. Section 4 Brief Summary of Literature Review .................................... 43

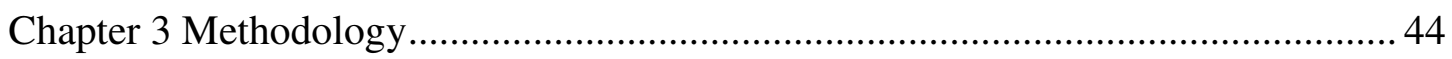

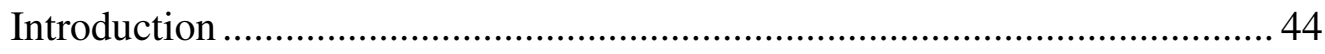

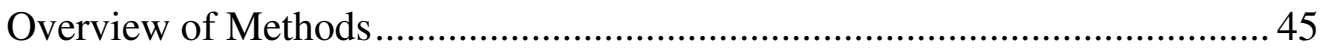

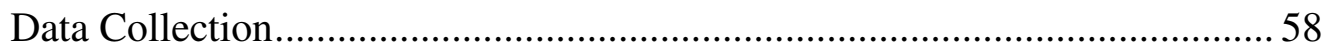

Document Analysis ............................................................................... 59 


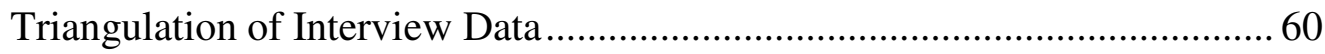

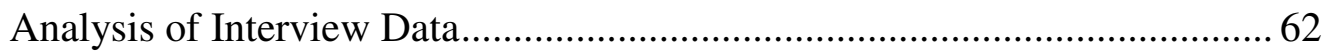

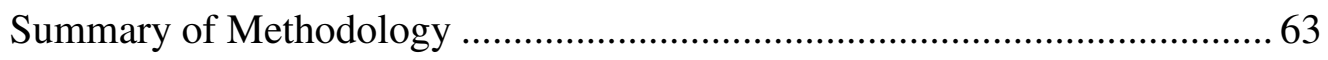

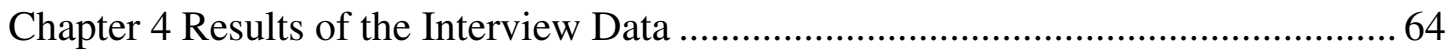

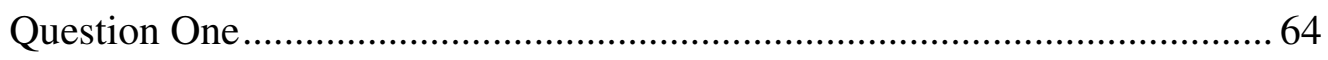

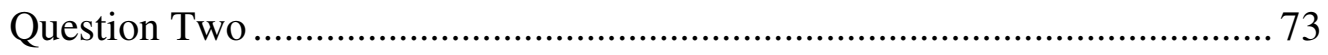

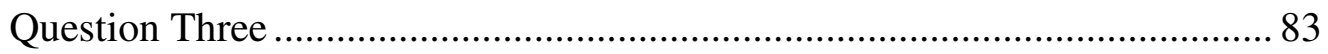

Question Four ................................................................................... 94

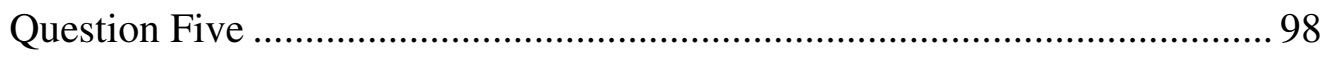

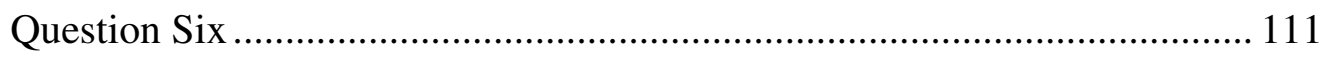

Question Seven ........................................................................ 116

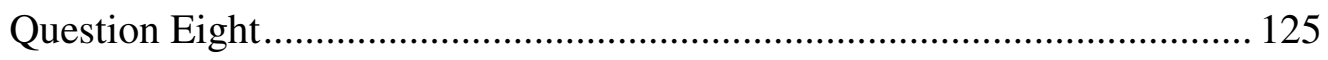

Question Nine ......................................................................... 133

Chapter 5 Results Answer Research Questions .............................................. 141

Data Answers Research Questions..................................................... 141

Research Question One .............................................................. 141

Overall Findings Address Research Question One ....................... 141

Interview Data Addresses Research Question One........................ 143

Secondary Sources Address Research Question One .................... 144

Research Question Two ............................................................. 147

Overall Findings Address Research Question Two ....................... 147

Interview Data Addresses Research Question Two ....................... 148

Secondary Sources Address Research Question Two..................... 149 
Research Question Three

Overall Findings Address Research Question Three

Interview Data Addresses Research Question Three

Secondary Sources Address Research Question Three.

Chapter 6 Conclusions

Similarities and Differences Among Research Data............................... 153

Teachers_Emergent Themes .................................................. 154

Overall Findings Address Teachers' Emergent Themes....... 154

Interview Data Addresses Teachers' Emergent Themes....... 155

Secondary Sources Address Teachers' Emergent Themes ... 159

Principals_Emergent Themes.................................................... 160

Overall Findings Address Principals' Emergent Themes ..... 160

Interview Data Addresses Principals' Emergent Themes ..... 161

Deputy Superintendent of Schools_-Emergent Themes

Overall Findings Address Deputy Superintendent's

Emergent Themes.

Interview Data Addresses Deputy Superintendent's

Emergent Themes. 172

Pooled Population-Emergent Themes 174

Tensions in Emergent Themes 175

Interviews Relate to Literature Review 177

Implications for Further Research ................................................. 180

Implications for Teacher Preparation and Professional Development 183 


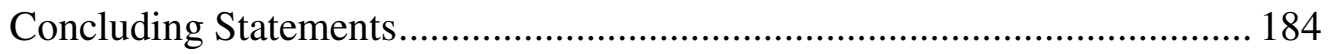

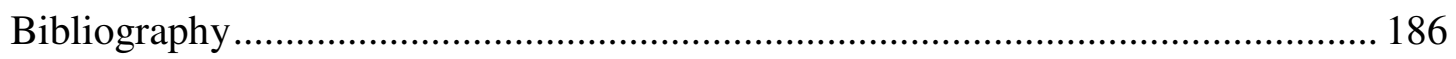

Appendix A: Teacher Interview Protocol and Letter .............................................. 194

Appendix B: Principal Interview Protocol and Letter.............................................. 196

Appendix C: Deputy Superintendent Interview Protocol and Letter ......................... 198

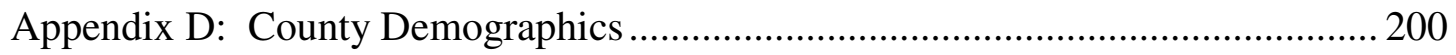

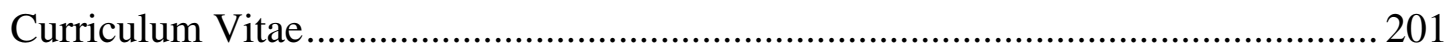




\section{LIST OF TABLES}

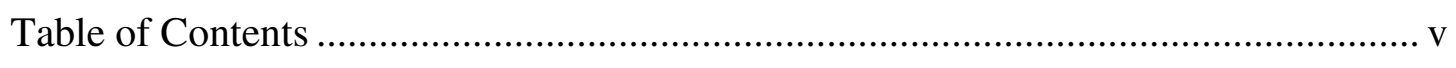

Table 1: Protocols Address Research Questions ................................................. 58

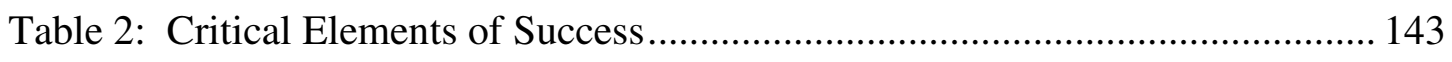

Table 3: Which Questions from the Interviews Relate to the Literature Review .... 177

Table 4: Number of Participants Discussing Themes from Literature Review ....... 178 


\section{CHAPTER I}

\section{RATIONALE}

\section{Introduction to the Topic}

Teachers' voices operate in a climate of political change and policy reform, while addressing individual differences in students and personal relationships within the classroom and the school culture. Theories of public education informing reform movements need to be accurate about the needs of the public and to listen to the voices of the professionals involved in helping students' lives if public-spirited reform is to take place.

The importance of hearing teachers' voices on success is that they give a focus on teaching as process and as an effort to influence ongoing learning and thinking in individual students, where the focus on numeric measures of learning leaves out development, selfconcept, and desire. Teachers influence lives. Their dialoguing on the subject of success shows how. The rationale for studying teachers' perceptions of their success is based on three principles-1. the principle of encouraging healthy and effective teacher-student relationships, so that a classroom is working together on improving the quality of life of each person involved in the learning process, 2 . the principle of enabling teachers better to reach their students through well-honed curriculum and thoughtful assessment, 3. the principle of seeing that educational reform is in touch with the practical work of teaching in culturally diverse settings. If educators are to protect their assets - their real successes - they need a language of success that can count their assets with sensitivity.

Teachers have many ways to measure and understand achievement, and when they voice their views of curriculum and instruction, they supplement existing literature about 
success in education. If there is a state-of-the-art in education, then collecting "in vivo" data helps one to understand that state-of-the-art.

\section{Statement of the Problem}

According to the literature, the greatest reward in teaching is feeling that the teacher helps students' needs. A teacher steers her practice in part by classroom climate and affective measures of success such as students' self-esteem and motivation in her students (Powell, 2004, p. 1). Her own beliefs and education allow her to work more closely with students' development while using the curriculum to engage her class and lead their knowledge-base forward through linking it to their experience (Stumbo, 1999, pp. 170-177). Working with large diverse classes limits what a teacher can do, and the range of U.S. teachers' experiences is shaped by socioeconomic status (SES), culture, and community just as the students' experiences in school are shaped by these factors (Rothstein-Fisch, Trumbull, Isaac, Daley \& Perez, 2003, p. 124). The literature defines effective teaching, but it is not always reflective of the variety of voices of differing teachers. Looking at voice allows inspection of the teachinglearning process and not just a numerical outcome measure of quality.

The one article in the Educational Resources Information Center (ERIC) database on "teacher voice" and reflection within a single school district is entitled, "Teachers' Voices: Reflections on the Boston University/Chelsea Public Schools Partnership and its Effect on the Literacy Initiatives" (Birmingham \& Garnick, 1994). Birmingham and Garnick study "the insights of teachers... [based on] a three-hour conversation [with] five teachers with histories of sustained participation in the literacy initiatives" (p. 1). Birmingham and Garnick make many observations about professional development, a form of teacher education. "Trust is a 
prerequisite condition for collaborative educational change... it was very important that the School of Education professors...saw firsthand what we were dealing with...there is no quick fix for inner city educational issues...The only agenda was the kids" (Birmingham \& Garnick, 1994, p. 2). The teachers feel close to the needs of their diverse students. The teachers in this article also suggest their beliefs shifting and being created newly through transformative teaching methods which in turn work to transform the teacher's understanding of herself. "I've shifted from teacher-based instruction with emphasis on skills to process-based instruction with a student-centered learning environment. I've come to an understanding about what I am doing and why I'm doing it" (p. 3). Beliefs and methods work together for these teachers, as in, "I think that flexible grouping helps to give students an opportunity to react to each other, and it allows teachers to address individual student needs" (p. 3).

Teachers' voices often describe growth. To research teachers' voice gives a strong understanding of success as subjectively articulated from the classroom. Birmingham and Garnick find that teacher education which gives teachers a voice both models teaching and enables a more focused understanding of the goals of a teacher as a leader of her students. The faculty at Boston University helped the teacher articulate for herself three goals of teaching—giving "information, inspiration, and support."

A good leader I think empowers the people, and then guides them...I was thinking that Boston University faculty have brought me information, inspiration, and support. I started to think that's really what we want to bring to our children, information, inspiration, and support...It's more empowering to guide growth rather than enforce change. (p. 5) 
When teachers conceptualize success and voice their goals, they add to the available literature a re-thinking of standards and of the relationship between the teacher and the student.

\section{Purpose of the Study}

The purpose of the study is to determine teachers' conceptions of success and to summarize their conceptions accurately as expressed in face-to-face interviews. The idea of "voice" in teaching means teachers expressing themselves and their knowledge and expertise with some present-tense spontaneity and some thoughtful understanding and conceptualization of their work. There is a gap in educational research when one searches for articles on successful teachers' voices. During the classroom visits, data was collected to address a gap in the literature in the important area of successful educators' voices. Working with "in vivo" language and discussion of lived experience brings examples of process and how teachers work with students, not just numeric outcome measures of success.

In the Birmingham and Garnick article, the partnership emphasizes voice and the affective and social implications of teachers' voice. Interviewing and analyzing voices in this study on success include some of the same topics—-belief in making a difference and socioemotional development. Teachers' voices tend to hold some beliefs in common according to the literature. Successful teachers feel in touch with students' needs and with their own desire to meet these needs (Birmingham \& Garnick, 1994). Teachers explain their qualifications and their accomplishments in terms of "inspiration" and "support" and not just “information" passed on to passive students. 
The purpose of the interviews in this study is to find several opinions and conceptions of success. The article from Boston on "voice" addresses many of the types of answers that these interviews may prompt just because it considers voice. One teacher explains her improved confidence in the following words: "Someone asked me to go to another school system to speak. I went to a [suburban community] to present what we have learned about literacy. I feel confident and proud to share our students' work" (p. 4). The standards of affect and community as measures of success come out through the teacher's voice. The teacher's motivations are quickly revealed through her voice as pride in her work with her children and as confidence built through good work. When viewed through teachers' voices, in the Birmingham and Garnick article, the success in the inner city school is clear. Articles on successful teachers' voices, however, are extremely rare, and the importance of live dialogue and personal narrative in describing teachers' work — the feelings involved, the relationships created, and the efforts to give to students-may best be found in books like John Goodlad's Romances with Schools (2004) or Jesse Stuart's The Thread That Runs So True (1949).

This literature illustrates the strength and importance of professional growth as an aspect of teacher success. An inner city school or a rural school can give excellent examples of teachers developing and being empowering guides (Stumbo, 1999, pp. 170-177). Considering lived experiences of success through the voices in interviews on success adds to success literature from a "fresh (original) perspective" (Kilbourn, 2006, p. 555). The following three research questions are addressed through interviewing teachers and administrators and through collecting documents: 


\section{Research Questions}

1. What are the critical elements of current educators' descriptions of their success?

2. How do educators in an elementary, an intermediate, a middle, and a high school within a single county conceptualize success?

3. What core beliefs and values do teachers express when describing their success?

\section{Importance of the Study}

Confidence and hope, then positive interactions, and, finally, a deep teacher-student relationship are the main criteria for successful teaching according to the literature (Jersild, 1955; Edwards et al., 1996; Starnes, 2005). As to what makes the most successful individual teacher in the eyes of education researchers, the literature reports that teacher efficacy, a core belief in oneself as a teacher, makes a good teacher.

Teacher efficacy, as defined by Gibson and Dembo (1984), comprises the constructs of personal efficacy (self-efficacy_- I can make a difference) and teaching efficacy (outcome expectancy - teachers can make a difference). Bandura (1977, 1986, 1993) defined self-efficacy as a person's judgment about whether he/she could complete future actions. Numerous researchers have found efficacy to relate to positive outcomes for students, such as reading achievement (Armor, Conroy-Oseguera, Cox, King, McDonnell, Pascal, Pauly, \& Zellman 1976; Tracz \& Gibson, 1986). (Edwards et al., 1996, p. 1)

A teacher's belief in her ability to make a difference comes out in her voice, and the perspective of a successful teacher indicates her feelings, education, and beliefs, in addition to her responding to diverse student needs with her teaching methods (Rothstein-Fisch,

Trumbell, Isaac, Daley \& Perez, 2003; Norton \& Benteley, 2006).

Specifically, the literature argues that a teacher's beliefs prepare her to meet student needs and to improve her methods as she improves her work through time within 
diverse cultural settings (Rothstein-Fisch, Trumbell, Isaac, Daley \& Perez, 2003). To a good teacher, knowledge is not "banking"--or storing stagnant facts (Freire, 2003). Rather, she is interested in relating her knowledge to her class by listening to her students and valuing their voices. To quote the literature directly, according to Love and Kruger's 2005 study of " 244 teachers, paraprofessionals, counselors, principals, instructional specialists, and media specialists," (p. 2) a successful teacher "combine[s] positive attitudes and high expectations with interpersonal interactions such as (a) insisting students work harder, (b) acknowledging students' efforts, and (c) exerting extra effort towards assisting students, [in order to achieve]...success.” (Love \& Kruger, 2005. p. 1). How teachers maintain a "positive attitude... and...interpersonal interactions" includes learning about the profession and having resilient core beliefs and values. Teaching allows a person to build on her understanding of good will and communication, and her stance in relationship to the other is explicitly framed by beliefs-either from theory or from her own realizations of core beliefs. The literature on positive beliefs which help to include students and respond to their needs is open-ended intellectually and responsible socially, but to understand teachers' beliefs in the classroom requires some training and experience (Britzman, 2001).

Success literature focuses on the teacher-student relationship as a supportive and close interaction, not as a distant authoritarian lecturing. An article reviewing literature on adolescent self-esteem asserts that, "By being supportive and giving tasks and challenges that raise self-esteem, [teachers may help] teenagers...to have success in school and develop self-motivation" (Powell, 2004, p. 1). According to the literature, if 
the teacher is mindful of the needs of the students, this will do more to insure the teacher feels successful than anything else. Community is viewed as starting with the relationships in the classroom and building from there outward. Teachers' voices on their success give their audience alternative contexts or frameworks by which to organize experience and set goals. 


\section{CHAPTER II}

\section{LITERATURE REVIEW}

The literature search divides the books and articles on success in education into three headings, quality of life, quality of teaching, and quality of educational reform. Quality of life can be measured affectively_focusing on affect in the classroom (Blackmore, 2004; Britzman, 1999; Jersild, 1955)—and in terms of communicating beliefs. Quality of teaching, more specifically, is improved by strong teacher education and teaching methods (Britzman, 2001; Hargreaves, 2001; Smith, 1988). Quality of education reform affects community building and culture (Meier, 2002), as well as teachers' immediate practices in the classroom (Britzman, 1991). The thread of affect as a measure of success includes affect in the classroom and teachers' core beliefs, but also includes their leadership skills. Teacher education and teaching methods work with teacher affect and with student affect to build on trust, enquiry, and participation in class and thus to build community (Meier 2002).

The whole literature review on teachers' and other educators' conceptions of success may be viewed as summarizing beliefs in education. Therefore, to introduce structure and hierarchy to the literature reviewed, I make headings that organize the conceptions of success from the most proximal to the most distal-from "affect" as the most internal success to a "culture" of respect and empathy through community building as the most external. Rarely does a school attain its optimal functioning without successful community. The main qualities of success to emerge from the literature are success in quality of life, success in quality of teaching, and success in quality of reform. 


\section{Section 1: Quality of Life-Affect and Core Beliefs}

Quality of life can be seen as feeling-driven or belief-driven. A person may feel successful through feeling well-being and generosity or through believing in certain ways of improving life. The first section of "quality of life" in this literature review looks at articles on affect or feeling. The second section looks at articles on belief. Studies such as Andy Hargreaves's study of emotional encounters between Canadian teachers and “students, colleagues, administrators, and parents" (Hargreaves, 2001, p. 1) measure emotional success. Other studies describe how teachers develop emotionally. Arthur T. Jersild's (1955) When Teachers Face Themselves includes results of interviews with teachers from half a century ago focusing on affect.

Affect

The affect of educators helps to make relationships and communities. Affect is informed by education, beliefs, and the history of educators and has the opportunity to express itself in meeting students' diverse needs within the school culture, the U.S. culture, and the worldwide culture (Blackmore, 2004; Meier, 2002; Hargreaves, 2001). Affect is the most internal measure of educators' success but influences external success. Affect can be seen as mere reaction to an external life or it can be seen as the motivator for choices in an external life, depending on how internal a person is. Suffering in a lifetime can be a forgetting or a learning, depending on how much a teacher's cognition interacts with her affect. In general, empathy and relationships go better for people more aware of affect (Jersild, 1955). To study affect with cognition involves working with two separate parts of the brain-the affective realm and the cognitive realm. The science of 
affect is psychology. In this portion of the literature review most pieces are at least somewhat psychologically based. Knowledge of teacher affect increases the likelihood of mutual fulfillment in the teacher-student relationship (Jersild, 1955). Understanding libidinal and resistant feelings towards knowledge and authority helps teachers accept and work with their students (Britzman, 1999).

This review of the literature on affect focuses on improving teachers' roles as healthy, mature leaders. An article from Deakin University, Australia, written in 2004 by Jill Blackmore, gives an excellent overview of a discourse clash between "managerial and market accountability and the emotional and messy work of teaching and leading" (p. 439). Blackmore's “article draws upon four research projects undertaken in Victorian public schools during the mid and late 1990s at a time of radical restructuring of the public system of education...The data in all studies were qualitative, gathered primarily through interview and focus groups" (pp. 441-442). She writes of "reform discourses emphasizing managerial and market accountability:"

These accountability exercises were often seen by teachers and principals to be distractions; more about reporting and recording, rather than addressing substantive educational issues. They simultaneously distanced teachers and leaders from the 'real' and 'passionate' work of education while appropriating and commodifying teachers' and leaders' emotions and desires to do well...[There developed] dissonance between teachers' professional and personal commitment to making a difference for all students based on principles of equity and the performativity requirements based on efficiency and narrowly defined and predetermined criteria of effectiveness and success that often undermined improvement for many students. In that sense performativity ('being seen to be good') and passion (for 'doing good') often produced counterintuitive impulses. (Blackmore, 2004, p. 439)

Agency-defined teachers and nurturing-defined teachers clash. 
Blackmore's discussion of emotion explains the motivation of teachers,

"Emotions are...about transformation and emotional responses were informed by their desire to 'do good', for example to make a difference, to improve the lot of the disadvantaged, to work creatively with colleagues" (p. 445). Success within this affective context was threatened in Australia by "Schools of the Future," a government program of reforms that made "teachers feel devalued."

A key aspect to [the]...sense of disengagement with their core work was the increased sense that emphasis of systems, schools and individuals was on image and self-promotion, on the performative rather than on the substantive core work of education or teaching and learning in ways that valued all students and teacher. (Blackmore, 2004, pp. 447-448)

Definitions of success in terms of the internal categories of affect and core belief, in methodology terms such as teacher education and teaching methods, or in terms of the external community in which the school performs can all be seen as what Blackmore calls "substantive core work."

Blackmore cites Hargreaves on diversity,

Hargreaves (2004, pp. 34-35) referred to the emotional politics of school failure, in which 'intergenerationally unequal societies, distributions of dignity create emotional economies of distinction and disgust.' Disgust as the opposite of distinction are both 'basic emotions of social exclusion' that 'demarcate success from failure' and marginalise racial or economic differences (Hargreaves, 2004, p. xx). (Blackmore, pp. 448-449)

The danger of school failure in the U. S. due to inadequate standardized test scores especially threatens the rural and inner city populations and threatens also to "marginalise racial or economic differences" with "disgust." Wealthy and poor U. S. "children live in truly separate worlds" (Kozol, 1991, p. 70). The Blackmore article is an extremely insightful criticism of the current trend to measure success by standardized test scores. 
The remaining articles on affect and Arthur T. Jersild's book can be summarized with reference to levels of affect and presented in order from the most affective language to the least. The literature review finds in education research a need for a more directly affective language. In Arthur T. Jersild's (1955) When Teachers Face Themselves, he studies 229 participants' answers to a Personal Issues Inventory, including answers of "I've felt this way" in response to the statement, "I feel cut off from others too much; I might say there is an invisible barrier between me and others" (p. 159). Jersild explicitly describes teachers' urges to work intimately with students' needs to express affect and become more self-aware.

It is through my self — and through your self - that the intimacy of individual existence is realized, and it is also through this self that intimacy and relatedness with others is achieved. The self is the citadel of one's own being and worth and the stronghold from which one moves out to others. (p. 135)

To be emotionally healthy, healed, and whole - able with expression and empathy-is to Jersild a priority life goal. He sees possibility for growth in that direction and he follows it. He desires to follow the life drives to develop and to connect.

Of aggression, which often helps achieve desire, Jersild concludes, "The more courage and humility we can bear in facing our hostility, the less destructive it is likely to be" (p. 117). Sometimes overwhelming force and discipline may feel needed to respond to aggression in class, but low levels of student aggression should be expected as part of the learning process. Teachers direct student aggression towards productive accomplishment and staying on task. A successful teacher helps students enjoy their activities and see the pleasure in learning (Stuart, 1949). She cares about her students' 
futures and relates the subject to her students' ambitions and desires. Teachers help frustrated or aggressive students to feel confidence, inclusion, and safety in class. Safety extends to feeling emotional belonging - that one may speak and be appreciated in the classroom, even if the class is large and the forum is speaking in small groups (Britzman, 1999). Teachers in touch with student affect tend to know themselves well first (Jersild, 1955).

Like Blackmore, Jersild believes passion has a place in teaching and in writing about teaching. To face passion squarely lets educators improve classroom climate. The need for safety is much stressed in schools. Jersild writes about anxiety, "Another form of flight is to treat emotional problems as though they were logical problems" (p. 50). Jersild's insights and careful writing help us out of this problem. Later he writes of anxiety escaped in another way, "driving, restless, relentless work" (p. 52). Ironically, teachers teach work ethic and later they may become a victim of "work that keeps one too busy to face oneself" (p. 52). A good worker will find her internal life complemented by her work, not destroyed by her work. This is to follow Jersild's idea of wholeness coming from the self. To include affect in education courses is essential to Jersild's vision of teaching that would be less anxious and more clear with feelings. He goes on to propose that specifically addressing affect in affective language will give teachers reference points for their experience and help them to understand how their feelings belong within the teaching experience. Jersild consistently maintains that to overlook affect in teaching will unhook the teacher from herself and from her class and increase self-doubt (Jersild, 1955). 
Forty-four years after Jersild's book, Deborah P. Britzman published a

provocative article on “"Thoughts awaiting thinkers': Group psychology and educational life" (1999). Her ideas on desire, aggression, and anxiety draw deeply on psychology, giving precise language and an honest picture of a number of issues in teacher affect. Britzman's article "draws upon psychoanalytical theory to study the problem of learning from experiences in group psychology...Three examples of leaderless groups are offered as illustrations of how groups transform institutional life and their own resistance to making meaning from new ideas" (p. 313). Britzman's article deserves the longest summary of articles on affect and explains affect using the science of psychology in important ways.

Britzman writes of desire,

As many educational researchers have pointed out...compulsory schooling involves erotic relations between adults and children, and yet consideration of the circulation and forms of Eros in schooling and questions of sexuality are considered controversial. Indeed, if sexuality is spoken about, it is usually placed under the category of 'problems.' Jersild (1955/1971) pointed this out in his chapter entitled 'Sex'. And, when sexuality is discussed in educational research, a great deal of space must be given over to why sexuality is so difficult to think of in educational contexts. For example, Tobin (1997) notes how dangerous it is to acknowledge pleasure in early-childhood education. In that same collection, while Phalen (1997) considers the pre-service early childhood educator's worries over the uses of touching in the classroom and the teacher's capacity to explore with children their questions and sexual banter, Johnson (1997) reviews the proliferation of 'no touch' policies directed at male educators. Indeed, taboos against discussing sexuality in teaching and learning seem to invoke new modes of social denial that take the form of moral panics, modes of censorship, or discourses in guilt, innocence, or harassment. And yet, as we shall see, to consider the structures and experiences of group psychology is also to investigate the making and undoing of libidinal ties to the group and to the leader. Analytically speaking, where there is Eros there is authority and the potential for knowledge. (pp. 321) 
Discussion of "libidinal ties" in the classroom may be taboo, but according to Britzman, understanding sexuality is important to understanding how thoughts form in the classroom. Britzman wants teachers to "experience the psychical phenomena of 'thoughts awaiting thinkers"' (pp. 332-333) to help classes become more thoughtful. She links love for the authority figure to love for knowledge and even to a group's ability to form thought at all. To enjoy learning and teaching involves desire. Britzman wants to help classes work through resistance and "develop language as a method of thought" (p. 316). She sees the potential joy in teaching, but through psychological theory, not through the interviews and time in schools that also make Jersild's writing from 1955 so rewarding to read.

An article on affective goals in education by McArdle and Coutts (2003), like Britzman's piece, tries to clarify the affective phenomena that characterize learning in school. Their paper "draw[s] on experience of designing, leading and teaching programs of continuing professional development for teachers...in a Scottish higher education context" (p. 226). On the first page, McArdle and Coutts write, "the work of Dewey (1916), within an educational context, established the importance of experience and drawing actively on experience as the basis for learning" (p. 225). The qualities McArdle and Coutts identify as desirable in a good teacher include as assumptions the ability to learn actively from experience. They describe the state of arrival of a good teacher and not the process of working with drives so as to become a good teacher.

McArdle and Coutts write, "an individual [teacher] will learn from different kinds of experience. She or he will be exposed to the ideas of others... will develop a sense of 
'feel', will reflect" (p. 229). She or he will also be able with "sense making as meaning making, or as a process by which 'knowing organizations' create, capture and share information" (p. 229). Such “"knowing organizations"” are not just scaffolding within her individual subject matter but enable "a sense of "feel"' and an ability to learn or make meaning from experience. The ideal teacher thus enjoys a strong knowledge of her affect and is open to the growing self-knowledge in her students. "Strength, balance, ballast and value maturity" (p. 236) are the destinations of the developing teacher. These qualities are consistent with knowing one's feelings of desire and aggression and how they blend with cognition. In defining success within an affective context, such destinations as "strength, balance, ballast and value maturity" give excellent goals, but they may not help a professor guide a student teacher's journey in those directions.

An article by Mitchener and Field (1998) studies how "mental health and education professionals have joined together around their similar interest in promoting children and adolescent development" (p. 508). In their study of a "program that fosters educators' development...[at the] DePaul University's School of Education," the authors draw on the "program's 34-year history" to "highlight specific tensions they experienced as directors of this collaborative initiative" (p. 508). The Mitchener and Field article, in contrast to the McArdle and Coutts article, focuses on tensions and surmounting them as a process of becoming. The Mitchener and Field article cites Jersild, “"The search for meaning is essentially a search for self. Meaning constitutes, in many respects, the substance of the self"' (pp. 507-508).

An educator acts in ways that extend her expertise in the service of others, beginning with her students and their parents and by extension with her 
colleagues. These relationships generate ongoing commitment and involvement, sustain and extend the learning and teaching process, and make professional and personal development intricately intertwined.

(Mitchener \& Field, 1998, p. 509)

While Mitchener and Field see process more clearly than do McArdle and Coutts, both of these articles explain ways to improve teacher affect and to move towards a more meaningful and fulfilling experience in the classroom by knowing oneself.

Seeing affect in teacher and student and seeing an affective response between the two is like hearing a dialogue without words. Even the very simple language of desire, aggression, and anxiety—three of Jersild's categories of affect—describes a good portion of classroom experience and helps us to learn from experience, Dewey's old ideal. When teachers begin with an internal focus, they immediately gain solidarity, community, and improved instruction (Lorenz, 2000). A teacher in training can focus on her own resistance to knowledge and learning when she learns what to look for in her students' learning styles (Alton-Lee, Nuthall, and Patrick, 1993).

Jesse Stuart in A Thread That Runs So True describes learning in the early $20^{\text {th }}$ century including classrooms that hum like productive bee hives and a student who "put all the fight she had inherited from her father—and she had inherited plenty—into her schoolwork. She directed all her energy and ability into learning and good citizenship" (1949, p. 244). To redirect aggression into school activities is one goal in the classroom, but teachers are usually aware of that aggression by some heightening of their own adrenaline. First they direct according to desire, then they know their students' and their own feelings, finally they confront their own anxiety (Jersild, 1955). A successful teacher, aware of her desires and anxiety to teach well, has faced herself according to 
Jersild. Teacher affect responds to student affect and helps to direct student affect.

Through desire to know and be known, teachers reach out to their students and establish trusting relationships. Developing a trusting feeling of the group in class is essential to school and provides community on a small scale (Meier, 2002). The desire to trust and enjoy rapport is often voiced in terms of community and democracy (Feiman-Nemser, 1990).

\section{Core Beliefs}

In addition to beliefs a teacher studies, a teacher holds a core belief system. One core belief identified in the literature is the belief in teacher efficacy. Efficacy can be an outcome of education or more of a personal sense of self. Teacher efficacy is a core belief in oneself that translates to student success.

Teachers' beliefs in their effectiveness consistently predict desired student outcomes... Teachers who anticipate that they will be successful set more challenging goals for themselves and their students, accept responsibility for the outcomes of instruction, and persist through obstacles...student achievement of cognitive and affective goals can be enhanced by strengthening [Teacher Efficacy] TE. (Ross, 1995, p. 227)

While some literature refers to the classroom as an island (Mathers \& King, 2001), teachers may still feel a unity with other teachers in their core beliefs. They share pleasure in teaching and learning. Being socially accepted by students helps selfacceptance and vice versa.

Bobby Ann Starnes describes her motivating beliefs as follows,

I love the intimacy of little inside jokes, having my students tell me when I have been unjust, helping them make their own ideas happen, and seeing 20 or more individual "I's" grow into the beauty of our classroom "we." (Starnes, 2005, p. 478) 
Teachers' beliefs both characterize them as people and characterize the profession. They give a system of values that work, being open to students and being challenging, and they give work that supports a system of values. It is important in educating teachers not to put beliefs on top of lives in a disconnected way but to work with core beliefs to better them in preparation for a career that will teach them. Teaching works out inner struggles rather than reinforcing them by the very process that Starnes articulates so well, "seeing 20 or more individual 'I's' grow into the beauty of our classroom 'we'” (p. 478).

Teaching is a culture of its own that has the potential to enhance the original cultures of students and of teachers. It makes possible working together.

A typical distinction between types of teachers is that "teachers may be friendly, give students freedom and responsibility, be understanding; or they can lead the classroom by giving orders, being strict and admonishing, and expressing dissatisfaction" (Shechtman, 2002, p. 364). In translating educational discourse into a language heard by policy-makers, an emphasis on caring such as Nel Noddings (2003) makes may be particularly hard to convey. Teaching is a helping profession but it has also been likened to corrections or the militia for its efforts to enforce conformity of behavior (Sipe, 2004). The spontaneous pleasure in seeing students' growth both drives teachers and rewards teachers, but the direction of growth is not always recognized outside the profession.

Strong core beliefs in efficacy, "we" making, and friendliness, extend into concepts of democracy for some teachers-developing the feeling of participating democratically. Zipora Shechtman in an article called, "Validation of the Democratic 
Teacher Belief Scale" (2002), describes the Democratic Teacher Belief Scale as part of a quantitative study of seven groups of teachers and counselors.

How the teacher will respond to classroom situations depends on his/her preferred general set of values. Democratic teachers (i.e. those who value freedom, equality, and justice) tend to be self-transcendent and open to change rather than self-enhancing and conservative. They tend to be more cooperative and affective than oppositional; influence is shared with students rather than dominating them. They are more understanding and friendly rather than strict and admonishing in their behaviour. Finally, they hold multicultural and anti-biased perspectives on ethnicity, race, and gender (Varvus et al., 1999)...For learning to flourish, learners' thoughts and voices must be heard and engaged (Beyer, 1996; Dewey 1997; Jones, 1996). (Shechtman, 2002, p. 364)

Teachers successful at addressing affect and bolstering resilient core beliefs improve quality of life for their students. Classrooms committed to "we" and community, a harmony of purpose and working together, may come across more clearly to an experienced teacher (Achinstein \& Barrett, 2004). The mature and successful teacher takes pleasure in the learning process of the student and is willing to change in order to improve that process. Beliefs in efficacy, in making a classroom community, and in approaching teaching democratically are core beliefs in a successful teacher. Affect and core beliefs, such as finding pleasure in teaching and learning and such as believing in self-efficacy and making a difference, allow a knowledge of the "citadel of one's own being" (Jersild, 1955, p. 135) to translate into effective professional development and teaching methods. In turn quality of teaching allows community building and a culture of respect and empathy. 
Section 2: Quality of Teaching —-Teacher Education and Teaching Methods Articles on quality of teaching include articles on teacher education (and professional development) and teaching methods. Training teachers through coursework and experience can be viewed as one step removed from the internal realms of affect and core beliefs. Through education, teachers form a scholarship in common, like building a school without walls. Teacher education and teaching methods include the affective development of teachers and their leadership skills (Jansen, 2005). The nature of the language on teaching success remains quite student-oriented in the literature despite standardized testing which may tend to lump students together. Success as seen by educators in the literature is a matter of responding to student needs by strong teaching methods and those needs include the psychological or affective domain in with the practical and cognitive domain. Internal success leads to external success.

\section{Teacher Education}

Deborah P. Britzman's article on "Cultural Myths in the Making of a Teacher: Biography and Social Structure in Teacher Education" (2001) "draw[s] on her experience as a student educator" (p. 179) and on her research of pertinent literature. Britzman finds that, "In order for prospective teachers to experience becoming a teacher as an activity of human agency, the structure of teacher education must begin in a social environment that enables prospective teachers to engage in their professional development as students and teachers" (Britzman, 2001, p. 191). The myth of the rugged self-made individual weakens the teacher because she does not have opportunity to reflect on the reality of her social situation, which may include powerlessness and doubt. She may feel a desire to bring about change while feeling stuck in routine. She may feel a desire to include 
students in how she instructs while feeling this is not possible within her school culture. When teachers define success for themselves, they gain power towards questioning "the values embedded in the institutional biography [—values that have] become sedimented and serve as the foundation for the cultural myths that legitimize a hierarchical image of authority, a reified view of knowledge, and a rugged individualist stance" (Britzman, 2001, p. 190). Britzman emphasizes that these mythic forms of power cut off the powers of connectedness, communication, and community building so integral to the profession of teaching (Britzman, 2001).

The contemporary Canadian researcher Andy Hargreaves describes cooperation in terms of "emotional geographies." In explaining the need to relate to parents, Hargreaves instructs teachers. Teacher education for Hargreaves includes emotion, beliefs, and the more external relating to parents. He interviews fifty-three secondary and elementary teachers primarily about their relationships with parents in the article "Emotional geographies of teaching" (Hargreaves, 2001). "Methodologically, the paper draws on a study of the emotions of teaching funded by the Social Science and Humanities Research Council of Canada... Teachers were asked about what brought them into and kept them in teaching...the paper describes five emotional geographies of teacher-parent interactions—-sociocultural, moral, professional, physical, and political—and their consequences" (Hargreaves, 2001, pp. 1-2).

Hargreaves' article challenges myths of "a hierarchical image of authority, a reified view of knowledge, and a rugged individualist stance," (Britzman, 2001, p. 190) by exploring sociocultural differences between teachers and parents. In his study, 
teachers describe taking pleasure in supportive parents and in collaborative relationships with the parents they understand. Teachers able at emotional understanding and who identify with their perceived professional values do not feel the need to "mask" emotionally as often according to Hargreaves. If caring is not an institutionalized value, teachers may be too busy in other tasks to relate to parents:

Policy must provide a framework that gives teachers the discretion, the conditions, the expectations, and the opportunities to develop and exercise their emotional competence of caring for, of learning from, and of developing emotional understanding for all those whose lives and actions affect the children that they teach. (Hargreaves, 2001, p. 25)

Relationships and policy ideally allow teachers to care, to reach out from their success in the internal realms of affect and core beliefs. Teachers educated in sociocultural differences teach more successfully according to Hargreaves.

Michael Smith (1998) addresses "the question [of] how to enhance collaborative efforts...between the Writing Across the Curriculum Director and an instructor in the teacher-education department of a state college" (p. 1). Smith describes the "Englert, Tarrant, and Rozendal (1993) report on the following benefits they observed during a long term curricular project between a university faculty and an elementary school faculty:

1) Teacher talk enabled teachers to make their tacit knowledge visible which allowed them to questions assumptions about common practice and generate possible alternatives.

2) Teachers gave each other support which allowed them to take curricular and instructional risks.

3) Teachers used each other's knowledge as a source of ideas for their ongoing development and implementation of curricular activities." (Smith, 1998, p. 2). 
Other articles echo the themes of Britzman on engaging student teachers, Hargreaves on the importance of sociocultural understanding, and Smith on the importance of ongoing professional development. Like Britzman on student teachers, DeMoulin and Kolstad (1999) find that age and experience are useful in graduate school learning. DeMoulin and Kolstad studied a group of "1,452 pre-teacher education students in the freshman through graduate year of studies in universities in California, Pennsylvania, Tennessee, and Texas" (p. 1). They used two "psychological test[s] considered to be in final stages of standardization prior to marketing...Each one of the tests contains 200 true/false type items" (p. 2). According to their study, "Graduate programs in the school of education contribute more to the democratic maturity of teachers...than any of the undergraduate programs" (DeMoulin \& Kolstad, 1999, p. 2). As with younger students, when a student teacher is "ready to learn," she tends to learn the most (DeMoulin \& Kolstad, 1999).

Other writers about what is needed in professional development emphasize affect and instruction. Jonathan Jansen writes about educators' affect as an essential part of leadership skills.

To me 'emotions' signal not a discussion about weakness or pathology, but a vital if neglected component of leadership in organizations. In the literature on leadership, organizational change, and educational reforms, the neglect and significance of emotions are being recorded simultaneously (Beatty, 2000; Fineman, 2000; Hargreaves, 1998;

Hoschild, 1983; Maddock \& Fulton, 1998). (Jansen, 2005, p. 308)

A teacher learns through education and experience to become highly qualified within her school culture. Ideally, "professional development sparks curiosity, motivation, and new ways of thinking. It is most effective when it is an ongoing process" (Kent, 2004, p. 2). It does not overlook the first need of teachers to "connect [with students]...on a personal 
level" (Holliday, 2005, p. 22). Improvement in "teaching thinking skills," as in an English program launched in 2000 (Stainton \& Bangs, 2003, p. 28), aids "teacher efficacy," as in a teacher's belief in herself and goodwill towards her classes. Educating teachers works best when it addresses internal successes according to the literature. "Teacher efficacy correlates with affective growth [and]...with student acquisition of school-approved values and attitudes [such as]...student motivation, increased selfesteem, improved self-direction, and more positive attitudes towards school" (Ross, 1995, p. 229). Professional development aids good and necessary methods in teaching as well as clarifying a teacher's values and beliefs.

\section{Teaching Methods}

At the turn of the previous century, John Dewey wrote his profound essay called, "The Child and the Curriculum." Student-centered methods of teaching are often inspired by Dewey. He writes "Literally, we must take our stand with the child and our departure from him. It is he and not the subject-matter which determines both quality and quantity of learning...Subject-matter is but spiritual food, possible nutritive material. It cannot digest itself; it cannot of its own accord turn into bone and muscle and blood" (Dewey, 2001, p. 108) (originally published in 1902). He defines a trend towards learner-centered teaching, which continues today although it may be threatened by the need to cover material quickly under No Child Left Behind legislation. Teachers work to include the students' experience in their lessons, aware that as Dewey writes, "The source of whatever is dead, mechanical, and formal in schools is found precisely in the subordination of the life and experience of the child to the curriculum" (Dewey, 2001, p. 
108). Teaching with reference to students' experience both enlivens the class and helps the learning process (Dewey, 2001).

Almost a century later, in an article by Brent Davis and Dennis J. Sumara called "Cognition, Complexity, and Teacher Education," the problem of bringing the curriculum to the students is seen in terms of the isolation or relation of the students' identities to the material. The teaching method of including student experience in the curriculum is predicated on a social and not fully isolated student identity. "The belief in the isolated subject further supports the notion that the 'individual' is contained in a context rather than regarding the individual as an integral part of a relational fabric" (Davis \& Sumara, 1997, p. 240). An individual is respected within a group, but is one of the group, Davis and Sumara explain. They believe teachers need the cognitive understanding of how a group relates in order to manage the classroom. When teachers conceptualize their classes as working together in "a relational fabric," their voices are not isolated.

Connecting with the material and connecting personally are the most important experiences in school. The curriculum addresses needs for belonging and safety and lets the student feel that her needs can indeed be met through life (Eggen \& Kauchak, 1997, pp. 352-354). Maintaining a warm classroom climate (Noddings, 2003) and the creativity of thinking students working purposefully (Britzman, 1999) is much of the art of teaching (Jersild, 1955). Raising kind citizens (Dewey, 2001, pp. 159-175) relies on this kind of emotional conditioning. Ideally, knowledge feels exciting or like a return to peace, and teachers are successful at conveying their love of subject (Britzman, 1999). 
Methods also respond to a diversity of needs in U. S. cultures. Jonathon Kozol in Savage Inequalities: Children in America's Schools speaks of different communities as follows: "The children in the group seem not just lacking in important, useful information that would help them to achieve their dreams, but, in a far more drastic sense, cut off and disconnected from the outside world" (1991, p. 70). When teachers work with the kind of ignorance that Kozol describes, they understand that the power of knowledge serves many purposes. In a sense, culture and community occur first in the knowledge of the members of that culture and community. If a child is not prepared to intersect with a given part of society, she is limited as absolutely as if she were on an island.

When teachers conceptualize success, they include talk on the topic of their students' needs. Kozol goes on,

In talking of some recent news events, they speak of Moscow and Berlin, but all but Pamela are unaware that Moscow is the capital of the Soviet Union or that Berlin is in Germany. Several believe that Jesse Jackson is the mayor of New York City. Listening to their guesses and observing their confusion, I am thinking of the students at New Trier High [a more privileged school nearby]. These children live in truly separate worlds. What do they have in common? And yet the kids before me seem so innocent and spiritually clean and also-most of all—so vulnerable. It's as if they have been stripped of all the armament—-the words, the reference points, the facts, the reasoning, the elemental weapons-that suburban children take for granted. (1991, pp. 70-71)

Kozol's description of the ignorance he finds in the South Bronx makes plain that these schools work with a different curriculum and with different children than the New Trier High School. The students in the South Bronx have much greater need for education. To be "public," the public school system needs to be sensitive to cultural differences 
nationwide and embrace the challenge of educating different cultures with an equal opportunity for feeling belonging, respect, progress, and success as growing learners (Norton \& Benteley, 2006).

Jesse L. Rancifer's paper called “Correcting Impaired Student Self-Concepts: An Instructional Leadership Strategy for Teachers and Principals" (1993) studied "a sample of 82 graduate school students...[who] completed a twenty item opinionnaire" (p. 4) "designed to measure the frequency of agreement and disagreement with statements in the areas of success, teaching, reward, and feedback/follow-up. Statements related to each of these areas confirmed the value of confidence-building strategies" (p. 1). Besides methods of student-oriented, social, and diverse teaching, Rancifer offers advice on instruction to build students from any culture. "Show compassion in daily interactions with students" and "help students visualize rewards to be received by setting and achieving long-range goals" (Rancifer, 1993, p. 1) are phrased as actions of the teacher, even though the focus is on students' self-concept. "The teacher must make a concerted effort to develop in each student the 'I can do it' attitude [which]...implies drive, persistence, determination, and confidence...[and] if students are to build their selfesteem they must experience the four A's - attention, acceptance, appreciation, and affection" (Rancifer, 1993, pp. 3-4). A variety of teaching methods help students to enjoy learning and become involved in schoolwork. Just to be able to feel linked and immersed in school is a kind of practice coping that students can use throughout life.

Some teaching methods make work easier, its relevance involving some reaching by the student but also involving acts of successful reaching by the teacher who 
communicates pleasure in the subject matter and works with the curiosity and interests of individual students. One example is designing research projects:

Motivational research projects are relevant to the student's life. For our students, World War II and the Trojan War both seem "a long time ago." By asking her students to interview local residents, Beth helped them add real faces and lives to history. The stories resonate with those doing the interviewing. So many times we ask our students to research important topics-environmental issues, historical issues, health issues-but fail to help them make the vital connection to why the findings are important to the people in the town in which they live. (Johnson, 1999)

A teacher who defines her work to include the job of connecting better is attuned more to the established connections of her students and looking for ways to use those connections in her teaching as Beth found (Johnson, 1999).

Carol Stumbo reveals that her own intellectual connections come with awareness

of social connections. As a result of taking her students to interview local residents, she is both more aware of her class as a group and more aware of where they are coming from socially (Stumbo, 1999). Her individual teacher testimony explains the need to connect with society when teaching.

We all live in different worlds, and only in rare moments do we obtain a glimpse of another person's world... Nothing in school seemed to matter to the students whom we taught, but their indifference had a great deal to do with the conditions they faced when they left school...In school, the students of this inner-city teacher were, like mine, hard kids, perhaps because they had to be... One afternoon, [the principal]...took me to visit some of the homes and families of the students I taught...I saw a world that day that I had not known really existed...I realized that the world around me was the best classroom I could offer my students...As mining moved into the Appalachian region, what happened to people's lifestyles and their values?... Now I have learned to listen to students...I have learned to respect the different ways that people learn and work. (Stumbo, 1999, pp. 170-177) 
As in life, a teacher's action may lead her praxis and understanding. Beliefs are often the culmination of experience and not the motivating seed.

In the Bronx, with "mostly urban teenagers from low-income families" an "inspirational" teacher manages to bring "his students...into the world of Carmen, Figaro, and Rigoletto." “"The whole secret is to start from where the students are and then bring them into this new world,' Dzik says. 'I try to start most of my lessons with a little gimmick that will attract their attention. That's how I teach."” "Dzik has been teaching for a quarter of a century...that one doesn't need to be white and wealthy to be moved by opera" (Guillaume, 2000, p. 2).

Connecting with the students, the subject, and the community begins with a teacher's listening skills. The ability to listen well to one's students is also brought up by a mathematics teacher who says that she learned "to focus on how kids think... when I walk around the room, to listen...more, as opposed to talking more...because that gives you a great insight into how they learn" (Henry, 1999, p. 13). Overall, articles on teaching methods fall mostly into responding to universal psychological needs or intellectual needs and then into specific methods that worked for specific populations. Teachers who want "to build relationships with colleagues beyond school boundaries" can also search the Web for instructions about teaching methods (Wood, 2000, p. 1). Love of students and of subject matter, a positive attitude, and ability to collaborate help the resilient and mature teacher to connect effectively with her students and to help them to learn. Teacher education and the experience of trying diverse methods in the classroom help to build trust and a kernel of community in the classroom. 
Section 3: Quality of Educational Reform—Community and Culture

This section includes research literature on, first, community and, second, culture. Schools build community and work within a cultural climate. Reform of education addresses the need to build community and respect cultural differences. This form of success, quality of educational reform, is the most distal or exterior quality of succeeding in the literature. Radiating out from community in the classroom or through activities, students ideally find themselves forming a larger community. Larger communities function within the culture and beliefs or the society in which students and adults live.

\section{Community}

Deborah Meier, a $21^{\text {st }}$ century scholar, lays the groundwork for describing communities and culture. In her book, In Schools We Trust (2002), she describes communities, what threatens communities, and what makes communities in schools today. The concept of community is important to the theoretical and practical background of any discussion of education. Community is built in classrooms, and schools are part of communities. Community is especially relevant to cooperation, relationships, and development. More recent literature describes how community and culture affects student achievement in an era of testing (Bokhorst-Heng, 2008; Rieg \& Marcoline, 2008). Involvement of parents in schools also builds community and promotes lifelong learning (Ouimette, Feldman \& Tung, 2006).

Deborah Meier conceptualizes communities in In Schools We Trust within relationships_-family and schools, African Americans and whites in the U. S., and humanity both as individuals and as a whole. The relationships create definitions of 
community by how they interact with and how they look at each other. When people with differences are able to overcome mistrust and to operate within relationships of trust and democratic respect for each other's interests, they are able to join in a new community such as the neighborhood—with families and the small school collaborating — or in a country working as a whole, or in a feeling of overall humanity within every understanding of what it means to be human.

Meier writes about teacher-student and teacher-community relationships:

Democracy assumes the prior existence of communities of people with shared loyalties, confidences, and understandings. It doesn't create them-they are far older and more persistent than modern (or even ancient) democracies. We have always taken such communities for granted...

It was in becoming a high school principal that I first noticed what was unusual: the absence of interest on the part of so many adolescents in the world of adults; the isolation of adolescents from relationships with anyone much different-above all in age and experience-from themselves; the lack of a sense of membership in any larger society that could be appealed to...never in the history of the species did one think of raising the young to be adults in the absence of adults... But the closer kids came to being adults, the fewer adults they encountered. (pp. 178-179)

The importance of empathetic teachers who enjoy the process of learning becomes more important to students in this state of isolation. The process of getting to know each other in class is the main community building for students raised "in the absence of adults."

Meier explains that there are communities within schools that help build community outside of schools.

The schools that work are small. Within them, people are not anonymous and interchangeable. Even in existing big schools, the kids that do best belong to small, intimate subschools with a strong culture of specialness. They hang out with "their teachers," "their clubs," and "their classmates." Feedback isn't bureaucratic, but direct and frequent, and everyone feels (and is) safer. It's harder not to know what is going on. (p. 159) 
"It's harder...to know what is going on" (Meier, 2002, p. 159) in large communities devoted to cognitive lessons working in ignorance of affect. People care for each other's feelings. Feelings are part of learning and being and becoming the persons we want to become. The fact that teachers are working on becoming from an adult viewpoint immediately gives them a valuable perspective to the student. Students look ahead to having more and different experiences, sometimes with anxiety about their abilities, sometimes with confusion about their ambitions, and sometimes with confident desire. Teachers aware of community building and of their students' development within their cultures are better prepared to work closely and compatibly with students' growth.

An article by Wendy D. Bokhorst-Heng, "School-Home Partnerships to Nurture Adolescent Literacy" (2008), describes "the effort to develop a workshop for parents and teachers in" the "Dewey Secondary School (name changed)." "Two different surveys were administered to parents. The first sought to determine issues deemed important to parents...The second survey focused on parents' perceptions of school-home partnerships in the schools. They were presented with a series of statements (e.g., This school makes me feel like we are partners in my son's/daughter's education) and asked to respond on a five-point scale from strongly disagree to strongly agree” (p. 43). Bokhorst-Heng surveyed 180 parents. Community building begins at home according to Bokhorst-Heng (p. 40). Reform of curriculum works hand in hand with education within the student's home-life.

The importance of parental involvement in children's education, even through the last year of high school, has been well established in the literature. Research indicates that a home environment that encourages 
learning is even more important to student achievement than the family's income, education level, or cultural background (Cairney, 2003;

Henderson \& Mapp, 2002). Among the key benefits to students distilled from the research are (a) doing better in school with higher test scores and grades, (b) being more likely to complete their homework, (c) exhibiting better behavior, (d) having more positive attitudes toward their learning, (e) graduating, and (f) being more likely to enroll in higher education. (p. 40)

While Meier emphasizes trust, other sources in the literature such as Bokhorst-Heng, quoted above, and Reig and Marcoline, quoted below, describe community building in terms of achievement.

Sue A. Rieg and Joseph F. Marcoline wrote a study, "Relationship Building: the First 'R' for Principals," in 2008. "Several methods were used to collect data for this study: 1) A thorough review of literature on principals and relationships was completed. 2) Five principals from China were surveyed regarding ways they build relationships with young children in their schools. 3) Principals were interviewed as to how they build relationships with students, teachers, parents/families and the community. 4) Teachers were informally questioned as to how principals currently work to build relationships and how they would like to see principals build relationships with people in their school community" (p. 2). In an era of testing, relationships and community building remain essential.

School leadership today demands skills, knowledge, and attitudes much different than those required a short time ago. With the increased accountability for principals to achieve and maintain adequate yearly progress, test scores are often seen by teachers and parents as principals' top priority. Relationships are seen as secondary and they should be higher on the priority list. It is our contention that if principals spend more time building relationships with students, teachers, parents, and community members, test scores will rise and discipline referrals will diminish. (Rieg \& Marcoline, 2008, p. 1) 
Community building may involve the principal or other administrators, but also, parents and community members may specifically help out in schools to build relationships with students and to make their education more relevant to their lives.

In their case study of "three high schools with successful community partnerships" in "sites...chosen to reflect different community contexts and school demographics,” Mavis G. Sanders and Karla C. Lewis write in 2005 about specific community involvement in schools as follows:

Common among the student-focused activities were student scholarships, awards for service, tutoring and mentoring programs, mock interviews, and job-shadowing programs. School-focused partnership activities included events such as fundraising projects for school equipment and building improvements, and resulted in refreshments, chaperones, hall monitors, guest speakers, and other volunteers for school events. Familyfocused community partnership activities included workshops, and family incentives and awards. Community-focused activities included cosponsored cultural events, community health fairs, advertisements in monthly school newsletters, food drives, and other volunteer activities that benefited community members.

These activities reflect the schools' different contexts, resources, needs, and goals for school improvement. Collectively, they show the kinds of activities high schools can implement when they integrate community involvement in their schools' improvement programs. In her study of family involvement in high schools, Simon (2002) concluded that, "Regardless of family background or school context, when high schools reach out to involve families, families respond with increased involvement (p. 16)." (p. 8)

The reaching out of teachers and administrators to families and the reciprocal involvement of families in the school enable not only better achievement, but also the trust and building of democracy that Meier mentions. Specific activities to include parents in schools are easier for elementary school parents to attend than for parents of students in the older grades (Ouimette, Feldman \& Tung, 2006). Reform of schools at 
every grade level, however, is enabled by parental and community involvement (Meier, 2002; Bokhorst-Heng, 2008; Rieg \& Marcoline, 2008; Ouimette, Feldman \& Tung, 2006).

A case study of parent engagement at Boston Arts Academy (Ouimette, Feldman \& Tung, 2006) cites a teacher's voice regarding parental involvement as follows:

The parents in our school are integral to the operation and the success of our students. I'm a big believer that education happens not only in schools, but it's a daily process and it happens from day one to forever. Students learn from their families, their communities, the larger world. But parent involvement is definitely, definitely a key to all the success that our students see here. We introduced student conferences and parent phone calls, and making sure the students' parents stay involved in the process, and we've seen much higher success rates. (BAA Teacher) (p. 98)

Community building involves trust, the building of democracy, and the connection of students to a broader society through the daily activities and communications provided by schools. Community building takes place within the larger cultural beliefs of society.

\section{Culture}

Deborah Meier (2002) sees community as involving who we are, how we know each other and how we know what is going on, our worlds. We look to others as part of knowing how to look at ourselves. If a student devotes himself to video games until the levels of danger in video games define his sense of community, community at other times grows more important not less so. Culture builds on a sense of community or a lack of community and culture defines community (Meier, 2002). Sometimes the people to whom we belong form a larger pool such as our race. Even Meier who has worked extensively with African American families feels that to keep an open mind and an open heart can be hard in the face of prejudices—learned despite our efforts to overcome them 
(Meier, 2002, p. 85). When teachers conceptualize an accepting classroom climate as part of success, they voice the achievement of trust that Meier prioritizes as a principal.

Trust can be particularly hard for schools to establish in minority cultures but an argument can be made that there is little correlation between low socioeconomic status (SES) and community building. Achievement may not be affected by low SES when one measures SES by number of students on Free and Reduced Meals (FARM). When a study looked at parental beliefs and expectations and parent-teacher communication as opposed to another study looking at number of books in the home and parent level of education, the former measure of low SES was found not to correlate with lower achievement (Ferguson, R. F., Clark, R., \& Stewart, J., 2002). "Ferguson finds that socioeconomic status is quite important as a predictor of achievement, while Clark finds that it is not. This difference may or may not be due to the differences in measures used." Strong parental beliefs and expectations and parent-teacher communication close the achievement gap according to Reginald Clark's study. A low number of books in the home and parent level of education, however, may increase the achievement gap according to Ronald F. Fergson.

In addition to low SES, racial and ethnic background may define a culture and influence community building and school reform efforts. In a "longitudinal actionresearch project that began with teaching professional development on differences in cultural values orientations" called the Bridging Cultures Project, researchers and teachers documented "observations and interviews" of schools "with more than 95\% immigrant Latino population" during their 5-year project in California (Rothstein-Fisch, 
Trumbull, Isaac, Daley \& Perez, 2003, pp. 124-130). The researchers found that in reforming schools, one always works within a cultural context.

All learning occurs in a social and cultural context, mediated by language and other culturally created tools (Vygotsky, 1978). What counts as knowledge or knowing, methods of teaching, and means of evaluating students' learning are all culturally defined (see...e.g., Nucci, Saxe, \& Turiel, 2000: Rogoff \& Chavajay, 1995). Likewise, the ways classroom activities are organized and the ways teachers communicate reflect and foster certain cultural values (Ryder, 2002). Yet culture is rarely addressed in reform efforts; schools seem to proceed as though there is one universally best way to teach all students. (Hollins, 1996). Unfortunately, the educational goals of schools, both implicit and explicit, and the means for achieving them may be incompatible with students' home values and norms, particularly in the case of immigrant students. (p. 124) [italics mine]

To find students' values and priorities or core beliefs works with being a studentoriented, hopeful teacher, but knowing the cultural context of one's school and class is how communication makes and maintains mutuality.

One study describes the immigrant's cultural experience in parent-teacher experience as follows and the problem is echoed in several other articles (Hu, 2008; Gilliard \& Moore, 2007; Pfeifer \& Polek, 2007) about other immigration groups and minorities.

Sylvia, a parent in Annandale High School's Immigrant Parent Leadership class, presented to the class a problem she had encountered: "One of my stepdaughter's teachers thought someone else did her homework. But the reason she is doing so well is that I am working with her at home." Sylvia emigrated from Guatemala as a child and attended U.S, schools from 4th grade on. She speaks English well and is committed to helping her stepdaughter, who recently arrived from Guatemala. "Call the teacher," the leader of the class advised. "This is clearly a misunderstanding, and the teacher would want to know what is actually happening." Sylvia was amazed: "You mean I can talk to the teacher? I felt I would be insulting her if I did."

This snapshot illuminates one of the lessons that administrators, faculty, and parent leaders at Annandale High School in Virginia have learned through our Immigrant Parent Leadership Initiative, a focused 
effort to engage immigrant parents and nurture two-way partnerships with them. Even when immigrant parents are fluent in English or have attended U.S. schools, cultural barriers to involvement often remain. (Sobel \& Kugler, 2007, p. 63)

Other immigrant groups also speak to the issue of not wanting to question teacher authority by asking questions or even participating in school activities. Coming from a separate culture and community from the school's or perceiving their culture as separate, some minority populations perpetuate separation through being loath to join in school activities. School reform efforts must focus on home lives in addition to school lives (Hu, 2008; Gilliard \& Moore, 2007; Pfeifer \& Polek, 2007).

One way to redress cultural separation is to teach about the racial and ethnic backgrounds of students. Another is to have members of the faculty who represent the minority population. The following abstract explains solutions to a problem with a school culture of racism against African Americans.

The trouble started when an anonymous e-mail alleged abuse of power at Centennial High School in Howard County, Maryland. Each week, the local paper reported new developments in the investigation. On top of that, the family of a Black student reported that a culture of racism existed at Centennial. At the end of the year, members of the community and the board of education held a meeting to discuss the issues at the school. The packed meeting deteriorated into a name-calling, shouting match tinged with charges of racism at worst and racial insensitivity at best. When the existing principal retired suddenly during the turmoil, the superintendent expected the new principal to make cultural proficiency his first priority. But how can a school become culturally proficient when parents and students do not know whether diversity is truly valued? The school community had to begin building cultural proficiency from the ground up. The administrators adopted several key elements as the scaffolding for the process: (1) building trust; (2) increasing diversity among staff members; (3) learning about cultural proficiency and its guiding principles; and (4) identifying a champion to lead the way. The 
English department became a model for the school as it furthered the culturally inclusive curriculum. Trust and a focus on the principles of culturally proficient schools combined to put Centennial back on track. (Pfeifer \& Polek, 2007)

Building trust echoes Deborah Meier's argument that community building, democracy, and human connection are predicated on trust. Increasing diversity among staff members is not always an option for schools. Learning about cultural proficiency and its guiding principals and having a champion to lead the way to cultural proficiency is more available through education courses and professional development.

Like Hispanics and Blacks, Asians need to be included in community building and are sometimes left out because of cultural differences. An article on Asian Americans in "The New York Times" says:

The district's superintendent...sees parental involvement in all aspects of school life as critical to improving communication and helping students become emotionally well-adjusted and socially successful... Deborah Lee said that after her son, Jason, started kindergarten two years ago, she dreaded going to his school because she felt that she was the only one who did not know how things worked. Once, she came to his class for a reading project but did not realize she was supposed to check in first at the main office until someone tracked her down. "It's my son's school so I don't want to mess it up for him," said Ms. Lee, 42, who grew up in Hong Kong. "Sometimes, if you don't do something, you won't make a mistake." (Hu, 2008)

Respecting cultural differences in schools as schools try to reform through community building requires appreciation of diverse cultures, but there is a commonality of making an extra effort to include parents and to be accepting of difference in schools that work best.

While Native American students comprise a small proportion of the population in many schools in the U. S., their culture exemplifies some of the issues that students from 
diverse cultures experience in school. In 2007, Jennifer L. Gilliard and Rita A. Moore investigated "how culture shapes instruction in three early care and education programs on the Flathead Indian Reservation [in Montana]. Interviews with eight early childhood teachers as well as classroom observations were conducted" (p. 251). Gilliard and Moore write:

It is often difficult for educators who do not share their students' culture to provide curriculum within the context of their students' family and community cultures (McIntosh, 1989; Moore with Seeger, 2005). The education literature suggests that a successful strategy for teaching children from diverse cultures and languages is teachers exploring who their students are in order to understand their students' family and community contexts (Jones \& Derman-Sparks, 1992; Luo \& Gilliard, 2006; Moore, 2004a; Van Horn \& Segal, 2000; Yang \& McMullen, 2003) as well as educators examining their cultural identities and how their cultural lens affects their teaching (Allen \& Labbo, 2001; Grossman, 1999; McIntosh, 1989; Moore, 2004a; Van Horn \& Segal, 2000)...During her interview one teacher described the powwow: "We had a powwow. We do this every year. It is usually the first Friday of May. Each child is given a pair of moccasins for the powwow. This year, our center and parents decided to make their own outfits, so we had someone (from the community) come in and help with ribbon dresses and the parents helped with that, too. And, some of them decided to do their own moccasins. So, the parents are really involved." (Gilliard \& Moore, 2007)

In considering reform efforts in an era of testing, relationships, community building, and culture must be embraced in order to succeed according to the literature. The literature suggests that teachers' voices may explain success in part as the way that teachers relate to students and build community within their culture. Within a particular culture and community, teachers discuss success in terms of relating to parents, local work, and how success is viewed outside of the school walls.

Thus, the most distal, exterior level of success ties into the most proximal, internal level of success, affect. Success in affect and core beliefs, in teaching education and 
methods, and in community and culture are all related in the literature, but the kinds of success can be organized from proximal to distal. The literature on success conceptualizes success in the classroom as intimately connected to success within a community and culture, and community and culture, conversely, succeed when schools succeed. When teachers and administrators talk about their successes in the literature, their voices are focused on a diversity of concepts that explain success from the most internal to the most external aspects of reform.

\section{Section 4: Brief Summary of Literature Review}

In summary, from the most internal or "proximal" (Harry, Sturges \& Klingner, $2005)$ to the most external or "distal" conceptions of success, the literature describes positive affect and teachers' beliefs as successfully aiding quality of life, strong teacher education and teaching methods as successfully aiding quality of teaching, and strong community building with respect for cultural differences as successfully aiding quality of reform. Confident teachers believe they can make a difference (Edwards et al., 1996). Teachers' education enables "state of the art" teaching methods. Finally, building community within a cultural context allows successful school reform. To turn directly to teachers' voices addresses a gap in the literature on success by considering actual practice rather than more abstract or theoretical ideals in teaching. 


\section{CHAPTER III}

\section{METHODOLOGY}

\section{Introduction}

The research questions addressed in this study ask how teachers conceptualize success and the sampling narrows down the teachers to those in K-12 schools in one county, looking at successful teachers in one high school, one middle school, one intermediate school, and one elementary school in the same rural county in a MidAtlantic state. As the successful educators recommend one another, and the sample size is limited to fourteen educators, the nine teachers in the study are each successful in the eyes of their peers and principals. The administrators' perspectives shed light on the perspectives of the teachers.

\section{Research Questions}

1. What are the critical elements of current educators' descriptions of their success?

2. How do educators in an elementary, an intermediate, a middle, and a high school within a single county conceptualize success?

3. What core beliefs and values do teachers express when describing their success? Having looked at the literature and found that there were not many studies of teachers' voices on success, the researcher seeks to engage teachers in a sincere and significant dialogue on the subject of success, giving them an opportunity to voice their conceptions. The protocol questions are designed to shed light on the research questions. The choice of participants is designed to highlight the experience of successful educators within schools from a single county with their geographical and cultural limitations and specificities. The culture and the 
community of the county within which the participants live give a backdrop to their ideas of where their students are going and how their teaching helps.

\section{Overview of Methods}

Interviewing the school principals and the deputy superintendent of schools, as well as studying a collection of school documents, adds more depth to the teachers' conceptions of success. This section includes description of the population, description of the choice of participants, sampling strategy, and description of participants. To capture participants’ conceptions of success, participants are interviewed who "have directly experienced the phenomenon of interest" (Patton, 2002, p. 104). Principals are asked to identify successful teachers and then to tell me why they consider the teachers to be "successful." Teachers are asked to recommend their peers. When participants give individual definitions they use to classify teachers as "successful," their criteria are explained in the sampling strategy.

\section{Description of the Population}

Interview data was gathered from the deputy superintendent of schools, the principals of four schools, and nine successful teachers as named by the principals and each other. The schools selected for this study are a high school, a middle school, an intermediate school, and an elementary school. The schools feed into each other to serve a population described by each participant in answering question one of the interview protocol, "Describe your students, school, and community."

\section{Participants}

The participants are all from a single local school system. The scope of the data is limited by geography and number of participants. The population for the study is participating 
teachers and administrators from a partially rural county in a Mid-Atlantic state. In this MidAtlantic state, indicators of educational merit rank the state overall as low-scoring as compared with the U.S. overall. Based on a state Department of Education report of Adequate Yearly Progress scores, in 2004-2005, "More than 83 percent of state schools met Adequate Yearly Progress (AYP) under federal No Child Left Behind (NCLB) legislation.” "594 schools statewide made the grade...121 schools did not meet AYP in 2005" (Cramer, 2008, p. 1). In the county considered in this study, however, 70 percent met AYP. Out of 23 schools tested, sixteen made AYP while seven did not in 2004-2005 (Cramer, 2008, p. 2). Of the four schools considered in this study, two made AYP — the intermediate and the elementary — and two did not— the high school and the middle school. (See Appendix D: County Demographics.)

In the county considered, there are fourteen elementary schools (Kindergarten to second or third grades), six intermediate schools (third or fourth to fifth grades), five middle schools (sixth to eighth grades), and three high schools (ninth to twelfth grades). The study looks at relatively rural and large schools in the high school and middle school level and relatively small intermediate and elementary schools. Specifically, the selection criteria for schools and teachers come from the initial interview with the deputy superintendent of schools, from principals recommending teachers, and finally from teachers recommending teachers. The deputy superintendent of schools identified the schools to be studied and gave permission to interview the principals and teachers. The principals identified the first "successful" teacher and the success criteria of the principal were recorded. The teachers identified "successful" colleagues and the teachers' success criteria were recorded. (This is 
called "snowball" sampling.) The success criteria of the deputy superintendent of schools were recorded to give a third perspective on "success" in teaching. The specific success criteria of each of the three perspectives - the teachers', the principals', and the deputy superintendent's, in that order-are discussed under Sampling Strategy.

Participants for this study are chosen by the principals and peers of nine teachers. The order of the interviews are:

1. The deputy superintendent of schools for permission to complete the study.

2. The principal of each school for permission to complete the study, and for his or her recommendation of a successful teacher to start the snowball sampling.

3. The successful teacher named by the principal.

4. A teacher recommended by the first teacher.

5. A teacher recommended by the second teacher in the high school level where three teachers are interviewed.

6. At the same time, principals are interviewed as their schedules permitted.

7. Finally, the deputy superintendent of schools is interviewed according to the protocol. Participants in this partially rural county represent seven grade levels and individual teachers have a record and reputation of being successful.

While every teacher may know some lived experience of success and offer some "in vivo" language about the lived experience of success, the participating teachers have been recommended by people who know them-either other teachers or principals. They have some confidence regarding being successful. Nine teachers are interviewed, three from high school, two from middle school, two from intermediate school, and two from 
elementary school. Not every school may be meeting Adequate Yearly Progress goals, but their teachers are nevertheless successful at preparing students for their futures. The teachers looked at are not "heroes" but show "successful" and "good" teaching (Fenstermacher \& Richardson, 2005).

\section{Sampling Strategy}

More specifically, "purposeful selection" of participants is used as follows (Kuhn, 2005).

1. Schools are chosen from one of the more rural of the three high school systems in the county. The study includes two schools, a high school and a middle school, which did not meet Adequate Yearly Progress requirements under No Child Left Behind legislation, and two schools, an intermediate and an elementary school, which did meet AYP requirements. The high school is on the urban fringe of a small city (population about 16,000.) In 2005-2006, its student population was 1,399 (Department of Education, 2008). Its number of teachers was 82. Its percentage of White students was 94\%; its percentage of African American students was 2\%; its percentage of Hispanic students was 3\%; its percentage of Asian students was 1\%. Its percentage of students eligible for Free Lunch (average family income for a household size of four $\$ 27,560$ in 2008-2009) (Federal Register, 2008) was $16 \%$. Its percentage of students eligible for Reduced Lunch (average family income for a household size of four $\$ 39,220$ in 2008-2009) (Federal Register, 2008) was $8 \%$ (Public School Review, 2008). 
The middle school is also on the urban fringe of the same small city. In 20052006, its student population was 1,094. Its number of teachers was 72. Its percentage of White students was 92\%; its percentage of African American students was 4\%; its percentage of Hispanic students was 4\%; its percentage of Asian students was $1 \%$. Its percentage of students eligible for Free Lunch was 23\%. Its percentage of students eligible for Reduced Lunch was $11 \%$.

The intermediate school is also on the urban fringe of the same small city. In 2005-2006, its student population was 438. Its number of teachers was 30 . Its percentage of White students was 89\%; its percentage of African American students was 5\%; its percentage of Hispanic students was 5\%; its percentage of Asian students was $1 \%$. Its percentage of students eligible for Free Lunch was $21 \%$. Its percentage of students eligible for Reduced Lunch was $13 \%$.

The elementary school is within the small city boundaries. In 2005-2006, its student population was 621 . Its number of teachers was 37 . Its percentage of White students was 90\%; its percentage of African American students was 5\%; its percentage of Hispanic students was $4 \%$; its percentage of Asian students was less than one percent; its percentage of Native American students was $1 \%$. Its percentage of students eligible for Free Lunch was $27 \%$. Its percentage of students eligible for Reduced Lunch was $12 \%$.

2. Grade level and subject matter criteria are chosen to be indicative of the broad challenges to success, so that Special Education and social studies teachers are included in the study as well as math and English teachers. 
3. "Successful" teachers are chosen by the recommendations of principals and peers.

4. A letter of introduction to the study was followed up with a brief meeting with the deputy superintendent of schools to OK the study. Four principals were discussed as participants in the meeting with the deputy superintendent. The four principals were then contacted by telephone. The principals were asked to recommend the first teacher in the snowball sampling. Every effort was made to have the teachers be the main choosers of the participants, as their conceptualizing of success and their voices on success are the main focus of the study.

There is some overlap in success criteria used by teachers, principals and the deputy superintendent of schools. Using the snowball sampling techniques, the majority of teachers are chosen by other teachers, then by principals, and, finally, the deputy superintendent of schools describes his criteria for success in a teacher.

In the high school, the teachers mention individual improvement, whole class momentum, and teacher growth as success criteria. In the middle school, the teachers mention presenting materials well and seeing students remember and apply those materials as success criteria. In the intermediate school, the teachers talk about making a difference and student learning as success criteria. In the elementary school, the teachers, like the intermediate school teachers and the high school teachers, talk about making a difference and individual student achievement as success criteria. There is consensus among the teachers that student learning is a success criterion. There is an overlap in mentioning making a difference and the individuality of student improvement as success criteria. Teachers differ in how they describe reaching the whole class—whether through 
individuals, through strong presentation of materials, or through teacher growth (professional development).

The high school principal mentions studying, preparation, and a passion for teaching as success criteria for teachers and says students will be more successful if teachers are more successful. The middle school principal mentions planning and keeping students engaged, happy, and excited as success criteria. The intermediate school principal mentions success through what students do but also through the respect of colleagues and of the administration. The elementary school principal mentions teaching methods and bringing students to a positive mindset to do the best they can do. All four principals view teacher success criteria in terms of student success. Two of the four - the high school principal and the middle school principal—mention planning. Student success and planning are the main overlaps in principals' definition of success criteria for teachers. A passion for teaching, respect from colleagues, and teaching methods are secondary criteria for success.

The deputy superintendent of schools describes success criteria for teachers as being well-trained, perceptive about children and where they are coming from, and able with differentiated instruction. These success criteria overlap with the teachers' and the principals' seeing success of the teachers as dependent on the success of the student. The concern with differentiated instruction goes along with the high school principals' and the middle school principals' mentions of planning as a success criterion. Differentiated instruction also goes along with planning for individual student progress. The deputy superintendent of schools did not mention in so many words, making a difference, but he 
did mention professional development_-differentiated instruction being part of a countywide program of teaching techniques being taught to the teachers. Thus, the participants reached a consensus that teachers' success criteria were student-based. They agreed on the importance of planning and teaching techniques for the most part. On the other hand, they differed in the emphasis on making a difference, teacher growth, teacher passion, and respect from colleagues as success criteria.

\section{Description of the Participants}

The following nine teachers participated in the study:

The high school English teacher has been in education for thirty-eight years. She has taught in the county for thirty-seven years and in her current position for thirty-seven years. She is a Caucasian female. She is warm, well-immersed in her subject, and has a good sense of humor. Her classroom is decorated with student poems, student shield posters with name acronyms, and posters of Greek gods. The classroom is quite spacious. The desks are in rows facing a whiteboard. She uses an overhead projector. She provided the following documents and artifacts to show how she engaged her students in learning: vocabulary, biographical, and autobiographical poems; a word-web guide; and a thought-provoking evaluation questionnaire on persona, emotions, and audience in a story.

The high school Special Education teacher has been in education for eight years. She taught Learning Disabled English for one year and has been teaching the Mildly Mentally Impaired for seven years in the high school. She is a Caucasian female. She is enthusiastic, quick to laugh, and strong-minded. Her classroom is equipped with a 
washer and dryer, a bathroom, an oven, computers, and a couch. She has chinchillas in a cage in the front of the classroom. She provided the following documents and artifacts to show how she engaged her students in learning: pictures of her students on field trips and working, class rules, and a recipe for cookies. She focuses on life skills in her class.

The high school math teacher has been in education for ten years, all of them in the county considered. She has been in her current position for eight years. She is a Caucasian female. She is impassioned about her work. Her classroom is relatively bare during the classroom visit because the students have just taken the standardized tests and the tests require that any posters that could aid the students be removed from the walls. She explains that the missing posters show instructional materials about Algebra such as steps for solving an equation and order of operations. The students' desks are spaced individually and lined up in rows. She explains she also curves the desks to face each other for discussions. There is a white board in the front of the classroom and an overhead projector. The classroom is bright and quite large. Above the whiteboard, posters include "Encourage Others" and "Always Show Respect." To the right of the whiteboard, posters read, "This is a positive thinking area," and "Any way you add it up, math counts." On the back wall, a poster says, "The most important tool for success is the belief that you can succeed." She provides handouts on word problems about a sample family budget and balancing a checking account. She also provides lesson plans for hands-on activities about statistics. In short, she is concerned with life skills and relevance to her students, as well as making lessons tactile and memorable. 
The middle school sixth grade social studies teacher has been in education for twenty-nine years, all of them in the county. She has been at the middle school for thirteen years and has taught Language Arts and Reading as well as Social Studies. She has been a social studies teacher for five years. She is a Caucasian female. She is sincere and caring. Her classroom is colorful and well-decorated with posters of the Statue of Liberty, Great Americans, and pyramids. Her students' desks are arranged individually with matching pouches of supplies on the back of each chair. She provides the following documents to show how she engaged her students in learning: an internet activity on ancient civilizations, a study guide to reinforce the subject of ancient civilizations, and a Bingo game again addressing the subject of ancient civilizations. She has lessons that build on each other to cover the material from the textbook. She shares a study guide used during a video. In short, she approaches her topic from diverse angles to engage her students.

The middle school sixth grade science teacher has been in education for twentyseven years and for three years at the middle school. She is a Caucasian female. She laughs easily and takes a strong interest in teaching science, especially the labs and activities. Her classroom is colorful with educational posters on the walls such as a periodic table of elements, a tree showing the seasons, and pictures of seeds germinating. On the cabinets in the back of the room are two old hornets' nests and animal skulls. There are laboratory supplies in the back of the room. The tables are set up in rows with pairs of students next to each other to form groups of four. She shares documents that include letters home, quizzes, and descriptions of activities. 
The intermediate school first fifth grade teacher has been in education for two years, both in her current position. She is a Caucasian female. She has recently received her Masters degree in education and has many wonderful ideas about how to teach. She turned around the class which she "inherited" last year. Her classroom has puzzle pieces in primary colors for jobs, and she has introduced the theme of teamwork through the metaphor of puzzle pieces fitting together. Her students' desks are arranged in two groups of five and thirteen individual chairs. She says she does not have room in her classroom for all the students' desks to be separated. She explains activities such as a classroom treasure hunt, a unit on the rationing during World War II, and a word ladder. She makes learning fun for her students and uses a variety of techniques to engage them in learning.

The intermediate school second fifth grade teacher has been in education for fifteen years and for five years in her current position. She is a Caucasian female. She is professional, passionate about teaching, and caring. Her classroom is decorated with Snoopy posters which say, "Things turn out better when we work together," "Life is like a ten-speed bicycle. Most of the gears we never use," and, "Everyone smiles in the same language." Her students' desks are in rows with most in pairs, but some individually arranged. She provides word problems, letters home, a left brain/right brain activity, and a map journey. She is inventive and concerned with differentiated instruction.

The elementary school first grade teacher has been in education for sixteen years, all in the county. She has been in the elementary school for five years and a first grade teacher for three years. She is a Caucasian female. She is sincere, "hard on herself," has 
a good sense of humor, and is very warm. She teaches in an open classroom, separated from the other classrooms by partitions. Her posters include a safari motif. Her posters say, "Welcome: Join Us in a Learning Safari," and, "Wild About Reading." She has a "Big Book of Rhymes" on a small whiteboard. Her rules include, "Speak and Behave Courteously." She is very good at communicating with her students and reaching them where they are.

The elementary school third grade teacher has been in education for three years, all of them at the elementary school in the county considered. She is a Caucasian female. She laughs easily, exudes enthusiasm, and has clear ideas about No Child Left Behind. She teaches in a trailer classroom which is brightly lit and cozy. Her classroom is organized with seats in rows and a circular table for group work. Her desk is in the front right-hand corner oriented so that she can see her students from the desk. Her motivational posters include one that says "Do your BEST" and another that says “Success: Don't just wish for it. Work for it!" She provides documents including rules, letters home, and descriptions of a creative spelling activity.

The following five administrators participated in the study:

The high school principal has been in education for sixteen years. He has taught for seven years and has been in administration for nine years, five years in his current position. He is a Caucasian male. He is caring, impassioned about students' well-being, and professional.

The middle school principal has been in education for twenty-eight years. He has taught for eight years, six as a sixth grade teacher and two as a Jobs Training Partnership 
Instructor. He has been in administration for twenty years, two as an assistant principal, fifteen as an elementary school principal in the county, and three years at his current position as middle school principal. He is a Caucasian male. He is energetic, has a good sense of humor, and is warm.

The intermediate school principal has been in education for fourteen years. She has taught for eight years and has been an administrator at of the intermediate school for six years. She is a Caucasian female. She is kind, concerned with the well-being of her students—with a soft spot for Special Education students—and is a team builder.

The elementary school principal has been in education for thirty-six years. He has taught for eleven years and been an administrator for twenty-five years, ten of which were in the county. He has been in his current position for six years. He is an African American male. He is calm and knowledgeable in manner and clearly cares for the children's growth and faculty relationships.

The deputy superintendent of schools has been in education for thirty-eight years. He taught for fourteen years. He was a high school assistant principal for three years. He was a high school principal for ten years. He has been deputy superintendent of schools in the county for eleven years. He is a Caucasian male. He is knowledgeable and cares about professional development and quality of teaching, believing that educating gifted students is the biggest challenge to public schools today.

Thus, all of the teachers are female Caucasians with an average of sixteen years of experience in education, whereas four out of five administrators are male and four out of 
five administrators are Caucasian with an average of twenty-six years of education experience.

\section{Data Collection}

The research strategy in this study is to engage in semi-structured and open-ended interviews with a range of teachers in order to better understand their conceptions of success. The background framework of a literature review focuses the protocol and my interpretive stance. The interviews are audio-taped and transcribed. Reading the results of the interviews follows the guidelines of Harry, Sturges and Klingner (2005) and includes an informed coding method to go along with a small sample size and limited time frame for interviewing. Following "Mapping the process: An exemplar of the process and challenge in grounded theory analysis," the method of coding is inductive and built from the ground up in the sense of iterative analysis of the language collected through interviewing. Facing participants with some familiarity of the extant discourse and rhetoric about success enables a better reading of their answers.

The protocol for the deputy superintendent, the principals, and the teachers can be found in Appendices A, B, and C. The protocols address the research questions as follows: Table 1: Protocols Address Research Questions

Research Question: Teacher Interview: Principal Interview: Deputy Superintendent Interview:

1. What are the critical Questions 2, 3, 4, 5, Questions 2, 3, 4, 5, elements of current educators' $6,7,8,9$ $6,7,8,9$

Questions 2, 3, descriptions of their success? 
Table 1: Protocols Address Research Questions (cont.)

Research Question: Teacher Interview: Principal Interview: Deputy

Superintendent

Interview:

2. How do educators in

Questions 1, 2, 3, 4, Questions 1, 2, 3, 4, an elementary, an inter$5,6,7,8,9$ $5,6,7,8,9$

Questions 1,2, mediate, a middle, and a high school within a single county conceptualize success?

3. What core beliefs and Questions 1,2,3,4, Questions 1,2, 3,4, Questions 2, 3, values do teachers express $\quad 5,6,7,8,9 \quad 5,6,7,8,9 \quad 4,5$ when describing their success?

The deputy superintendent questions are asked in a twenty minute interview, while the teacher and principal interviews are given in one forty minute sitting. Each interview is followed up with member checking against the excerpts from the transcripts used in this dissertation. The teacher interviews are followed up with looking at documents in the classroom and requesting examples of other pertinent documents.

\section{Document Analysis}

The documents are compared with the interview data collected through the interview process. The documents include artifacts suggested by the teachers, such as assignments about activities, class rules, letters home, or posters. The findings from the documents are explained briefly in Chapter V as they parallel the "in vivo" terms from the interviews described in Table 2 on pages 143-144. Next, axial coding is considered through study of the perspectives shown by the different teachers' documents and how the teachers on various grade levels address the research questions. Finally in Chapter VI, on the level of thematic coding, the documents are compared briefly to each other and to the interview data. The 
observations of the educators and their classrooms are considered in coding the data and compared and contrasted with perceptions of the fourteen educator interviews. An explanation of where the language of documents and the language in the interviews are redundant and where they have similar themes is provided in Chapter VI.

\section{Triangulation of Interview Data}

The study's methodology includes collecting data through the interview process and gathering texts of documents and viewing artifacts. The interviews include the three perspectives of 1 . the teachers of nine different classes, 2. the principals of four schools, and 3. the deputy superintendent of schools. By comparing teachers' interviews with principals' and the deputy superintendent of schools' interviews, three-way perspectives on such issues as the relationship of student success to teacher success are gained. As Stoner et al. explain in their description of "Triangulation," "Triangulation is the process of corroborating evidence from different individuals, different types of data, and different methods of data collection (Creswell, 2002)" (Stoner et al. 2005, p. 41). By comparing the three views of county teachers, principals, and the deputy superintendent of schools; the different data types of multiple interviews and document collection; and the different methods of collecting data from interviews and the documents, a more accurate understanding of the critical elements of success is gained.

Another way to increase the accuracy of observations is through "member checking." "Member checking [is] the process of providing participants with a transcript and [checking the accuracy] of all their personal quotes" (Stoner et al., 2005, p. 41). Through inviting the participants to comment on a draft of the findings describing their 
participation, each case of voicing success becomes better grounded in reality. Thus, the design of the study includes opportunities for triangulation through multiple participants, multiple data sources (interviews and documents), multiple perspectives (teachers and administrators), and member checking.

\section{Researcher}

I bring to research on success a successful education with a B.A. in Honors English from Harvard University, an M.A. in English from the University of Virginia, and an expected Ed.D. from West Virginia University. My most successful teaching has been in schools with high academic standards, but I have actively sought to serve diverse populations and increase my strengths at reaching a broad range of learning styles. My career as a teacher began in independent schools with a close mentoring process as an elementary school teacher and then with the public school certification process in San Francisco. I have taught overseas, in a community college, and at the university level as well as teaching English in public high schools. In addition to teaching, I have worked for the U.S. Congress's Office of Technology Assessment comparing health care in rural versus urban areas, and am interested in government policy and local applications.

I have taught in communities and cultures where the vocabulary and reasoning of students led to ease with standardized testing and also in communities and culture where the vocabulary and reasoning of students led to difficulty with standardized testing. In my opinion, one kind of test is not encouraging of every kind and level of learning. To me, teaching is a mutual pleasure: cognitive advances in students have been a pleasure to my students and seeing my students succeed affectively has been my measure of success. 
Because I have taught in small classes and had the time to devote individual attention to students, I have seen them work through frustrations and come to clarity and confidence as individuals developing. Therefore, when I began this study, I came with a bias that teaching successfully has an affective and an aesthetic side involving trust and joy. I have had the opportunity to contribute to joy in learning and to help to promote lifelong learning and, having participated in bringing excitement and motivation to classes myself, I empathize with the successful teachers in this study.

\section{Analysis of Interview Data}

The example of Harry, Sturges and Klingner (2005) is followed in coding the entire data set as the first level of inductive inquiry, including "in vivo" terms that repeat across all the interviews. The interview data is compared and contrasted. After categories of meaningful units are found, themes from the interviews emerge. The steps of the process of analysis are "open coding," "axial coding," and "thematic coding" (Harry, Sturges \& Klingner, 2005). When the conceptions of the teachers, the principal, and the deputy superintendent of schools are redundant, they suggest dominant categories (Harry, Sturges \& Klingner, 2005).

\section{Cross-case comparison}

The participants' answers to interview questions are compared: across teachers, first; then across principals; and, finally, across all the participants-including the deputy superintendent of school for his shortened interview answers-pooled as a single sample population of educators from one school district. Within each of these cross-case comparisons, different categories and themes emerge to suggest the conceptions of success of 
teachers, administrators, and local educators taken collectively, thus answering the research questions. After a comparison of the interview data in Chapter IV, Chapter V presents how the findings address the research questions.

\section{Responses answer Research Questions}

The responses from the interviews address the research questions as outlined in Table 3 on page 177. Findings from the interview data answer each of the three research questions, as discussed in Chapter V.

\section{Relevance of Findings to the Literature Review}

Findings from the interviews relate to the literature review, as discussed in Chapter VI: Conclusions.

\section{Summary of Methodology}

The main data from the study is the answers to the interview protocols shown in Appendices A, B, and C. The interview data is summarized in Chapter IV, comparing and contrasting the data participant by participant and then pooling each group of participantsthe teachers, the principals, and the participants as a whole, including the deputy superintendent of schools. The sample population of educators within a single county focuses on successful teachers as chosen by the principals first and then by each other. The teachers' voices on success are compared to the voices of the administrators. Chapter VI shows how the emergent themes from the interview data compare and contrast. Conclusions about how the interview data relates to the data from documents and observations are included in Chapter VI. Triangulation of data is achieved by comparing and contrasting the perspectives of the teachers, the principals, and the deputy superintendent of schools (Patton, 2002, p. 247). 


\section{CHAPTER IV}

\section{RESULTS OF THE INTERVIEW DATA}

The results of the interview data are presented question by question from the ninequestion interview protocol. The answers to the questions participant by participant begin with the high school English teacher and end with the deputy superintendent of schools (except for those questions not included in the protocol of the deputy superintendent. See Appendix C). First, similarities and differences in the voices of the teachers are considered, then in the voices of the principals, and finally in the voice of the deputy superintendent of schools. From the "in vivo" language of the interviews, more general themes emerge. These themes are explained after an explanation of the individual perspectives. From the three perspectives of teachers, principals, and the deputy superintendent of schools emerge three axiomatic themes which offer triangulation of interview data, as discussed in Chapter VI. From the axiomatic themes compared together emerge the general themes found in Chapter V: Results Answer the Research Questions and Chapter VI: Conclusions which discuss, respectively, how the findings address the research questions and how the findings relate to the literature review. In being brief and in making comparisons among the perceptions, a great deal of interesting data is of necessity left out, but every effort is made to include enough of the voices of the educators to show their views honestly.

\section{Question One}

Question one, "Describe your students, school, and community," elicits descriptions of a rural area growing into a suburban area. Positioned south of a small city 
(population about 16,000), the southern end of the county considered in this study was "rural" ten years ago, according to the deputy superintendent of schools. High school teachers answered question one using the language of caring, of statistics, and of community involvement. In a school of roughly 1500 students, growing fast, community feeling remains a high priority. The high school English teacher says:

The community is very caring and it's very supportive of education and very helpful, constantly offering help to the school, and the students for the most part are good to work with and we usually get positive reinforcement and assistance when we need it if we call home. There are some that don't always respond, but a wide, wide majority are still—they almost feel like family.

Her language of caring continues as she describes the growth of the community. She says that as the school includes more children of parents working in metropolitan areas, the caring and helpfulness of the community diminishes, "Some. But not to get rid of it. Not yet." Her description of the community being "like family" is repeated in the voices of other participants using various phrases such as "close-knit" and "community involvement." The growth of the high school population sometimes threatens the closeness of the community according to the three successful high school teachers who participated in this study.

The Special Education teacher mentions community growth just after describing her students' IQ's and ages. She says:

The school is a public high school in [the southern end of the] countyapproximately 1500 students, maybe a few less in the school. It's one of three public high schools in the county. And the community, we're on the cusp of the...metro area. We have a lot of people whose parents commute into the city to work, but they come back here to live. And juxtaposed to that, we have the people who've been here for generations who grew up with apple orchards and farming the land and using the land for their 
income. So we have kind of a conglomeration of city folk and country folk coming together and we're kind of like Green Acres here at [the] high school. So I guess we'd be classified as a rural community because we actually have land that rolls on and on without development, but it's becoming more suburban in my opinion.

More specifically, she explains how school growth has led to portable units and traveling teachers, adding, "So that in itself makes it kind of hard to be a teacher in a growing area, but...we pull up our bootstraps and we go with the flow and make as positive an atmosphere for our students as we can." Both growth in the community and growth in the high school have pros and cons. The Special Education teacher explains, "I like the change of the influx of people because that brings new cultures and new opportunities and ultimately maybe more businesses to the area. I don't like the situation that it seems like we're struggling to keep up with the growth." As the community and the high school grow and diversify, teachers find the close-knit feeling of community fraying a little.

The high school math teacher speaks to the problems that come with growth. She, like the other high school teachers, only with a more impassioned voice, explains at once:

This south end of [the] county tends to be a close-knit community. We have lots of traditions in the school. We do spirit week. We try to involve the community. And we're trying to maintain that level of community involvement. Like I said, with the growth, that seems to be becoming harder and harder. There seems to be more of a disconnect of the community from the school. It seems like everybody used to know everybody and now that just isn't true any more, and it's really harder for people to connect anymore. That's something that the school would like to maintain and that we're trying to maintain. But I have seen that we're starting to lose that close-knit small community type of feel.

The teachers at the high school value highly the feeling of community characteristic of the south end of the county. The similarities in language among the teachers are striking and the differences are relatively minor. The high school English teacher speaks of 
family and caring. The high school Special Education teacher describes growth and diversity more statistically although she is clearly another very caring teacher. The high school math teacher speaks of community involvement and connection, a slightly differing perspective on the strain of a growing population.

The middle school teachers also teach in a large and growing school, "the biggest [middle] school in the state," as the principal explains, roughly 1200 students. The middle school social studies teacher talks about the changes she has seen over the years in terms of support from the child's home. She says, "You have to consider the child's background now—more so than when I first started teaching." In voicing her perspective on the change in population, she draws on twenty-nine years of teaching experience, having started teaching in 1971. She compares teaching in the seventies to teaching now in the following words:

We have students who come from families who-education is a priority in their lives, and then we have students who come from families who can barely hold it together where education is not a priority. And so we have to deal with all of that, and there's not any one set way you can deal with a classroom of children anymore because of where they come from and what kind of support they have and what the focus is on the family.

She finds now that families are moving a lot and that when families came from more rural, albeit lower socioeconomic areas, they were more involved in their children's education.

The middle school science teacher has taught at the middle school level for three years, having taught at the intermediate school level for twenty-four years. She differs from the other teachers discussed so far in celebrating the pleasure of teaching in a rural area. 
The school that I'm teaching at is kind of in a rural area. The students are very enjoyable. They aren't quite-I don't see the behavior problems here as much as I see in town more where I live-now, I've never taught at those schools. But there's a lot of parental backing here, a lot of support from the parents. It's just a real nice area to work in.

Like the other successful teachers who participated in this study, the middle school science teacher cares about parental support and involvement. She finds positive community involvement to be untainted by recent growth in the population.

The intermediate school has a population of roughly 450 students. The fifth grade teacher with only two years of experience teaching likewise looks on her community with fresh appreciation.

The community I'm not all that familiar with because I didn't grow up here. I've lived here for about a year, but it seems to be, especially in this area, a really close-knit community and it seems as though-when I first started working here, I thought it was the same as [the nearby small city], but it seems very different from [the city]. It seems to be a much smaller community feel. It's a really nice community. And the school is very familial I guess in that teachers all really care about the students and the parents all really seem to care about the school and the teachers. So it's really kind of nice. There's no apathy as to what it's going to be like here. Everybody tries and everybody works hard to make it a nice school.

Her more experienced colleague who has been teaching for fifteen years says the southern part of the county "is a family of their own." In terms of diversity, she describes the student population as, "I don't think there's very much diversity here. There's some and each year it continues to grow, but it's not as much as other schools." Both intermediate school teachers find the community to be close-knit and neither describes trouble with growth in this smaller, younger grade-level school.

The elementary school is a Title I school with a population of 525 students. The first grade teacher who is now a librarian describes her community as: 
We are basically a suburb. Within our community, we are getting students who live in a more rural area and also-I don't know how to describe it any more because it is heavily populated. We have a big influx of students from... [a bordering state]. So a lot of students are coming from well-educated homes and we also get a lot of students who fall below what we consider the poverty level. We are a Title One school due to the fact that we have a lot of students on Free and Reduced Lunch. So we really have a mix of students. As our area's changing, we just don't really have a way that we fit in. We're not a rural country school anymore. We're trying to become a metropolitan area I guess. We have a mix of kids. We really do. I still think of it, because I grew up here, as a rural area. I really do.

Both elementary school teachers describe parents as very involved. Two years ago, "We were the very biggest PTA in [the state]," in the words of the first grade teacher. With high community involvement and good connection with parents, the elementary school seems to enjoy positive relationships outside the classroom as well as inside. The third grade teacher also finds parents supportive. She says enthusiastically in her first words:

I would say I work in the best possible situation, but in all seriousness, I really do feel that way. I've always taught here, but traveling to other places and telling people my story, they're like, "Wow, you live in an ideal place because of the growth here and the community and how supportive the community here is." We actually have extreme parental involvement, and some people don't like it or don't encourage it, but I do. I very much value that parental support that we get here.

The valuable parental support that builds a sense of community is especially strong on the elementary level.

Among teachers considered as a pooled population of participants, there is consensus that community and parental involvement is valuable. For the most part, answers to question one included language finding growth difficult in the high school and the middle school. On the other hand, the high school Special Education teacher specifically mentions appreciating growth in cultural diversity and the middle school 
teachers meet the challenge of growth from the perspective of individual relationships

and from the perspective of fresh appreciation of a new position. For the most part, in the smaller intermediate and elementary schools, teachers find the community supportive regardless of growth. The younger grades enjoy more parental involvement and familial feeling. On the other hand, there is some nostalgia among more experienced teachers for the time when the area was more uniformly rural.

Principals in general describe community and growth more objectively and statistically in answering question one. The high school principal gives an overview of the school's growth without protesting the loss of connection with the community. $\mathrm{He}$ does at the end of the interview explain that he misses the personal contact of classroom teaching as do other principals. To select from his story of the growth of the area:

The size of our school is approximately fifteen hundred students with almost one hundred faculty members and an additional forty to fifty staff. So in describing our students, we have mostly rural students who come from that background, but we have had an influx of — growth—of students coming in from urban areas... [and more urban counties from bordering states] which has brought in an array of different types of thinking. So we've got students from a diverse dichotomy who have brought in urban thinking, dress, ways of life, mixed with students whose great grandparents went to school in this area. So it's very diverse...We also have an increasing diversity in race. We've gone from ninety-eight, ninety-nine percent mostly white population to probably ninety, ninetytwo percent, and - these statistics I'm giving you are estimates off the top of my head-probably four percent African American; four or five percent, four percent Hispanic; and we've got a mix of some Asian and others in there.

The middle school principal tells the story of growth using language of trust and communication more like the teachers and less like the other principals:

Our students are basically — previously our school was more of a rural setting. We have transitioned over the past ten or maybe even fifteen 
years into a more suburban and bedroom community that basically has had a large influx of folks from metropolitan areas, with their expectations [which] are a little more closely associated with a bedroom community. They've expected a lot more communication. They expect a lot more quickness whenever we are dealing with problems. Their trust level is not as high as what it was because they don't have the background knowing what the community is like and knowing what the schools have been like over the past years. So you have to prove yourself a little bit more often.

The intermediate school principal describes her school's growing diversity succinctly.

We have roughly 450 students spread out between the ages of nine and eleven years old. We only have fourth and fifth grade. The school is-we do not have the diversity that you'll find in some school districts, especially in [this state]. But we do have some diversity and it's growing. We do have more of an ESL population, English as a Second Language, than any other and that's mostly Spanish speaking... Last year, I think it was $12 \%$. [The African American population is] about 4 to 5 percent.

The elementary school principal describes the diversity of his school's student

body as follows:

Our school is approximately_about $40 \%$ Free and Reduced Lunch attendees which means to me not so much having a high level of poverty but having a good diverse population of students that live in the area. At present, we have 525 students Kindergarten through third grade—seven classes of Kindergarten, seven classes of first, six classes of second and five classes of third grade students. And our student population covers the gamut from those that are really low as far as mental capacity and abilities are concerned to as we would say the gifted students or accelerated students.

He describes the ethnic background of the students as, "97\% Caucasian and then African American would be the next group of students and then some Hispanic students. We have one Asian student presently, and I think we have three Native American students." All the principals describe strong parental involvement except the middle school principal who says that, "parents who are tired from the elementary process and the 
elementary side are now at the point where they say, 'Well, I'm going to back up a little bit. I'm not going to put as much energy into watching my child to be sure that they're successful.' And we as a school have to spend a lot more energy on keeping parents involved." The high school and middle school principals in the larger schools describe growth in the community population. On the other hand, the intermediate and elementary school principals describe the population as a mix of rural and urban without emphasis on growth.

The deputy superintendent of schools describes the overall community of the county, including the southern end of the county which participated in this study.

I'd say we are a community in transition. Let me say that I think as short a time as ten years ago - that would put us in the late nineties-we were probably still pretty basically three separate units. We have the northern end of our county, the southern, and the central. The northern and the southern were rural. The students for the most part were from rural backgrounds. And the kids going to [the] high school in the central part of our county were basically kids that lived either in the suburbs of [the city] or directly in the city. So I think over the last ten years, both the northern and the southern ends have become more suburban than they are rural. I feel like our farms are decreasing and the orchards are decreasing and there are not as many kids whose families are involved in agriculture on those ends of the county as there were even five years ago. So it is a changing community. We have an influx of Hispanic children. They're primarily attending the city schools. And that's probably been the biggest demographic change in our school system along with the influx of kids from the more urban areas... and their suburbs. That's where our population increase seems to be coming from.

While participants for the most part agree the county, especially the southern end of the county, is growing, the effects of that growth are felt more keenly in the higher grades. The intermediate school and elementary school teachers and principals tend to 
differ from the high school and middle school teachers and principals in describing familial feelings and diversity in the population.

\section{Question Two}

Question two, “How do you define 'success'? How do you see personal success and how do you see student success?" prompts thoughtful and quite expansive answers. Points of comparison and differences help to select from these answers as they are considered in the order of teachers, principals, and the deputy superintendent of schools.

The high school English teacher uses language similar to other teachers in defining her success by student success and in speaking of the learning moment as enjoyable, using the "in vivo" term when "the lights came on." On the other hand, she differs from many other teachers in her years of experience and in her focus on college. She says of her definition of "success":

I define my success by my students' success. And what keeps me here and has kept me here for thirty-seven years is not, obviously, the money or any other perks along that line. It's the students who come back and say, "Man, I did great in college because you showed us this and that and the other and I was prepared. I knew what I was doing." As well as just even having a student in the classroom for the day that finally the lights came on and they know what you're talking about.

The high school Special Education teacher likewise defines her success by student

success and speaks of "the light bulbs going off." She differs from other teachers in teaching the moderately impaired class and in her emphasis on real-life skills. She says of her definition of "success":

I achieve success with my students when I see the light bulbs go off. We've been working on telling time for three weeks and suddenly they go, "Oh my gosh to do three o'clock, the big hand is on this and the little hand is on this." They've learned it. They've achieved that. So that's one way, 
by their work performance. Also, I think it's an emotional success. When I see them take risks - maybe go up and talk to somebody new that they've never talked to before-or maybe want to take part in a school activity that they've not taken part in before-go to the homecoming dance-those are huge things for them. And when they want to do that and they're able to do that and achieve success, that's for me [and] for the students. A life skills-oriented success-when they know that if a recipe calls for salt and pepper, they know what the salt and pepper is. If a recipe calls for a quarter of a cup, they can measure a quarter of a cup. Those are all real-life, tangible successes that I see them achieve. So I guess that's how I achieve success.

The high school math teacher defines personal success and student success as, "I would like to be able to put kids on an individual basis...I see personal success and their own personal success and their achievement as a success." Thus, she, for the most part, agrees with other teachers that student success determines personal success. On the other hand, she differs from other teachers in how she separates personal success from student success, saying:

Success, personally, for me, is to always do better. I'm someone that is intrinsically motivated and driven to be the best. Anything I choose to do, I want to be the best at it. So I've chosen teaching as my profession. It's something I want to be one of the best at. And I also have the feeling at the same time that that's something you can actually never achieve. I think the way that you become the best or you are one of the best is if you're always trying to grow as a teacher... I just think the best teachers continue to grow and they don't just do the same thing and aren't satisfied with doing the same thing from year to year. So that's personal success for me.

The high school math teacher defines student success as harder to measure than personal success. In a fuller quotation, she discusses test scores.

Student success for me is a little harder to decide what that is. I would like to be able to put kids on an individual basis, but I see personal success and their own personal success and their achievement as a success. But I think that really cannot be done with standards, and all states have standards, and then there's No Child Left Behind...I think for example our 
test-our [standardized test] is for tenth graders - I can have a tenth grader that is not the best in math and is not going to do real great on the [standardized test]. But as a teacher I can see that they have improved over the year for me. This kid has been successful, but unfortunately he hasn't met the standards, so someone else is telling them and me that, no, they're really not successful.

While many participants discuss the inadequacy of standardized test scores as measures of student and teacher success, the high school math teacher differs from some other participants in raising the issue of No Child Left Behind when defining student success so early in the interview, in answering question two.

The middle school social studies teacher agrees with other teachers that personal success is defined by student success, saying, "Personal success-I want my students to enjoy social studies." She does not use the "in vivo" phrase "light bulb going on," but she describes the moment of learning in terms of enjoyment and interest. "I want them to enjoy. So I think I measure it by sometimes just by their comments or by how I see them all looking in their books or listening intently to me. It's not just in a paper, pencil test that I use." The middle school social studies teacher differs from other teachers in the strength of her emphasis on individual expectations. She says, "I have different expectations for different students depending on what kind of abilities they have and depending on what kind of a home life they have and how much help they have at home."

The middle school science teacher, like the other teachers, measures her success by student success, saying, "As far as success goes, if I teach something and either in worksheets, quizzes, or in applying it to the lab, if they can take what they've learned and remember it and apply it, then I feel pretty successful." She describes student learning by enjoyment as do other teachers, saying, "Oh, they must have really gotten that concept. 
That must have been something they really enjoyed." While, for the most part, she agrees with other teachers about her definition of success, she differs about how she specifically measures success. She explains:

I ask them, I say, "I want you to be honest with me,"-my honors class"What did you like about the class? What didn't you like about the class?" And the feedback was really good because they really enjoyed what I thought was good about the class-the hands-on activities, the labs. So that's good.

Her request for direct feedback from the students is a technique which she mentions which other teachers do not mention.

The less experienced intermediate teacher agrees with other teachers about personal success relying on student success in the present, but she is uncertain about her concept of long-term success. When asked, "What about personal success? How do you see your own success?" She answers, "I don't know. I've never thought about it—my success in teaching. I don't know that I can really answer that question." She goes on to agree with other teachers that student success is "when the light bulb goes on."

“Teachers always talk about that 'aha' moment when the light bulb goes on and it really is-there's kind of a high to it. When you see that, it's just amazing that, 'Yeah, I turned on the light bulb." More than other teachers, the new intermediate school teacher stresses lifelong learning.

I'm a big reader. I want them to love books all their lives. And really just—it sounds cliché—but I want them to just love learning all their lives and realize that learning isn't just in a classroom and that they can go home and learn and that their entire life they will be learning new things. And I try to reflect that. When I get excited when they tell me something that I didn't know, I'm hoping that they'll always have a love of learning because there's always new stuff to know. 
The more experienced intermediate school teacher agrees with other teachers that personal success relies on student success. She puts it this way, "[Personal success is] going home and knowing in the evening that I made a difference in somebody's day that I taught something that they get. That makes me feel a lot better, makes me feel successful that I've taught somebody something." Like other teachers, the more experienced intermediate school teachers sees student success as excitement and pleasure in learning. "I see student success when the little light bulb goes on and when [they] say, 'I get it. I see what you mean when you say...' or, 'Now, when my Dad says such and such I know what he's talking about.' You can just see their facial expressions, sometimes the things that they say, and tracking their growth." Her story of tracking growth is different from that of other teachers as an overall measurement of success. She says, "If you take samples of their work at the beginning of the year and compare it to samples of their work at the middle of the year and at the end of the year, you can see how they've grown as writers and as readers."

In the elementary school, the first grade teacher agrees with the other teachers that her personal success comes from student success. She defines student success as individual achievement and growth. She does not speak of excitement and pleasure in the learning moment but she speaks of compassion and kindness. In her own words:

Basically, what I like to define as success is when I break it up. I don't count a test score or the majority of my students passing as success. I don't necessarily count if I give an informal reading inventory for the day and they all pass, I don't count that as success. I look at individual success of students. I had-just in the kids that I had-they range from LD to-just had a whole spectrum. I really had to stop and look at individual success. So when I do success in my room, it's based on the individual and what they have achieved for the year. I cannot any longer 
do it as a class. I'm not the kind of teacher who will make an

announcement, "OK, all my students got $100 \%$ on the spelling test today."

Continuing to define student success, she speaks of compassion.

I want them to be above all compassionate with each other and to understand that not everyone is going to be the same. And it's hard for them to understand. We try to be the best that we can, but I'm only part of their day. So we work on that and citizenship and understanding that everybody is different and that we like each other and that we get along. But then they get out to the real world and they realize that not everybody does get along. Maybe their parents don't get along or their parents don't get along with the mailman or whoever. So it is a big job and we try to do the best we can while we're here and, hopefully, teach them to be kind to each other. That's the big thing is just to help them to be kind to each other.

The third grade teacher differs from the other teachers in defining her personal

success as similar to student success, as opposed to as relying on student success. Like

the high school math teacher, she mentions No Child Left Behind in her first response to question two. Like the first grade teacher, she emphasizes individual growth. In her own voice:

I think the way I see success for my students or for me or for anybody is when they accomplish something they've been working towards. One of the things that I see as successful - actually, I have a poster in my room that says, "Success. Don't just wish for it. Work for it." Something that you're constantly working towards. And there's a point at which you attain success and then you set a new goal for yourself. And you can be successful again, taking that goal to a new level. That's the biggest thing, just making improvements or achieving goals that you've set for yourself. See growth. I know one of the pet peeves that I have about No Child Left Behind is comparing a group of students to another group of students and it's not really accurately portraying whether this particular student made progress from the beginning of the year to the end of the year. If this child started the grade on a first grade reading level and is now on a two and a half reading level, they've made a lot of success! They've improved a lot. 
Taking the teachers as a pooled population, for the most part, they agree on defining personal success by student success and defining student success as the light bulb going on. On the other hand, teachers define student success as long term individual growth, especially in the elementary school. Individual differences among teachers' responses to question two depend on subject matter, grade level, and experience, as well as on personal perspective. Differences include seeing teacher growth as similar to student growth but not as measured by student learning, emphasizing seeing student learning as individual versus as a whole class or as a group on a standardized test, and sometimes in using the language of "achievement" as opposed to the language of excitement and pleasure in learning.

The principals tend to define success by school environment. They also mention having their schools' success measured by test scores. While most principals find standardized test scores to be a poor measure of success, the elementary school principal is more positive about standardized testing. Considering the principals one by one from the high school to the elementary school shows common concerns about school environment and differing concerns unique to each voice.

The high school principal answers question two overall as how other people view success but personally by whether he would have liked to attend the school. He thus defines personal success by student success like most of the nine teachers. He says:

I've been forced to look at how other people view success, so number one, you have to look at your test scores; you have to look at your attendance, graduation rate. All of those things are at the top of every principal's list because if you ignore them, then the state comes in and tells you you're not a good principal. Those are things you have to have immediate attention on all the time. But personally, when I look at a principal's job, 
[I ask] is the school a reflection of the principal's personality? Is this school a place that I would like to have attended as a student? Is this a place that I would like to have my children attend? I'm blessed in here because I live in the school district and I want it to be that way.

The middle school principal speaks of school safety and a caring environment first. Like the high school principal, he mentions test scores and attendance. He explains personal success in terms of relationships and student success in terms of the wellrounded learner. To quote rather than to paraphrase, "I think first thing is seeing we maintain a safe school...leading teachers and students and staff members to watch out for kids and show a caring atmosphere in our school." Continuing to define success, the middle school principal, like the high school principal, mentions test scores and attendance. "Working towards success, test scores are a little part of it, but they're very important because that's some of what's a very clear-cut, easy way to measure whether things are going well. Attendance rate is also critical—making sure that you feel like kids are attending and that they're doing well.” In defining personal success and student success, he explains:

As to my success, I also like to develop good relationships with people. I want them to know that I'm going to be responsive to their concerns and needs as a faculty and staff and parents. But also I am trying to make high expectations for both. Kids' success? I believe you have to have a wellrounded learner. I'm really thrilled when we can point out-whether it's school contests, school opportunities, but it's also making sure that the kid also is involved in outside activities outside of the school, that they're also involved in other things, that we can also highlight those interests and opportunities.

The intermediate school principal explains that standardized test scores are not the only way she measures success. She defines success by student success, but she differs 
from other principals in specifically talking about social and emotional success. She says:

We have to be very careful about when looking at success both personally and professionally and with students. It's not all what I can see on paper and pencil, what I can see in standardized test scores. We're just so driven by that. Our schools are measured by that Adequate Yearly Progress and it's based on those test scores. I don't judge success just on that.

Specifically, she defines success differently from other principals in highlighting the socioemotional side to student success. "We have success here both academically—but there's also emotional and social successes that we celebrate greatly." In celebrating learning, she sounds like teachers, and, in focusing on relationships, she sounds like the middle school principal, "I try very hard to have strong relationships with students and their parents."

The elementary school principal also talks about measuring success by test scores. He talks about having a good school environment. He emphasizes the partnership between parents and teachers. "The student success as everyone knows now, the big measure is whether you made [Adequate] Yearly Progress. And we have made [Adequate] Yearly Progress for the last several years as well as being a distinguished Title I school. So those are some of the things that we look at." He speaks of personal success in terms of school environment. "Personal success, I would look at if things are going well, the environment is good, the students enjoy being in school, the staff enjoys coming to work, I think those are some of the measurements of success that we can have in a school building." He also sees relationships as central to success: "I talk to the staff often about making a partnership. We can do only so much. [The parents] have another 
part that they can do that we can't do, so that both groups working together...insure success for the students."

Overall, the principals agree with the teachers that personal success depends on student success. They agree with one another that a caring school environment is essential to success. The principals differ from the teachers in explaining the importance of test scores as opposed to the importance of the learning moment. Like the teachers, however, for the most part, principals think standardized tests go only so far in measuring success. Specific differences among principals include emphasis on the individual student's experience, emphasis on relationships, and emphasis on the socioemotional side of learning. Not every principal stresses each of these emphases equally.

The deputy superintendent of schools answered question two similarly to the other participants in his basing personal success on student success. He differs from teachers and principals in emphasizing consistency in teacher training. He does not mention standardized tests in answer to question two and in this respect he differs from principals. He says, "Success is based on the ability to see a consistent, effective, and efficient system in place to deliver instructional programs which then hopefully would ensure success in our kids, in our students. But the biggest job that I have is keeping consistency, being sure that our teachers are trained because of the transience of our teachers and our students." The deputy superintendent of schools gives an overview of the instructional system in the county.

Participants as a pool, for the most part, see teacher success as dependent on student success. They mention caring relationships with students. On the other hand, 
some teachers define their personal success as being similar to student success rather than relying on student success. The principals tend to emphasize whole school environment over particular classroom success. The deputy superintendent of schools sees success in terms of an overall instructional system which helps students through teacher training. The commonalities and repetitions in answering question 2, especially in seeing personal success as the success of students, outweigh the exceptions to the overall trends in data.

\section{Question Three}

Question three, "Describe a time when you have experienced success-with an individual student; with a class; and as a professional, faculty member," prompts enthusiasm and sympathy from the teachers. The high school English teacher refers to the success she discussed in answering question two, students winning a writing contest. With a class, she experienced success when she won a grant to bring in a poet in residence for a week. As a professional, faculty member, she describes an Appalachian folk culture unit, "And I want my students—-that's the main reason I do this unit so that they get a flavor and a taste of the pride, the success that can be achieved by [the state's residents] that are so often looked down on."

The high school Special Education teacher had likewise already described success with a single student in answer to question two. She described a student that had Down's syndrome starting to read. She said, "I still get misty [eyed] thinking about it." In answering question three, she says that with a class, she found the lesson successful when two students from the local college came into her class to teach sign language. "And they came in and together they taught the kids the story of 'Little Red Riding Hood' in sign 
language. My two classmates would be on the side and they would be narrating and the kids would be signing, and the kids really got into it." As a professional, faculty member, she describes writing letters to every senator and every member of the house in the state to explain the predicament of teachers in the county. While teachers' salaries are on a par with the rest of the state, "We don't pay the same for property taxes and we don't pay the same for housing." She concludes, "So I think that gave me a lot of professional success because I was able to further the cause of the teacher in the field-give us a voice, give us a face and maybe things will change. So professional success that way I guess. As an activist. (Laughs.)"

The high school math teacher describes success with an individual student as, "me seeing the light bulb come on for somebody_after you've taught them fractions fifteen times and then finally they get it and they tell you and they're so happy with themselves." With a class, she speaks of hands-on activities. "I teach Probability and Statistics and we're able to do a lot of projects with that class, a lot of hands-on activities, more so than with any other math class because of data collection, and...they actually get to see why math can be fun and why it is relevant." As a professional, faculty member, she says, “Success is kind of to me where I've set my heart. As long as I'm doing what I've established that I want to achieve, I consider myself to be successful. I guess it's also a level of success when - this is my eighth year here-and people start to trust you enough that people start coming to you for answers."

The teachers in the high school agree that individual success is when a student learns, class success is when students are involved in and taking pleasure in learning, and 
professional success or success as a faculty member involves larger success outside the classroom. On the other hand, they differ on specific student successes, which engaging unit works for the whole class, and how they succeed outside the classroom.

In the middle school, question three likewise prompts individual stories. The social studies teacher sees success with an individual student in terms of relating personally to that student. "I would measure success in the fact that my children don't only relate to me educationally, but they can come to me and say, 'My mother got into a fight with my aunt last night and she's in jail and I'm upset.' I think that when a child can relate to you on both levels, then you've truly reached them." With a whole class, she talks about making the class interesting. "My class control doesn't come in the form of verbal demands. I kind of control this class by making this class interesting." On the same subject, she describes success as a professional, faculty member. "Certainly, on a professional level, teachers that I've been a mediator for, when they observe my class, when I observe their class, and I can see techniques that truly are controlling children other than being very verbally demanding on them, then I feel success in that."

Often similarities among participants' language arise in different parts of the interviews. Most teachers address the importance of hands-on activities in one part or another of the interview. The middle school science teacher explains that activities are part of her definition of individual student and whole class success. She answers question three as follows, "When students come up to me after class and say to me, 'Do you have any more activities that I can take home and do?' When I teach something and they really get into it, that makes me feel good too." As to success as a professional, 
faculty member, like the high school English teacher, she mentions winning grants. She also mentions feedback from her peers as did the high school math teacher. "As far as my success, I've done grants, but I guess it's the feedback I get from my peers and my team."

In the intermediate school, the new fifth grade teacher describes working with a struggling student as did the high school Special Education teacher. She describes a student who hated math in the beginning of the year saying, "I can't do math." After her tutoring him, "He's gotten to the point where now he's volunteering in class to answer problems." She stressed the student's increase in confidence. With a class, the new fifth grade teacher discusses a successful writing activity from the day before the interview. "Yesterday, we did an activity, 'Seeing like a writer,' where we had to talk about interesting sentences and using lots of adjectives and everything and they had to actually look at the picture that's right behind you and write about what they saw... I know from walking around the room when I was here that they were just writing things that I didn't know that they were capable of!" As a professional, faculty member, she discusses maintaining "the close-knit nature of the faculty. Everybody really cares about everybody else."

The more experienced fifth grade teacher in the intermediate school also describes success with a struggling student:

I had a student this year who's really struggled with everything and she's finally — especially reading comprehension and questions-you know if you ask her a question, getting an answer that applies to that question. She would just give me something that was a true statement but had nothing to do with the question asked, and we finally, working with a speech pathologist, we figured out where the break down is inside her and we've 
figured out how to reach her and she's actually answering questions appropriately that make sense now. And she's doing it consistently-even with different stories from the reading textbook and different questions in different subjects. She's been able to carry it over multi-subjects and that's just been wonderful. So that's a success with a particular student.

With a class, the more experienced fifth grade teacher cites success on the standardized test. "Last year, all of my students that were not Special Ed students scored mastery or above on the [standardized test] — the math part of the [standardized test]...We scored real well and I'd call that personal success and success with a whole class." As a professional, faculty member, she mentions being "asked by the county office to be on different committees."

The intermediate school teachers, like the high school and middle school teachers, see individual student success enthusiastically and sympathetically as they watch students have breakthroughs in learning. With a class, the teachers talk about units or activities that went well or when a whole class "gets it" or performs well on a standardized test. For the most part, to teachers in the high school, middle school, and intermediate school, success as a professional, faculty member involves connections beyond the school. On the other hand, a few teachers see success as relating well within the school.

These general similarities and differences continue in the elementary school. The first grade teacher, like the more experienced fifth grade teacher, speaks of finding the particular place where a student was struggling with the reading process, again, like the fifth grade teacher, finding help from a speech pathologist. "I said, 'He's not hearing that words are made up of sounds. He's not hearing it. He doesn't understand reading therefore because he doesn't understand that that's what our language is. It's sounds."' 
The first grade teacher describes his progress, "At the end of the year, he could know that 'cat' had three sounds and possibly spell that word and identify it by sound. And he just made a lot of progress." With a class, the first grade teacher finds success in managing a great diversity of learning styles. "I think this was one of my most challenging years as a class because I did have LD and I did have gifted—two of each. It was very hard this year. But I felt very good at the end of the year because I was really able to manage...working with all those students, they really did come far." As a professional, faculty member, like the less experienced of the fifth grade teachers, the first grade teacher describes close relationships within the school. "Being at this school makes me feel successful—just the working relationships...People generally are friends outside of school and we all get along really well."

The third grade teacher describes a struggling ESL student who made tremendous progress as an example of individual student success. Evaluating success for a class, she talks about student character and tells of her kids being "role models." She says:

And to have another teacher or a faculty member, a secretary, a principal, whoever, stop in the hallway and say, "Wow, you guys are doing such a nice job, and you're being role models for the rest of the kids." To me, that's a success for my class because as a whole then they're being complimented. "You've done a good job or you're showing good manners or you're being polite and respectful." And it kind of makes me feel like that's a success for me too then!

Thus, her students' success defines her as a professional, faculty member outside the classroom.

Overall, teachers answer question three, about a time when they experienced success, with agreement that individual progress involves turning a student around 
academically. They agreed for the most part that a successful class is engaged in an activity or unit that helps them to learn with pleasure and enthusiasm. For the most part, they agree that success as a professional, faculty member includes experience outside the classroom or the school. On the other hand, the teachers differ in seeing individual student success as "when the light bulb goes on" or when a student publishes a poem versus when a struggling student has an academic breakthrough. Teachers differ in viewing success as a class in terms of successful moments, successful units, or successful character. Teachers differ in finding success as a professional, faculty member in terms of success with a class, success with peers, or success within the county or state. In general, question three prompts vivid and individual description.

In the principals' voices, question three again prompts a variety of language of lived experience. Question three is phrased slightly differently for principals in the last phrase, "Describe a time when you have experienced success—with an individual student, with a class, and as an advisor to faculty members." The high school principal gives an example of helping an individual student's success:

If you look on the board behind you, this is an example yesterday, I had a young man from a Special Education class that came to me, was frustrated in the class because he just was really struggling, and came to me between classes and sat down in the chair, and he was very upset because the rest of the class got it and he didn't get it. So we worked for about twenty minutes, trying to understand line segments and rays, trying to figure out how that translates into real life because he didn't see a need to understand what those were. And when he left here, we were measuring line segments and writing things up, so something as small as that can be very significant to students. To me that's a success. First of all, knowing that the student's going to come to the principal of the building if he's got a problem with math class because a lot of places I've worked didn't have that openness - the students wouldn't go to the principal. 
He describes success with a class as school participation in a leadership class that is run through the student government. Two thirds of the school population takes advantage of the leadership class. For the third part of the question, as an advisor to faculty members, he says:

Well, the most recent success for me is last Monday, eight days ago. We had a visit from the state department; a branch of the state department was here to do a review. They're constantly coming into the schools, but in comparison to the visit that we had a year and a half ago, they were very impressed with being able to maintain a high level of expectations with so many...new faculty. So I was able to sit down with the faculty at a meeting, in a formal faculty meeting, and say all the hard work is paying off.

The middle school principal says of success with an individual student that he has had success with his "Providing Academic Success through Self-esteem" (PASS) students. He also says, "I will see probably fifty or sixty kids in a day and I'll make sure I know who I'm working with and who I'm looking out for." "Like last week," there was "a little girl...who was going through some very serious health issues and a serious operation and I told her I'd be thinking of her and she'd be in my prayers." "As for a class or a whole group... sometimes it comes down to trying to go ahead and guide a group of kids to make a better choice during the school day. Sometimes it'll come down to seeing this, don't mess up here, make sure you're doing your best for your teacher, take care of business. Those are neat opportunities to help steer some things." Of success as an advisor to faculty members, he describes helping a new faculty member. "I find particular pleasure in seeing a new faculty member who needs a little bit more support, maybe some help in getting their certification together and working some other 
things, trying to go the extra mile to go ahead and watch out for them. Again to see them successful with kids and turning it around is really a real pleasure."

The intermediate school principal, like the high school principal, describes work with one student as an answer to "Describe a time when you have experienced successwith an individual student." Like the middle school principal's PASS students, the intermediate school student received individual, caring attention from the principal. The principal explains that a student she helped individually "opened up and talked about things because I would have lunch with her and check on her. And just knowing that someone was checking on her, she really gained some momentum." Like the high school principal, she describes starting a class program but for Special Education students. "We set up a small weather station that just had the temperature and the rain...Then on Fridays, they took turns giving [the weather] report on the intercom. So those children felt that they weren't excluded because some of those students that do have severe learning disabilities I think oftentimes feel excluded from everybody. And we never want them to feel that way." As an advisor to faculty members, the intermediate school principal defines success by giving an example of professional development. She encourages a teacher to go to "a conference on setting up your classroom and establishing boundaries." "And there was an improvement after that in the classroom, but it happened without pointing out things that were insufficient. It was more positive. And that's the way I like to work with staff because they're professionals.”

The elementary school principal describes working as a teacher "for eleven years" as when he experienced success with an individual student and with a class. "I felt that I 
had several years of working with students that were successful. They have gone on and finished high school and went to college and several of them became teachers. Several of them went to the business field. And I just look at those types of learning while I was with them were important and a good foundation and an inspiration for them to continue through with their education into college and beyond." As an advisor to faculty members, he describes success with a particular teacher. "One particular young lady has been selected as a member of the district reading committee which is a committee that people within the district look at for people that have good reading skills and teach reading in a very understandable way and I feel that she has become an outstanding teacher."

Overall, the principals agree with each other that success with an individual student comes from the opportunity to work one-on-one with a student. For the most part, they find that they had more time with individual students when they were teachers. On the other hand, the elementary school principal is the only principal to describe working as a teacher in telling of success with an individual student as opposed to describing working as a teacher in response to a later question within the interview. Two of the principals agree that success with a class involves starting a program while two describe helping students as a group. As advisors to faculty members, two principals describe helping new teachers, whereas the high school principal describes success in terms of the state visit to the school and the intermediate school principal describes professional development. Thus, there is little overall agreement among principals as to 
what it means to experience success. Like teachers, the principals use varied and vivid language to answer question three.

Question three is phrased slightly differently for the interview with the deputy superintendent of schools. "Describe a time when you have experienced success-with an individual student, as an advisor to faculty members, and with a program or with a school." The deputy superintendent of schools answers as follows:

I have very little contact with kids in this current job. I do on occasion have an opportunity to help kids when they maybe run into a wall in a particular school by talking with either a principal or an assistant principal and helping them to get into a particular class they want to get into or things of that sort. And that feels good from time to time, but as a high school principal, there were many times that I felt like I was able to directly help a child, guide a child, maybe even help them to turn a corner just by basically monitoring the process, letting them know that people do care about them and there's a right way to do things and a wrong way and they need to do things the right way and if you do, you're going to see some successes. I felt like there were a lot of instances where that occurred and particularly when you're directly involved with kids in a school. But from this perspective, you kind of get out of the way of the kids and you don't have much contact with them. I miss that part of it.

Speaking to the question of experiencing success as an advisor to faculty or with a

program or a school, the deputy superintendent of schools describes an implementation of teaching strategies.

First of all, there's basically skepticism and, "Another program dah, dah, dah, dah..." basically all these reactions from teachers. Then you start to see a few people getting on board, you hear them talking about it. They start using the lingo. A few teachers are actually using the strategies. And then more teachers begin talking the talk and implementing but not really letting go what they always did. And then the next step is they're implementing. They're not only talking the talk, but they're using the strategies and they're becoming second nature and they' re part of their tool bag. And I'm hoping that that's what we're going to be starting to see here in the next couple of years. 
Repeatedly, participants show caring for individual students, desire to see the whole class learning, and ways to support teachers in answering question three. Specific trends in the interview data are more alike in descriptions of the individual student and class success than alike in descriptions of success as a professional, faculty member; as an advisor to faculty members; or with a program or with a school. From individual relationships to seeing the light bulb go on, participants for the most part celebrate caring and learning. Teachers find success as professional, faculty members to involve influence and relationships outside the classroom. Principals find success as advisors to faculty members to be professional development (either through individual help or through sending a teacher to a conference). The deputy superintendent of schools finds success with a program or with a school to be professional development. On the other hand, these general findings come with the specific variations described by the individual language summarized and quoted above.

\section{Question Four}

Answers to question four, "How does student success compare with teacher success?" can be summarized more briefly because there is a lot of agreement among participants on this question. The participants are almost uniform in agreeing that student success and teacher success go hand in hand. The high school English teacher has already indicated that her idea of success relies on student success in answering questions two and three. She explains further, "I still feel it is my job to advance them as far as I can no matter how much I have to push, prod, praise, complain or whatever it takes... as long as they're better and they've gained something, then I've been successful." 
The high school Special Education teacher says, "Hopefully, the more successful you are as a teacher, that facilitates more success within your students. And I think they feed off each other because I get really jazzed, excited when I see my students achieve and then I want to do this much more and then they achieve that and then I want to do this much more. So it's kind of like a circular feeding frenzy."

The high school math teacher likewise sees student success as closely comparable to teacher success. She puts it in terms of teacher growth. "I'm really passionate about teachers growing. I think that if a teacher is growing and they're trying to improve the way that they teach every year, you're going to see the results in the students as well."

Like the high school teachers, the middle school social studies teacher sees good teaching as comparable to student success. "I definitely think that the way that materials are presented and how a teacher takes into effect what she's working with has a great deal to do with how successful the students are." The middle school science teacher puts it this way, "If my students are successful then I'm successful and if I'm successful then my students will be successful. It's a two-way street."

In the intermediate school, the newer fifth grade teacher says in answer to how student success compares to teacher success, "I would say it's pretty similar. They want to have fun and learn and I want to have fun and learn, so we can have fun and learn together." The more experienced fifth grade teacher says, "If students are successful, then a teacher should feel successful."

In the elementary school, the consensus on student success being comparable to teacher success still holds. The first grade teacher answers question four with, "Well, it 
does kind of go hand in hand." The third grade teacher says, "I think they are interrelated...I totally think that students' success has a lot to do with teacher's success."

There are also, in comparing student success to teacher success, some differences among the teachers' answers. Overall, the teachers describe a close link, but sometimes they go on to explain that one group of students is not the same as another, so measures of student success will be incomparable to measures of teacher success.

Principals for the most part agree with teachers that a good teacher will turn around a class, but they sometimes find teachers hold less responsibility for student success than the teachers find. The high school principal answers the question by immediately pointing out the exception. "Well, that is a trick question because...in any group, there are a percentage of students that are going to succeed... For a small group of students, they're going to succeed no matter what, but for a majority of students, the better the teachers are, the more studying that they do and the more preparation that they do and the more passion that they have, the more successful the students are going to be."

The middle school principal says, "If a teacher's successful and they have a good plan and they're keeping kids engaged and they're real happy about and excited about what they teach, kids by far and away will do better." More specifically, he describes teacher experience as critical to student success. "But student success does relate, I think, to teacher experience. I think the bigger bag of tricks that you have to choose from-if you have a problem happening, you can say, 'Well, I can come at this this way.' And a new teacher may only have two or three things to choose from—say, 'Well that didn't 
work well for fractions. I've got two other ways to do it, and beyond that, I'm really going to be stuck.',

The intermediate school principal expresses well the distinction between one group of students and another. "Sometimes [student success and teacher success] are one and the same. A teacher always feels successful if their students are successful-if they're getting it. The light bulb goes on. They're moving forward. They're progressing. But we have to separate that as well because it isn't the teacher's fault if the students aren't being a success. It depends on the group of children."

The elementary school principal says, "Oh, student success—and that's one of the questions I ask in interviewing teachers-how much responsibility does the student take for their own learning? And I think we have to look at students really having an interest in learning... I feel that student success, we basically measure through the grades that the students receive each nine weeks, and with staff success, I look at the work that they're doing with the students and how successfully they use teaching methods to bring students a positive mindset to do the best that they can do."

Unlike the teachers, the principals do not reach a consensus on how student success compares with teacher success, although there is strong agreement that positive teaching brings out the best in students. Three of four principals, all but the middle school principal, point out that in addition to a good teacher turning around students, the group of students taught can make a teacher more or less responsible for success in teaching. The deputy superintendent of schools gives unqualified agreement with the other participants that there is a strong correlation between student success and teacher 
success. He describes this correlation in terms of the "highly qualified teacher."

“There's a direct relationship between a good teacher, a certified teacher and student success. The more certified teachers you have in their subject areas or, to use the language of No Child Left Behind, highly qualified teachers, the more success you're going to see, the higher your test scores are going to be, the better the instructional program's going to be. There is no doubt that there is a correlation between highly qualified teachers and student success. And we know that for certain." Except for some qualifications as to different groups of students performing differently despite teachers, the participants all agreed that student success compared directly with teacher success.

\section{Question Five}

Question five leads to lengthier responses with a lot of agreement as well on the issues of learning, grades, and standardized testing. In response to, "How do you see others defining success - students, other faculty, principal and other administrators, parents and community, school district, and state?" repeatedly participants stress the importance of the standardized tests in the eyes of others, but stress their personal beliefs that testing under No Child Left Behind fails to measure student learning. The participants see some good as coming from the trend of standardized testing but also see frustrating weakness in Adequate Yearly Progress measures, especially in measures of the two subgroups of Special Education and low socioeconomic status. While overall students engaged in learning seem to be considered a higher standard for success in the eyes of participants than "bubble tests," the majority of the participants also see some worth in raising a "bar" to keep teachers "on the same page." Teachers talk about 
excitement and joy in learning and the work ethic of students as more important than their ability to perform on standardized tests. Principals and the deputy superintendent of schools stress character and preparation for the work place.

The high school English teacher responds to question five with an immediate reference to test scores. Her first words in answer to question five are, "Principals and administrators are defining success by test numbers, test scores out of necessity because superintendents and the general public are insisting upon it. Therefore that is something that's major, something that has to be addressed, but to me it's not an end all or a be allnever will be. If it gets to the point where it is, then I'll say goodbye." Like many other teachers, she answers the rest of the question by explaining that students measure success by grades. Other faculty, she sees as measuring success by being able to support themselves. This answer differs from other participants' answers. She says, "You can either stay and moonlight and work yourself to death or go somewhere else where you can make a salary that can pay the bills... I'm not talking about an elaborate standard of living, pay the rent, and just pay the bills. Teacher's salary is tough.” While the high school Special Education teacher raises the issue of teacher salary strongly in answer to question two, she does not see teachers as defining success by answering the need to support themselves. As to parents, community, school district, and state, the high school English teacher finds:

Parents, I think, definitely want their students to be well-rounded, polite, courteous, and learning as much as they are capable of learning, so that we can turn them out as responsible adults who can make a living and support themselves; then they were successful, the school was successful. I don't know state — that's a little harder to judge — of various things I've done through the state with other teachers and so forth, probably the same thing. 
That's part of this unit [on Appalachian folk culture]. Appalachia had a strong Scotch-Irish work ethic that stayed longer and more basic and primitive than other areas because of being isolated in little mountain hollows. And I'd say that's still in effect. Maybe not as strong as it used to, but it's still there hopefully and always will be.

The high school Special Education teacher answers question five holistically:

I think a lot of the times it's done more extrinsically than intrinsically... So we have to set up goals and ways for students to achieve those goals that motivate them to want to do it themselves just because. They have to become self-actualized and have to be able to want to do that. So I would like to see programs move more towards balancing the extrinsic motivators that we have like go on this trip if you get this grade point average or get sweet tea for lunch as opposed to the intrinsic stuff like I do it because it makes me feel good, because I want to learn, because I love the way I feel when I've accomplished reading a book or when I've accomplished working with my hands to build this piece of furniture that I built in my shop class.

When she is prompted to break down her response, she says of faculty success, "Of course,...we are all under No Child Left Behind held accountable for [Adequate] Yearly Progress and we have to have so many of our students attend school so many days and there are specific guidelines set up. We have to be concerned with that, but that should not be the only way that we value achievement or success or that we determine achievement or success." To summarize her view of students, principal and other administrators, parents and community, school district, and state, she speaks of balancing "the ribbons" with more intrinsic accomplishment.

The high school math teacher, like the high school Special Education teacher, immediately responds to the question as a whole:

Well, everybody has their next person up, their boss in that whole bureaucracy that they have to accomplish certain things in order to be considered successful by that person. So really I think that can be almost a maddening thing if you think about everybody who has to be made 
happy... the kids think the teachers are out to get them; the teachers think the administrators are out to get them; the administrators think the board office is out to get them; the board office thinks the state; the state thinks the federal government. And the reason they think people are out to get them is because they just have so many things put on them. Teachers put things on students. Administrators put things on teachers. It almost feels overwhelming. It's just so much...They're so many people that have a marker for success. By the time you get down to the student it's so thick, you can get lost. I'm not sure how to fix it, but I think it needs to be fixed.

The commonalities and trends within the high school interview data include a frustration with testing and bureaucracy. The high school teachers describe student success in the earlier answers and in answering question five as defining success by student learning rather than student test scores. The middle school teachers likewise define how others see success both negatively—as what does not measure success—and positively—as what ought to measure success. Like the high school teachers, they find the extrinsic measures of success, grades and test scores, draw attention away from the more important intrinsic measures of success in the day-to-day learning in the classroom.

The middle school social studies teacher answers question five:

Well, I definitely think that students and parents look at grades. I mean that's probably about their most verifiable way of measuring the success of their child. I wish that they looked at day-to-day things that we did and papers that the students take home, but a lot of the students simply do not take those things home. Certainly, I think the state, the county, and the nation used standardized tests. That is their way of measuring what we have done in the classroom. And if we had [content standards] that were truly ones that we could cover in the school year, then I would be perfectly happy with standardized tests.

She also says of faculty and principal and other administrators, "It's definitely standardized test scores." 
The middle school science teacher says, "In terms of the parents, they want their child to be successful. They want the high grade." As to teacher success, the middle school science teacher puts it in terms of her own performance. "But as far as success goes, if my students do well and do the tests and quizzes and a variety of activities, to me, that's being successful on my part." As to principal and other administrators, parents and community, school district, and state, she says, "they want the test scores up." She says of No Child Left Behind:

There are some things with No Child Left Behind that I agree with. I think it's made all teachers more responsible for what their job is - as far as what they need to be teaching and that everybody's on the same page. But at the same time, I had a hard time with the Special Ed section of it where you're teaching children on a third grade level year round but you're tested with the fifth grade and then those test scores are what play into the school's formula. I know the school I was at before, we were put on probation-where parents had the choice, if they wanted to, to send their child to another school. And I just didn't think that was fair because as teachers, we couldn't tell them why, but we knew which segment of that test pulled us down.

In the intermediate school, teachers also speak of measuring success more by test

scores as one went up the ladder. The newer fifth grade teacher puts it as follows:

I think all the teachers here pretty much agree that student learning is the most important thing. The administration also does, but they have to, by the nature of their jobs, be worried about test scores more than the individual teachers. So they do what they can to make sure we have the test scores that we need to have in order to get to whatever level we're supposed to be getting to. The county-I think the farther up you go, the more worried they are about test scores, the farther away they're getting from the students. So it's kind of like a little chart - the farther away they get from the students, the more they're worried about test scores because they're not in the classroom. They don't see the every day successes. They have to measure the successes by the test scores. And that's just the way it seems to be at the moment. So on the state level, it's a lot about test scores. There's not a whole lot of money in [the state] for education. So I just think the best way to sum it up is the farther up the ladder you go, 
the farther you are getting away from the individual student. And that's just the way it is. And the test scores become more and more important.

The more experienced fifth grade teacher mentions other measures of success before addressing No Child Left Behind.

I see students defining success as A's on their report card. If I get A's and B's-some of them are happy with C's if they're used to D's and F's. Students seem to be so focused on what that report card says. Other faculty? I think a lot of us feel success is going home feeling good about what you do at the end of the day. You know you taught somebody something. The light bulb went on in a student's face and then they feel successful. Some people don't feel successful unless they get awards. It's probably different with everybody.

As to other people's definitions of success, the more experienced fifth grade teacher speaks of "just word in the community and the ball field" and then in describing the school district's definition of success, she speaks of Adequate Yearly Progress.

The school district? Their definition of success is making Adequate Yearly Progress according to No Child Left Behind and my assumption is that they are the big push on test scores, test scores, test scores. We're sick and tired of hearing it, but that's the way we're measured. And the state, I really think the same thing, having good test scores and meeting the mandates of the No Child Left Behind laws which hopefully will soon be changed to accommodate Special Needs kids.

In the elementary school, the interview data continues to fall into the trend of seeing more pressure to master the standardized test as the perspective goes "up the ladder." Like the higher levels, on the elementary level, teachers determine their own success by individual learning. The first grade teacher describes the differing perspectives on defining success as follows:

Well, students, they see it on their letter grade because that's what their parents identify with. It's a shame to see so early on...At this school, other faculty determine success just like me by what a child has done, what they're capable of doing, and I think they're really good at looking at 
the individual child...Now, in terms of our principal and our assistant principal - we turn grade sheets into her so she kind of looks at the grades-but she also [will] go through that folder and they may have an A for the year, but have a subtest or a skill that they didn't pass, and she'll document that, knowing that children need all their skills...I think once we get past our school, as far as school district, community, parents, theyit's all about standardized testing and how they do on the [standardized test] and letter grades. And I think once you get past that, their individuality is gone.

The third grade teacher makes similar observations.

Unfortunately, I think a lot of students still see success in the eyes of-in terms of-report cards... Maybe the parents are even more looking at the report cards...I think other faculty define success as I do mostly. They define success as does this child move from where they were in the beginning of the year to now. Does this child show improvement?...I'd say the principal and administrators have more the teacher's perspective as well, but because of the whole system — and they don't like No Child Left Behind probably as much as we don't...The school district is concerned with what schools are making the AYPs. The Journal prints the list of schools that are making it. They see that as a tool to make their school system a success. Well, if there are this many schools on the list of those that didn't make it, then they're not doing a good job. They definitely do look at those standardized scores.

A review of the teachers' interview data shows their observations that others view success more extrinsically than do teachers and especially that others value standardized test scores more highly than do teachers. Question five leads to lengthy and varied answers, but, overall, teachers agree that measures such as grades and test scores get in the way of measuring day-to-day learning in the classroom, individual improvement, and a love of learning. Interestingly, the principals and the deputy superintendent of schools share teachers' frustration with No Child Left Behind, not corroborating the teachers' views of who put pressure on the students and the faculty to succeed on standardized tests. The principals and deputy superintendent of schools, like the teachers, are skeptical 
of test scores measuring student success. They care more about a teacher's ability to relate to students than about a teacher's knowledge of subject. In a school system where class sizes are quite large (close to 30 per class often), individual attention to students is consistently encouraged. Thus, there is substantial agreement among participants in how success ought to be measured while there is agreement that "others" define success by standardized test scores instead.

The high school principal answers question five with the following language:

Everybody wants to have a bottom line and say, "OK, I got an A in the class. I'm succeeding. I got a B in the class. I'm doing pretty good. I got an $\mathrm{F}$ in the class, so I know nothing"... the community, the parents, I think they view what those students come back and do in the community as... what the school is doing for us. Is the teller at the bank a...graduate [of the high school]? Is it something that they recognize? Are they proud to be a high school graduate? Do they talk about it? If so, then you're looking at a success... I think the community and parents are looking at individual things-whereas schools look at a whole group. And I'm able to quote a percent of students that go to college. And I'm able to tell you what a graduation rate is. And I'd venture to say that if you went to anyone across the street, any of the community members, they could not tell you that. So the school is looking at a whole-the county is looking at not just our school but other schools. If you ask how it precipitates, I think the state is setting out these are state minimums; these are state highs and lows, and wanting to know where you fit into that.

Of standardized test scores he says, "There [are] different levels of what different people look at. [People] look a lot at test scores. And I expect that changing a little bit in the future because we're just getting a snapshot—in my school, we're just getting a snapshot of what four hundred students can do, and they're still eleven hundred of them out there." Where parents and students look at grades, and "[people] look a lot at test scores," the high school principal thinks success ought to be viewed as being "proud to be a high school graduate." 
The middle school principal also talks of grades and test scores in describing how he sees others defining success, but he also talks about whether "essentially good things are happening at the school."

Students-I would say students really look at grades. "Did you get an A? Did you get a B?" on individual papers, report cards, things like that, so those are very important. That also measures out very closely with what parents see as success. Students do not see the [standardized test] or our yearly annual measurements as that much of a measure for them. They really don't pay that much attention to it. Sometimes it gets home. Sometimes it doesn't... Teachers do measure success by the [standardized test] a great deal... All of us as principals, we realize we just kind of sink or swim based on our [standardized test] scores... Community? I think community looks at our college going rate. They look at whether or not we're a safe place to be, whether or not they have confidence that essentially good things are happening at the school.

He mentions that teachers measure success by the standardized tests when the successful teachers interviewed in the study all say that principals or those higher up the ladder are the ones measuring success by standardized testing. When the middle school principal describes how school district and state define success, he mentions Adequate Yearly Progress as measured by the standardized tests.

It's just one of those things-I know I can in at least one category-we always worry about our Special Ed kids. We always worry about our low SES kids. Those are the two groups that typically we always will struggle with. We have [not] yet solved this last problem, the low socio-economic kids, but it comes and goes. It'll-every year's a little different. Typically everything else flies just beautifully. Our kids for various ethnicities, we don't have problems here. It works great. Those kids are all supported, doing well, and coming right along...For all the little micro categories that you can have something, we're missing in two. And going, "OK, so now we failed." We missed two of the forty or fifty. I mean that's-that's what I rail against. I mean that's what I'm frustrated with.

The intermediate school principal describes how others define success as impacting whether her school feels successful or not. For her a definition of success 
ought to be the individual student's progress, the moment of learning, but, in fact, others define success as more "data driven."

I know that with the county and the state-even though our county is very supportive and we do a lot of things to promote success - not just data driven success but when it comes down to reports-what is put out to the public in the media - they don't care that a child that has never been able to do math suddenly can add and subtract with regrouping. The general public is not going to celebrate that because that's what school is for. And that's difficult for school employees to hear. And there is-negative is out there far more than positive. You can call the newspaper and television about having an event or something good happened to your school. We raised this much money for flood victims or the children did this for the walk of hope for cancer research and they won't come take pictures or anything. You have something happen at your school, and it's front page news. And that makes it difficult for us to feel successful.

She talks of the pressure to succeed on the standardized tests. "I'll tell you when we go in August all the principals will sit in a room and go over, 'How did we do on last year's test.' When your school's flashed up there, if your school didn't do as well, you can feel either administrators get angry and upset or you can just feel them shrink back into their seats. And that's awful because you don't know all the circumstances that went into that."

The elementary school principal, like the high school principal, sees different people defining success in different ways. For him, success is better defined as students' skills, social interactions, and students' contributions to their society than it is defined by extrinsic measures.

It's somewhat difficult with those several different groups because I think it's what they're looking for as far as programs and activities and things like that that they're providing or they want to provide. And so looking at what I consider success and what someone else considers success, there can be different degrees of success. My thinking is always that you see progress towards a continual goal. And I think the biggest goal is to have 
students be able to read and to do math and basic skills as far as social interactions are concerned and being able to contribute something to the society in which they live.

Like teachers, the elementary school principal sees students defining success as, "Making good grades. As long as they're not making failing grades, I think they look at that as being a success." Of faculty, he says, "I think they look at how the school as a whole is moving. And I think the idea of achieving AYP on a seemingly continuous basis as right now is looked at as success." Of school district and state, he says, "AYP is very important. If you don't meet AYP, then the areas of improvement are areas that have been pointed out and that you need to work on so that the next time around you successfully meet AYP." The elementary school principal does not voice frustration at No Child Left Behind as did the middle school principal and the intermediate school principal, but, in defining success in terms of "social interactions" and " being able to contribute something to the society in which they live," he does not define success as he sees faculty success, by "achieving AYP."

While the deputy superintendent of schools has a shorter interview which does not include questions five to nine, he does speak to the question of test scores in his answer to question four. I also asked him, "What does a successful teacher look like?" The deputy superintendent of schools does look at test scores as do the other participants, but he says, “Technically you have to measure student success by, from my point of view, by test scores. I won't say that I agree with that." Higher up the ladder, there is still skepticism as to the worth of standardized testing in measuring success. In describing success as a teacher, he never once mentions test scores. How he does define success in answers to 
his questions four and five ("How does student success compare with teacher success?" and "What does a successful teacher look like?") is what makes a "good employee" in students and having an "understanding of where kids come from" in teachers. To quote the deputy superintendent of schools more specifically, he says:

I think that a school's success can't totally be measured by test scores. But by a good administrator and a good staff of teachers, there's a feeling in a good school when you walk into it. And you measure the success of that school and those students not only by how well they're performing on the test but a lot of other things. Are they polite? Can they work in groups? Can they follow directions? Do they get to school on time? Do they attend school? Those are all factors that make for a good employee once they leave our school system, and we have attendance rates and those kinds of things that I can see and this and that, but I think that the true measure of the school is if a highly qualified principal says, "This is a good school. These kids are doing good things." And you walk in and you get that good feel about that school and you see the kids and they're polite and they're where they're supposed to be and they're following directions and in the classroom they're raising their hands and they're talking and they're participating, those are the signs of a good school. And how do you measure that? I'm not sure that you can totally.

He defines success as a teacher in the following language:

A successful teacher is well-trained in their subject area, is in tune with the age level of the child they're dealing with, is perceptive regarding individualizing instruction for kids, is perceptive in dealing with the particular way each child learns, is willing to change, is a teacher that is a team person, is willing to share their good ideas with other faculty members, and understands that there is more to life than what he or she is doing in that classroom, that those kids have other things that are important to them, and - most importantly—has some understanding of where their kids have come from. Did they have a good night's sleep last night? Did they get three meals? How important is it to a child who doesn't have a pencil today whose mother and father argued all night and the kid was on the porch. Well, a pencil is not important to that kid because he's tired, he's sleepy, and he's hungry, and a great teacher has a knack for knowing about all those things and what makes those kids tick. 
Like the principals and teachers, then, the deputy superintendent of schools thinks that success ought to be defined by the moment of learning and the teacher's relationship with the student.

As a pool of participants, teachers, principals, and the deputy superintendent of schools see others as defining success by test scores, whereas they see themselves as measuring success by relationships, doing one's best, or the moment of learning. There is general agreement that others view success as measured by standardized tests but that the participants look at more intrinsic measures of success. There is a lot of agreement for the most part that success ought to be a measure of students' growth, day-to-day learning, and teachers caring about individual students, but on the other hand participants disagree about who is defining success as test scores instead. While there is agreement that students and parents measure success by grades, "unfortunately," there is not agreement as to who is putting pressure on teachers and students to succeed as measured by AYP and standardized testing.

The results of collecting verbal data from question five indicate that while standards in teaching and coordination of teaching are helpful, the pressure to perform well on standardized tests is for the most part seen as not conducive to student success and learning. On the other hand, there are differing reasons offered by the participants for this conclusion: "bubble tests" fail to measure student character and individual academic improvement, the threat of restructuring the school based on the performance of a subgroup such as Special Education is unfair, or the content standards that prepare for the standardized tests are too many. But there is general agreement that the system 
under No Child Left Behind exerts the wrong kind of pressure-pressure to teach to the test rather than to allow the process of learning to make students better people. By better people, participants mean being "compassionate," having a reliable "work ethic," "listening," and finding pleasure in "lifelong learning," to use the words of the participants as a pool.

\section{Question Six}

Question six, "How do you make decisions about what to teach in your curriculum?" prompts the answer "content standards." Beyond the short answer, teachers and principals comment on the strengths and weaknesses of the content standards. Often, the teachers are content with the content standards and especially appreciate curriculum mapping so that teachers are on the same page. Sometimes, however, teachers complain that there are too many content standards to cover well.

The high school English teacher speaks briefly about content standards. She finds them sufficiently flexible and not too narrow or expansive. The high school Special Education teacher says, "I look at what real life skills my students need to have almost and then I find the content standard to match it, and that's how we cover the content standards in my class." The high school math teacher, on the other hand, is very frustrated by the content standards.

I think, with all the standards we have, there are too many-especially in math. It aggravates me to no end-it makes me so mad-that they are teaching elementary students algebraic concepts. I understand the brain, and I understand that that is when they are most absorbent, but they need to be absorbing basic skills. And my sister's a fourth grade teacher and she has four pages of standards - forty or fifty standards for math-when I get them in Algebra, they don't know how to do fractions, decimals, or percents. And that's crippling in an algebra class. If a fourth grade 
teacher could spend the entire year on fractions, decimals, and percents, I think the kids would be ready and more successful in Algebra.

The middle school social studies teacher, like the high school math teacher,

strongly believes there are too many content standards to cover in her field.

The mapping comes from the [content standards] that were given by the state, but we're given too many. It's just too many to cover. So, I mean, when you have a social studies book. [Shows me the book.] And you look at this and it starts with the beginning of civilization and it ends with the Vietnam War all the way up through-I mean, we're talking about a phenomenal period of time. And look at this material. If I slow this down and teach it the way that it should be taught so that these children could truly internalize what they're learning, it would take two years to cover this book...The [content standards] are too broad. That isn't just my opinion. We've been complaining about this for years. I'm not the only social studies teacher that will tell you that. But we don't seem to be able to get any help. So I don't know. I just know what children are capable of now, and I know that we cannot do it. Unless you just want me to briefly introduce-but I can't study-when I used to do this, we could do an intense study of the geography of the area, and the children could memorize the countries, the capitals. We could talk about the present culture, as well as talking about the ancient cultures. I can't do any of that anymore. I go from Mesopotamia to Egypt to Greece to Rome to...the Middle Ages to the Renaissance. I mean, it's just wham, wham, wham, wham, and, I mean, it's just so much. And these children haven't had any of this, none of this. So it's not like I'm building on past skills like they do in other classes. I'm presenting a whole new curriculum.

The middle school science teacher agrees that "having to follow the [content standards], there are so many that I feel I'm just giving them a little spoonful."

In the intermediate school, however, both fifth grade teachers find the content standards not to be excessive in number and to be sufficiently flexible. The newer teacher says of the content standards, "They're very vague which I guess is a good thing. You can interpret them however you want." She also explains, "We're all on the same page... and the students like it because they can talk to other students about what they're 
doing." The more experienced fifth grade teacher explains curriculum maps. "They're pretty flexible as to what is taught in which nine weeks. We have committees of teachers that work together to make them in a logical order, so that it flows. We meet. I'm on the science and the math curriculum mapping committee and we make sure that from one grade level to the next that it flows smoothly. And then each nine weeks, everything's in a logical order."

In the elementary school, the first and the third grade teachers both saw pros and cons to the content standards. The first grade teacher explained that, "Before, they were Benchmark Standards and they're very good to go by." On the other hand, she feels a little rushed. "Once I get my requirements done, I'm going to use the rest of the time where it's needed. There are some days when I think, 'Boy, if I just had a half an hour more today." The third grade teacher appreciates the coordination of curriculum that comes from curriculum mapping so that, "When you have kids move from one school to another school they don't get capital letters at the beginning of the year in one school and then get them again at the end of the year at another school." Another positive aspect of the content standards for the third grade teacher is that she does "have leeway in presenting it." As a con to the content standards, she finds, "We teach Language Arts separately from Reading which I don't like. (Laughs.) Another one of my pet peeves." Considering teachers in a pool, they answer question six with two teachers definitely believing there are too many content standards, three teachers feeling there is some pressure from too many content standards, and four teachers believing there are the right number of content standards. These discrepancies come largely from which subject 
matter is taught and partially from more subjective impressions of content standards. The high school math teacher and the middle school social studies teacher have too many content standards to cover. The middle school science teacher and the two elementary school teachers have some pressure to cover too much in order to teach according to best practice. The high school English teacher and the high school Special Education teacher and the two fifth grade teachers have a better choice of content standards. Some of these perceptions, on the other hand, seem related to interpreting the content standards more generally or more literally for the four teachers who feel content with the content standards and the three teachers who feel moderately pressed.

The principals are uniformly positive about the content standards in answering question six. Their consensus is that the content standards and curriculum mapping help teachers to coordinate learning and cover subject matter. The high school principal explains, "The [curriculum] mapping is throughout the county...it started because of the mobility of [the] county...students transferring from this school to that school and back to this school. It makes it a lot easier on the teacher and the students if they read this novel over there and then they transfer here second semester, we don't read that novel again because we read it at the same time."

In the middle school, the principal also views content standards positively. He again explains how curriculum mapping of the content standards helps students but in terms of the content within the school.

[Mapping] pretty much provides for the content—if you're looking at a spiral content where basically you're coming back to go and hit those same concepts again but at a higher level. You'll know when, say you're in the sixth grade, it's hit really strongly. You've got to make sure this 
concept is clearly taught because in seventh grade when you come back around, it's just going to be touched upon and it's going to be looked at at a higher level and it's not going to be even the main thing. And when you get to eighth grade, they're not even going to touch that one because they should have already taught, should have already been mastered and then we're moving on. So that's the whole idea of concept mapping.

The intermediate school principal explains how she keeps the content standards

positive in her school.

We do, of course, have our curriculum and our state-mandated mandated curriculum goals and objectives we must follow. We also have in this county what we call "curriculum maps" which maps out what you should teach the first nine weeks, the second nine weeks, the third nine weeks, the fourth nine weeks. And though we do target our instruction based on the curriculum, goals and objectives and following the curriculum maps, I never make my teachers feel that's all in stone... Our teachers do a wonderful job of covering the curriculum. They also do a great job of working collectively as a team and doing activities that cover curriculum in a creative way. Then it's not mundane and it helps students to get excited about learning.

In the elementary school, the principal answers question six as follows:

We follow the state [content standards] and the state curriculum. And so the teachers will add to that or supplement that but there are specific [content standards] that the teachers have to teach each year. The district has done a fine job at mapping out those that really need to be taught to insure success for the [standa. But for the younger students, we still have that mapping, so they take reading progress checks-reading and mathwe have math progress checks and reading progress checks that's done periodically throughout the year, so that we have a good gauge as to how the students are doing.

While each of the principals sees the positive side of the content standards for the most part, the principals of the three schools with younger students mention some loss of flexibility and being able to do "interesting and fun things" (in the words of the middle school principal). Often the principals explain their feeling that the content standards are too broad in answering question seven, "How do teachers in your school make decisions 
about how to teach in terms of instructional methods?" They explain that too many content standards take away the opportunity to use "teachable moments." The middle school, intermediate school, and elementary school principals share this concern with five out of the nine teachers (the high school math teacher, the middle school social studies teacher and, to a lesser degree, the middle school science teacher and both elementary school teachers).

Question Seven

Question seven, "How do you make decisions about what to teach in terms of instructional methods?" prompts diverse answers. Teachers and principals stress using a wide variety of teaching methods to reach a wide variety of learning styles. One teacher, the middle school social studies teacher, specifically mentions Robert Marzano and APL (Anastasio, Perry, Lane) techniques. The principals also often mentioned Marzano and APL techniques as part of county-wide professional development. These techniques call for questioning and wait time as well as graphic organizers and hypotheses testing and a variety of strategies to help keep students engaged in thinking and learning. The deputy superintendent of schools also explains the importance of differentiated instruction and of the Marzano and APL techniques. He is quoted at the end of the summary of answers to question seven.

The high school English teacher says, "We are strongly encouraged to use as much diverse methods as possible. In fact, we have a book called Marzano that we've had training in...I use group work for jeopardy reviews which I'm going to get on the board for a class tomorrow, to review comprehension, take notes and be ready for the 
test. I've used that religiously...There's lots of different pair and share ideas...they

appreciate any type of activity, of hands on."

The high school Special Education teacher answered question seven at greater

length. She uses as an example of an engaging activity making cookies.

You kind of break it down and give everybody the task that they can do and they can achieve success in because every little success builds a bigger success. Then maybe the next time we rotate that. And maybe the one who's not as strong in reading will struggle with an aide beside them but they will read the recipe and they will figure out, "OK this is what the ingredients are." This is the step. And then this is the next step. And then this is the next step. And we kind of shift it around so that everybody gets to try it. But if you start first with the people that you know are going to be successful and their classmates see them be successful in that role, then it encourages them to try to take it on. They work hard to achieve their successes. They inspire each other too.

In addition to describing appealing to the strength of each learner and then challenging each learner to try a new task in a group activity, she describes positive social interaction outside the classroom through sharing the cookies. She says that administrators, teachers and the school secretaries appreciate the cookies and the students who made them. "It also lets them know that they're just like everybody else."

The high school math teacher, like the other high school teachers, talks about engaging the students through differentiated instruction, rotating stations, and group work. (Carol Ann Tomlinson defines "differentiated instruction" as "at its core, differentiated instruction means addressing ways in which students vary as learners" (Rebora, 2008).)

High school teachers can get into a routine of come in, do your bell ringer, check your homework, go over the topic, start the problems. And I'm not saying there's anything wrong with that for some kids. Some kids want that level of routine, but some people, you do that three days in a row, and 
they're done. So you just do something different. You do-you get up and have them go to the board and do a problem. Have dry erase boards at their desks. "Here try and do a problem on the board." You break them up into three stations where they spend ten minutes at each station. We're still doing the same problems that they' $\mathrm{d}$ be doing on a work sheet. But you're changing position every ten minutes, so that they feel like, "I'm not just sitting here day in and day out." So that's what I mean by differentiated instruction. And that really helps the kids to stay entertained and involved which is helpful to you as a teacher. (Laughs.) It takes more planning. It takes a lot more planning. It's easy to just do the same thing over and over again, but I really really tried this year to do the differentiated instruction and it's worked out really well.

She too describes positive social interaction, "My real goal...is to get people to work collaboratively, and the questions that I tend to use are ones that if you were by yourself...you probably wouldn't get...I'm definitely seeing better communication among the students."

The middle school social studies teacher is specific about how she differentiates instruction and uses Marzano and APL techniques. She answers question seven, "Oh, what works. That's exactly how I make decisions-what holds their attention, what they are successful at, what they can apply to what they have learned—note-taking is good for this age...Diagramming is excellent. Any time you use any kind of a Venn diagram or any kind of a diagram where they organize their notes because it helps them get them organized in a framework that they can visually see...You have to vary your instruction." She also says, "I love Marzano," and, "I love APL." She does not mention group work but nor is she prompted by being asked about group work. She did say in answer to question three, "You have to teach them the kind of skills that they need to be accepted in the group." Also, in describing hands-on activities such as making a mummy, she clearly uses group work and positive social interaction. 
The middle school science teacher also uses differentiated instruction and group work. 'I guess I'm the 'Read it. Write it. See it. Hear it.' person. I try to cover all bases. Like the hands-on things. Even though there is a diagram, I really try to cover different realms of that so that the auditory kids are getting it, but yet my tactile students are also getting something from it." Of group work, she explains, "We do the labs and that is group work. And usually how I group my students is to put a real high student, a low student, maybe a shy student, so that they're really mixed up and I do not use the same groups for every activity."

In the intermediate school, the newer fifth grade teacher says:

Just coming from...grad. school, I came away with lots of ideas that are I guess different from traditional teaching methods. You know, read the section do the section or do the worksheet. We try to do more hands-on activities. So basically, I use a lot of the things I learned there where it's a lot more hands-on. And I try to integrate a lot of different things like I try to integrate social studies and science into reading. And I always do art activities and I have music playing and everything. So I like to do things that have a lot of integration and that's just because everything is somehow interrelated. With reading, if we're reading, we have to have our ninety minute uninterrupted reading block, and social studies are reading and in science you're reading, health you're reading. You're basically reading with everything. There's a lot of integration and, basically, like I said before, I try to do activities that engage. So I can be in the middle of a lesson and if it looks like half my class is going to fall asleep, I change what I'm doing and I come up with a game in my head that will somehow teach the same thing.

Thus, she is very specific about engaging learners through differentiated instruction although she does not use the term "differentiated instruction." Her description of handson and art activities imply group work even though she does not explicitly use the term (nor is she prompted to use the term). 
The more experienced fifth grade teacher, like the middle school science teacher, explains how she addresses various learning styles. Like the less experienced fifth grade teacher, she does not explicitly use the terms "differentiated instruction" and "group work."

I kind of make a variety. At the beginning of the year, I do a survey to see if they're auditory, visual, or tactile learners. And this year, everyone in my class except for three, twenty-five out of twenty-eight came out auditory, highly auditory learners. So I try to make sure that I meet the needs of the different kinds of learners. You know, when we're doing reading things, I always make sure we do some silent reading, some where we listen to a book on $\mathrm{CD}$, some where we read out loud to each other. I try to vary all my methods each day and each week so that everybody's needs are met in some form or another. You know Howard Gardiner's multiple intelligences and you have the people who want to do the visuals and do everything in pictures and we try to differentiate our instruction to meet as many needs as I can. It's hard when there's twenty eight kids and one of me, but I do the best I can.

In the elementary school, the teachers also indicate that they differentiate instruction. They describe varied activities and specifically mention group work. The first grade teacher says enthusiastically, "I do it all...I do a lot of station work...You don't want to rely on any one thing... You want to do...differentiated instruction...We do manipulatives. We do auditory...I have picture clues and I draw things on the board." Of grouping, she says, "Even in the course of grouping, that's in the context of teaching small sub-skills to smaller groups." As to positive social interaction, she has already addressed this aspect of instruction in answering question two, saying, "I want them to be above all compassionate with each other."

The third grade teacher also describes varied activities and group work. She does not use the language "differentiated instruction" but explains ways she appeals to 
different learning styles and integrates the curriculum, like the newer fifth grade teacher. She uses as examples class performances - a Thanksgiving play, writing and reading aloud poetry, and "individuality awards." "I have individuality awards which is like our classroom's version of the Oscar's or the Emmy's. The kids get all dressed up and they each get an award for something unique about themselves and then they all gave speeches that they wrote. And I was totally impressed this year. They blew my socks off with how wonderfully they did." Of group work, she says, "We do partner work. Sometimes I'll work in groups of four or five...I love...making them work together because sometimes kids can pick something up just like that. I can explain it to them ten times, but then if they get with somebody else, they get it. (Laughs.)"

Considering teachers as a pooled population, for the most part they describe a variety of engaging techniques and activities including group work. Only the high school math teacher and the first grade teacher explicitly use the term "differentiated instruction" in answering question seven, but all teachers describe a variety of approaches and explicitly or implicitly refer to addressing different learning styles. Teachers are especially enthusiastic about hands-on activities and, overall, their answers to question seven are lively and animated. The middle school social studies teacher specifically mentions Marzano and APL techniques.

The principals are asked the same question, in terms of the teachers' instructional methods, "How do teachers at your school make decisions about how to teach in terms of instructional methods?" The high school principal is the only principal to use the term "differentiated instruction" in answering question seven. The high school principal says: 
A large part of [the teachers'] decision [about how to teach in terms of instructional methods] is left to them to decide, a large part of it. It all goes back to their background, what they're comfortable with, what they were taught when they were in college. However, there are a variety of professional development strategies that the county offers-APL strategies - they talk about everything from wait time on questions to how you organize the plan, the bell ringers; it's just one of many types of staff development for instructional strategies. Differentiated instruction, the Marzano strategies that [the] county has gone through for the last four years, dealing with effective classroom strategies-in other words, they will go over graphing and charts, summarizing and note-taking, all of those types of things and would arm the teachers with information that they could keep in kind of a strategy toolbox that they can pull out for a variety of things.

The high school principal does not specifically mention group work. Of field trips into the community, he says he believes they are important, "So [the students] can touch it and make something special to them, so we do as many as we can."

The middle school principal explains the APL technique of "think, pair, share" and the Marzano technique of making comparisons to develop high level thinking. He does not use the term "differentiated instruction" in answering question seven. Like the high school principal, he does not mention group work specifically. When specifically asked about group work, all participants agree that teachers use group work. Some participants spontaneously, without prompting, say they use group work as one of their instructional methods. Regarding the social interaction of field trips, the middle school principal explains, "[We use] field trips to back up our instructional methods, [but] you've got to justify it pretty strongly."

The intermediate school principal does not mention Marzano or APL techniques. She does mention group work, and, like the high school principal, she says that the 
teachers are largely free to decide their own instructional methods. She expands on

teachers' freedom to decide their instructional methods as follows:

[Our teachers] do a great job of working collectively as a team and doing activities that cover curriculum in a creative way. Then it's not mundane and it helps students to get excited about learning. And I always encourage that. And my teachers are very free to-as long as they can show me they're covering the curriculum, they're covering the maps, their instruction is their individual style... The same style of instruction doesn't work for everyone... Sometimes, the teachers need to change their styles depending on what the students' needs are. So instruction always has to go hand in hand with student need because you can give wonderful instruction but if your children aren't there yet, you're doing a great job, but they're not following. So it has to really go hand in hand.

Thus, the intermediate school principal addresses differentiated instruction in terms of teachers meeting student needs. She does not specifically mention Marzano and APL techniques, but she does specifically mention group work as follows, "We do do a lot of group work and cooperative learning because one thing we have learned: kids learn better from other kids."

The elementary school principal answers question seven in terms of Marzano techniques, saying:

We just finished training with Robert Marzano's work and principles of learning... one of the things that we look at is making sure that you begin the day with a type of what we call a bell ringer. And beginning the daygetting the students' minds focused on learning is very important. One of the other things is giving children time when you're working with them and questioning, giving them an opportunity to digest information. Then make sure that when you're presenting your information you're always checking for understanding and as you are ending a lesson, then make sure that you review the things that are taught at that particular time. However, the next day, you go back and you pick up the things from that lesson that you had taught previously, review that and then add new information. And it's always review and present, checking for understanding, and reviewing, so it's a constant cycle you're going through. 
He does not mention the term "differentiated instruction," but he does describe group work and stations. "Teachers will begin with group instruction and then we divide the students out into learning centers and in those centers are activities that the children are involved in. The teacher is a part of one of those centers. So as the children rotate through a particular center, through the centers of the classroom, they're always having a period of time that they'll meet with the teacher. And the teacher's able to check their progress, check again their strengths and their weaknesses as well as give them some hands-on instruction."

The principals, for the most part, answer question seven with an explanation of differentiated instruction, Marzano and APL techniques, and group work. On the other hand, the only principal to use the specific term "differentiated instruction" is the high school principal. The intermediate school principal does not mention Marzano or APL techniques. Only when prompted do the principals mention group work. The principals agree with teachers for the most part that a variety of teaching styles are needed to meet a variety of learning styles.

Like the principals, the deputy superintendent of schools describes differentiated instruction and Marzano and APL techniques. "[A teacher] might write it on a board, or on an electronic board or whatever and I see that and I remember it, but maybe I have to write it, and maybe you have to hear it. A good teacher knows that and that's the differentiating of instruction which is important and it takes a lot of work and a lot of planning and that's the other aspect of a good teacher is just to be well-planned." He says that the county has offered "extensive training" in Marzano and APL techniques and 
asks, "Are we really seeing what we've been preaching? Are we seeing the teaching strategies? Are we seeing the APL strategies in place? Are those things working? Are the teachers talking the language? So that's what we want to do this year." He adds that after teachers "start using the lingo" then "the next step is they're implementing." Sometimes, in the case of differentiating instruction, teachers appear to be differentiating their instruction without using the actual "in vivo" term.

As a pool, the participants answered question seven with pride and pleasure in the specifics of instructional methods. They mention addressing a variety of learning styles with a variety of activities and techniques. Among these techniques are the Marzano and APL strategies mostly mentioned by the principals and the deputy superintendent of schools but also mentioned by a few of the teachers. Group work also is an important instructional technique. In addition to these three main points of similarities and differences, there are differences in the verbal data arising from question seven that include discussion of integration of curriculum, learning stations, and field trips in the community.

Question Eight

Question eight, "If you could teach however you chose, would you teach differently?" usually prompts the answer, "Yes," but in the case of the high school English teacher prompts the answer, "No." The ways teachers would teach differently varied from having more computers, to having more hours in the day, to having smaller classes, to having fewer content standards, to integrating curriculum more, to having different text books. If teachers ask, "If money were no object?" they are answered, 
"Yes, if money were no object," to see what teachers would consider ideal teaching. There is some overlap in the answers of the nine teachers, but a summary of answers to question eight mostly generates a wide variety of language.

The high school English teacher answers question eight, "If you could teach however you chose, would you teach differently?" "Probably not because I'm teaching the subjects I prefer all the way down the line—ninth grade honors is my preference because of the literature and that is in the ninth grade book. And in terms of style, probably not a whole lot different because of what needs [to be] covered—and it seems to be effective, from former students and grades of students and test results of students." She does explain that her teaching has changed over the years and she especially praises a "writing institute" "which changed my approach more to priming the pump and brainstorming...I am much stronger in the work that I've done through the writing institute." Overall, the high school English teacher is content with her teaching and would not choose to teach differently.

The high school Special Education teacher says, "I'm pretty much teaching the way I want to. The only thing I would change is to be able to have more money-to be able to get the hands-on manipulatives that they need... If I had more money to get different computer software, so that we could have touch screens, that would be an asset. Just things like that...And to have my kids be more a part of the regular community in the school." She explains that they do have a lot of interaction with the school community but "if we could have more interaction like that all year long, that would be great with me." 
The high school math teacher answers question eight, "I would like to do even more differentiated instruction, more activities, more standards-based, more problemsbased learning than I do...standards-based math...is a lot like problems-based learning where they are presented with a situation or a problem and they tend to discover some kind of property...You have them go through an activity that they discover what the postulate or theorem or purpose is. They kind of take ownership of that...It takes a lot of planning...I would like to do that more often. But it's too much time." She shares with many of the other participants the wish to have more time. Often the participants also mention time in answer to the second half of question nine, "What forms barriers to your success?"

In the middle school, the social studies teacher answers question eight by saying she wishes she had a "smaller class size." "If I could teach ideally, I'd have twenty students, and we would take our time and really learn about what we're doing. We'd do a lot of activities...We'd take lots of field trips...I'd have a more relaxed, comfortable situation. I'd probably teach blocks, rather than teach forty-three minutes. I might teach ninety minute blocks where I could start activities and completely go through them and do different buried things about what I'm teaching...We'd do a lot more writing than we do because I'd have a lot more time." Like the high school math teacher, she would rather do more activities that take more time to prepare and to do than she is currently able to do. The middle school science teacher answers question eight similarly, telling me, "The only thing I would change would be doing some more activities that I think the students would enjoy instead of teaching all the [content standards]." 
In the intermediate school, the less experienced fifth grade teacher says she would integrate her curriculum more if she could teach however she chose. She also mentions time, "I would do so many more things if I had time... if I could do reading in the morning, math in the afternoon, and integrate the other subjects into them, I think it would be perfect...I would focus on two subjects and put everything else in when I have time."

The more experienced fifth grade teacher says, "I would ditch some of the textbooks that we have. They're terrible—like the social studies—-the readability is so high and these kids just really struggle." She also agrees with the other teachers who voice the wish for "more time. The biggest difficulty I think we have is not enough time to plan meaningful lessons and units." Like the high school math teacher, she mentions problem-based learning and the planning time required to do such a lesson. She says, "It'd be nice to keep working all summer or part of the summer to" "deeply think about what you're doing and why you're doing it." She also mentions money: "If I had all the money I wanted, I'd have a lot more trade books. Every kid would have an i-pod, each kid would have a computer, so they could have their own listening station so that they could do everything more at their level." Like the middle school social studies teacher, she also mentions smaller class size.

In the elementary school, the first grade teacher also says that she would change the books if she had more money. "I'm very disappointed with the reading series that they have adopted...there are ones out there that are the right level for the students." She explains that she would organize the reading thematically so that "everything blended 
well." She adds, "But I'm happy doing what I do and finding what I need to find on my own." The third grade teacher, like the less experienced fifth grade teacher, talks about integrating English: "I would incorporate all my reading, language, and spelling. It would make sense to me to have spelling words that were incorporated into your vocabulary, language concepts that go with your reading." She also finds the content standards too many: "I would rather see them have a few less concepts per grade level and really hit those concepts hard." Like the high school math teacher in answering question 6, the third grade teacher especially finds that the content standards in math do not allow enough "really in-depth" learning.

Considering teachers as a whole, for the most part teacher would teach differently if they could teach however they chose. While the high school English teacher says she would want to teach the same way, the other teachers offer a variety of ideal changes, even though many of them are also basically content with teaching as they do. The most common way that teachers would teach differently would be to have more time as stated by the high school math teacher, the middle school science teacher, and both intermediate school teachers. The second to most common way that teachers would teach differently would be to have more activities as stated by the high school math teacher and both of the middle school teachers. Connected to time and activities, the third most common way that teachers would teach differently would be to have fewer content standards to cover as stated by the middle school science teacher and the third grade teacher. As discussed under question six, these are not the only teachers to find there are too many content standards. 
Two teachers, the high school Special Education teacher and the more experienced fifth grade teacher, would teach differently by having more money to spend on computers. Two teachers, the middle school social studies teacher and the more experienced fifth grade teacher, would teach differently by having smaller class sizes. Smaller class size is connected, of course, to having more time to plan, to grade, and to give individual attention to students. Two teachers, the more experienced fifth grade teacher and the first grade teacher, would change the books used in their classes if they could teach differently. Thus, teachers, overall, want more time for activities, planning, and grading. Two teachers mention wanting new computers and books.

The principals also consider that teachers would teach more in depth or do more "fun" activities if the teachers could teach differently. The principals, like the teachers, address pressure to cover material under the content standards. The principals do not specifically mention more resources in the form of time, money, and a higher teacher: student ratio in answering question eight. The principals' version of question eight is split into curriculum and instruction: "If teachers at your school could teach however they chose, would they make any changes in curriculum or in instructional methods?"

The high school principal says, "I think given that freedom, teachers would kind of migrate towards the things they are best at, that they like. We still try to give them enough freedom to do that, but give them the guidelines to say, 'Hey, you're all going to go over that for this amount of time.' You're not going to spend the whole semester going over one battle in the Civil War because you like to reenact the Civil War.” Of instructional methods, he answers, "I think that they would migrate to what they're 
comfortable with. I do. I think for some people it's very difficult to give freedom to students-you feel like you're giving up control when you allow students to stand up and walk around and talk to each other and work in group work, but it's been proven that students sharing with students helps them retain the information much more than just straight teacher lecture."

The middle school principal gives examples of activities that teachers would do if they could teach however they chose.

I think a lot of them would go back to the things that are a little more fun to teach. They'd do the volcano unit when we tell them, "Look there's nothing in your book to give us a volcano unit." (Laughs.) Building a volcano, and putting in all the chemicals to make it erupt, isn't necessarily part of the critical curriculum, and the three weeks that your work on it or the two weeks that you work on it won't work. Some of my teachers still do their catapults and things like that because they do force and motion and it works great, and the kids are involved and engaged and they love it. And I think that's wonderful... We try to do that balance between hard work and doing the things we have to do; some teachers don't want to.

The intermediate school principal, like the high school principal and the middle school principal, explains that sometimes teachers have to give up certain activities in order to cover the content standards. She speaks of "[the teachers'] freedom [to] do their individual thing. But we have to stay within the curriculum and the [content standards]. We have to. So many teachers-you know I always do a unit on dinosaurs or whatever it is you do—if it doesn't fit your grade level curriculum, you're going to have to give that up. Because you have to stick to the curriculum so that we know that we're covering the foundation and basis of that year and grade level."

The elementary school principal speaks of some sweeping changes teachers would make if they could teach however they chose. "I would say there would be some 
changes. One I know in particular would be doing away with report cards and using progress checks because we're primary...Especially with kindergarteners coming in at five years [old], they're not all at the same place. But I think having a check sheet of progress and understanding makes learning much more fun for them than having to rush through these stories or these particular concepts." As for the content standards, he says:

I feel that the primary content standards should be broader than what they are. And of course I'm one who also believes that children should not start formal education until they are seven years old. I just think we take away too much childhood time and play time and social interaction time. We have a lot of children entering school who are not able to get along with other children. They haven't had the time to play. They haven't had the time to do the types of things that you expect children to do growing up. To expect the child to come in formally and sit in their classroom in their desk for periods of forty-five to fifty minutes, that's a lot to ask. But because we have guidelines that need to be taught... we have to follow those. Many children are just not ready.

He also, like the less experienced fifth grade teacher, mentions integrating the curriculum around reading and math, "I just think the reading and math should be more—at this level, primary-more integrated units of teaching and then bring in science and social studies and so forth as a part of the unit rather than individually teaching math or teaching science or social studies."

For the most part, then, principals, like teachers, say teachers would teach differently by devoting more time to activities if the teachers could teach however they chose. The high school, middle school, and intermediate school principals do not express strong disapproval of the content standards although they voice a fondness for the activities which teachers do not have time to teach. The elementary school principal more strongly and unequivocally disapproves of the pace and pressures the content 
standards make for students and teachers. As a pool of participants, teachers and principals think that teachers would teach differently if given the opportunity. While teachers stress more the resources of time, technology, and texts, principals stick more to describing activities. The elementary school principal, however, discusses more sweeping changes from changing report cards to allowing more play time and starting school at a later age. There is, for the most part, agreement among the participants that, "Yes," they would teach differently. On the other hand, there is contentment with how the teachers are teaching at present.

\section{Question Nine}

Question nine, "As you work to succeed, what is supportive and what forms barriers to your success?" draws both professional and personal responses. Some answers draw on the issues already raised by previous questions in the interview. Other answers draw on personal support such as feeling support from family, peers, and administrators. Each answer is discussed before agreements and disagreements are summarized regarding question nine.

The high school English teacher says, "I really think the biggest support has been co-teachers. But the current administration-we're getting much more support than we had a few years back." She also says that the parents of the students help her to feel supported-“"very much so. Just even the comments that have drifted back, 'So and so

really helped my student. They helped them get through a good year. I appreciate that.", As to barriers, she says, "Some of the biggest barriers would be the paperwork...meetings we have to go to that we gain nothing from...Sometimes 
administrations can be difficult... Not being able to get a hold of parents that you need to see and talk to to try to straighten out any problems is frustrating."

The high school Special Education teacher first mentions support from her family, her husband and her parents. Then she mentions support from the parents of the students. Also, she states, "My support staff are fabulous at supporting." As far as barriers, she says, "Sometimes there are administrative people who are not comfortable [with] dealing with these populations, [and] that's a hindrance—when you are seen as, 'Let's just put them away in the closet,' and I want to bring them out front and center stage and show them off." She also gives two examples of the administration, "turning a deaf ear sometimes." First, in her classroom she had a problem getting the administration to take care of scabies going through the room. Second, "This is the first year we haven't had to fight to keep our support staff."

The high school math teacher, like the high school Special Education teacher, mentions the support of her husband, her mother, and other family members. But her first response is, "What helps me: I love teaching." She goes on to say, "My personal passion for teaching is something that helps me succeed and want to grow." She finds the administration supportive and says, "My principal has told me often how much he appreciates how hard I try to do all these things. And I appreciate him appreciating me." As to barriers, she says, "Things that hinder me? Sometimes I can get pessimistic about everything that needs to be done. I never feel that I want to give up, but I feel like, 'I don't feel like this is working. What else can I do?' I feel confused. I don't know what 
else could work. Like with kids not knowing how to do fractions when they're in Algebra class. That's a huge barrier."

In the middle school, the two teachers stress what is supportive. Like the high school Special Education teacher and the high school math teacher, the middle school social studies teacher mentions a supportive husband. She also says, "The difference in being a young mother and in being an older parent with children who are on their own is tremendous. It's just-I've been able to do a lot more." Like the high school teachers, she has found faculty and staff to be supportive. "I've not been in a school building where I have not found faculty and staff to be supportive." She mentions only one barrier to success, “The only barrier I can see right now is some of these parents who don't support you and aren't able to-some of these parents would support you if they just didn't have so many problems."

The middle school science teacher, however, sees the positive side to parents first, answering question nine, "The parents are very supportive." She describes a two day camp with the intermediate school in which the parents actually taught the lessons. She also mentions her team, her principal, and the board office as being supportive. She does not describe any barriers to success.

In the intermediate school, the newer fifth grade teacher says, "I would say everybody else in the school is the biggest thing for being supportive." Of barriers, she says, "Parents are often a barrier. Time is a barrier." The other fifth grade teacher finds the administrators supportive, the Special Education teachers supportive, and the overall teamwork in the school supportive. Of barriers, she mentions, "Too many kids in my 
classroom," and, like her colleague, "Not enough time." Like the high school English teacher she says, "Some of the paperwork that we have to do, sometimes it seems needless, but there's a reason for a lot of it. It's getting better."

Like the high school and middle school teachers, the elementary first grade teacher answers, "Well, as always, the people that I work with are the support system." The barriers she explains are varied. She says, "The barriers come from people you don't work directly with — the county and the state and all these people who kind of put a stop to what you do. In some forms, parents can be a barrier." She further explains that parents can be a struggle when a teacher needs to retain a child. "I don't consider it so much a retention as, 'Hey, we're just taking more time to grow."”

The third grade teacher first says, "Supportive, I think definitely here the parents are supportive." She says, "Another support is that I guess we're pretty well supplied...I do feel that I have a lot of things to help me and a lot of resources to pull from." As to barriers, she says, "The only barrier would be to have a student who was very unmotivated and unwilling to do his part. And that's not necessarily a barrier to my success, but I see it as, 'I'm not making a difference with this child.' So I'm feeling unsuccessful even though it's that child who is being unsuccessful. I don't know anything else about that. (Laughs.)"

Considered as a pool, teachers for the most part agree that colleagues are an important support. Some mention that administrators are supportive. Some mention parents as a support, while others see the non-supportive parents as barriers to success. Some teachers mention their own families as importantly supportive. There is more 
agreement as to what helps or supports teachers than there is agreement as to what hinders teachers or forms barriers to their success. A couple of teachers, the high school English teacher and the high school Special Education teacher, find that the administration can sometimes hinder success. The high school English teacher and the more experienced fifth grade teacher mention too much paperwork. Both fifth grade teachers mention not enough time as a barrier to success. These are the main overlaps and trends in the teachers' answers to question nine.

The principals share some of the teachers' views as to what is supportive and what forms barriers to the principals' success. Like the teachers, the principals mention as supportive the administration in the board office, family, and parents and community. Like the teachers, the principals also see time and difficult parents as barriers to success. There is variety among the principals' answers. The high school principal says:

When you're trying to determine success, the most important thing is making sure that you put the students first...As long as [the teachers] are making decisions based on what's good for the students, we all get along and everything's honky dory. They come up with ideas, and I try to help them with that. Every now and then, at least it appears to me, someone will try to make a decision to-and say that it's for the kids, but I don't believe it's in their best interests which causes hard feelings and at any place if you have hard feelings, you have barriers. I think communication is the key to both of those things. Good communication can help break down the barriers. Lack of communication or incorrect, improper communication builds up the barriers. So the biggest thing for me is communication.

Throughout the interview, the high school principal stresses individual student success. His focus on how he views supports and barriers to success is professional not personalwhat helps the students and the school rather than what helps him personally. In stressing communication with teachers about putting students first, he gives priority to individual 
student success again. As a barrier to success, he also mentions not having enough time,

“The individual attention that I liked so much as a teacher, I'm unable to give. That to me is frustrating."

The middle school principal credits the central board office, the community, the Parent Teacher Organization, and business partners as being supportive of success. "It's just a lot of good people that care about kids." Like most of the teachers, he mentions parents. Parents can be both supportive and barriers to success.

Getting kids to be motivated and to do their work is the next thing. And I know we as parents, we're doing the best we can sometimes and the kids will still be acting goofy and not doing. But I still need parents to try. I still need parents stay in touch with us; I still need parents to do their best to try to help us through the situation, and to expect your kids to do the job. And if we have that generally, we're going to go much farther. We have a lot of good supportive parents, but there are some out there that are just not buying in, and you can tell which are which very oftentimes.

The intermediate school principal, like the middle school principal, says that the board office is very supportive. "Our superintendent of schools... is wonderful. And he is very complimentary and very helpful...And [the deputy superintendent of schools] is so kind." Like many of the teachers, she credits her family as being supportive of her success. Like the intermediate school teachers, she says, "I think my success also comes from the positive relationship I have with the staff because we do feel like a team." She mentions the positive side of parents: "Parents—-when you work with parents closely and they get excited about what's going on at school." As to barriers, one barrier she mentions is, "Sometimes, parents can be just very negative."

Like the middle school and intermediate school principals, the elementary school principal mentions staff, parents, school district, and community as supportive of success. 
Like the high school principal, the elementary school principal is concerned with attention to the individual student, but he sees as supportive of success having more staff.

I would like to see more staff being put into a school building than what we have presently. Resources are always important. Working with children at a young age, I think it's even more important than what some people who provide the funding look at. The more one to one, two to one, three to one, that you can have with young children, I figure that's the most successful way to work with them. And they need time to be able to play. And from my experience, the play that they're able to do when guided correctly is far more important than sitting at a desk, using paper and pencil to find out and to learn things...Giving children time to explore with manipulatives and I think that's one thing is having manipulatives to use and that would be a part of the play that I'm speaking of.

Among the four principals, three say they see support for success from the board office and the parents. The middle school principal and the elementary school principal also mention the community as being supportive of success. The middle school principal and the intermediate school principal see parents as sometimes barriers to success. The high school principal sees communication as the key to success and defines success as students first. The elementary school principal prioritizes students by seeing more staff as the biggest support to success. There is no uniform consensus among the principals as to supports and barriers to success.

As a pool, the participants answer question nine for the most part by crediting others as supportive of success. They implicitly thank family and peers. To varying degrees, they credit people outside the school—parents, the community, and the board office with supporting success. As to barriers to success, the participants for the most part find there is not always enough time and not always enough parental support. The biggest support and the biggest barrier to success are parental help or hindrance. In 
answering question nine, participants are grateful for supports and find overall that supports well outweigh barriers. These successful teachers and principals are enthusiastic and warm about their work, wanting time to do even better jobs, and concerned and caring about parents who are sometimes barriers to their success. 


\section{CHAPTER V}

\section{RESULTS ANSWER RESEARCH QUESTIONS}

The research design addresses the following research questions:

1. What are the critical elements of current educators' descriptions of their success?

2. How do educators in an elementary, an intermediate, a middle, and a high school within a single county conceptualize success?

3. What core beliefs and values do teachers express when describing their success?

This chapter summarizes how the language of the participants answers the research questions. The participants as a pool are considered and how the "in vivo" terms, the three perspectives, and the overall themes of the interview data address each research question is discussed. How secondary sources answer each research question is also considered.

\section{Data Answers Research Questions \\ Research Question One}

\section{Overall Findings Address Research Question One}

Question one asks, "What are the critical elements of current educators' descriptions of success?" The critical elements are pupil-based, practice-based, and policy-based. The current educators' description of pupil-based success include excitement in learning, intrinsic motivation, and participation in society. While these three educational goals describe pupil success, they also suggest best practice in school: engaging learners, fostering lifelong learning, and working on strong relationships. As to whether policy helps or hinders success, it does both according to participants: raising 
the bar, forcing equal treatment, and coordinating curriculum, on the positive side; raising the bar too high, ignoring differences, and rushing through curriculum, on the negative side. Success is thus measured in terms of pupils, practice, and policy.

Taken as a whole, the interview data addresses research question one forcefully and clearly as participants explain with enthusiasm and passion the importance of engaging instruction, instructional methods, and the role of policy. Teachers mention the learning moment, "when the light bulb goes on," as an example of teacher efficacy and students' cognitively grasping the material and also as an example of a spark of student joy in learning and success on the affective level. The fifth grade less experienced teacher mentions the "high" of seeing her students learn. The high school Special Education teacher describes her excitement at seeing her students learn as follows: "I get really jazzed, excited when I see my students achieve...it's kind of like a circular feeding frenzy. The more they succeed, the more it makes me want to succeed." Successful teachers say they can see pleasure in learning on their students' faces, so that the positive affect in the classroom is mutual. Even as successful teachers enjoy learning, they recognize and nurture their students' enjoyment of learning. Teachers mention whole class momentum and excitement. They mention relationships and compassion. Administrators speak more of techniques and planning, but they also emphasize relationships. All the participants address No Child Left Behind legislation, for the most part seeing it as negative, but, on the other hand, seeing its potential to be positive. In addition, participants describe the people and resources supportive of success and needed for success. 


\section{Interview Data Addresses Research Question One}

A summary of the elements of success in a matrix form shows the main elements of success in bold type, the "in vivo" terms in parentheses, as the rows. For the columns, the interview data are split into the three perspectives of teachers, principals, and the deputy superintendent of schools. The number of participants who mention each critical element of success (out of nine teachers, four principals, and one deputy superintendent of schools) are then filled in. While this matrix covers "in vivo" language very literally and closely, without paraphrasing, the discussion of participants' voices in Chapter IV covers their language as a whole. The critical elements of success as described by current educators in the study include: student learning, socioemotional success, teachers' practice, curriculum and evaluation, and supports or needs. Pupil driven success includes enjoyment of learning — an intrinsic motivator-and social success_-a means of later contributing to society. Practice driven success includes hands-on activities and reaching different kinds of learning styles and is not always seen in terms of techniques. Policy driven success includes not always counting standardized testing and the ensuing content standards as the strongest ways to measure success and to plan curriculum.

Table 2: Critical Elements of Success

Critical Elements: (in vivo terms)

Student learning:

(enjoyment)

(students get it)

(light bulb goes on)

(raising their hands)

(engagement)

\section{Teachers Principals Deputy Superintendent}

$\begin{array}{lll}\mathbf{7} & \mathbf{3} & \mathbf{1} \\ 7 & 3 & 0 \\ 6 & 1 & 0 \\ 5 & 0 & 0 \\ 1 & 1 & 1 \\ 1 & 1 & 0\end{array}$


Table 2: Critical Elements of Success (continued)

Critical Elements: Teachers Principals Deputy Superintendent (in vivo terms)

\section{Socioemotional}

success:

(social success)

(caring)

(relationships)

(trust)

(growth)

(emotional success)

Teachers' practice:

(hands-on)

(activities)

(sharing)

(group work)

Teaching techniques:

(Marzano)

(planning)

(differentiated instruction)

(APL)

(passion)

$\begin{array}{lll}\mathbf{6} & \mathbf{2} & \mathbf{1} \\ 6 & 2 & 0 \\ 3 & 2 & 0 \\ 3 & 2 & 1 \\ 2 & 3 & 0 \\ 1 & 0 & 0 \\ 0 & 1 & 0\end{array}$

\section{Curriculum and}

evaluation:

(Not standardized testing)

(Not content standards)

$\begin{array}{lll}\mathbf{8} & \mathbf{3} & \mathbf{1} \\ 8 & 1 & 0 \\ 7 & 2 & 0 \\ 3 & 1 & 0 \\ 2 & 3 & 1\end{array}$

Supports:

(Students' parents)

(Supportive co-workers)

(Supportive family)

$\begin{array}{lll}\mathbf{2} & \mathbf{3} & \mathbf{1} \\ 2 & 3 & 1 \\ 2 & 1 & 1 \\ 2 & 1 & 1 \\ 1 & 2 & 1 \\ 1 & 2 & 0\end{array}$

(More money)

(More time)

$\begin{array}{ccc}\mathbf{7} & \mathbf{3} & \mathbf{1} \\ 7 & 3 & 1 \\ 5 & 1 & 0 \\ \mathbf{8} & \mathbf{4} & \text { N/A } \\ 8 & 4 & 0 \\ 8 & 3 & 0 \\ 4 & 1 & 0 \\ 4 & 0 & 0 \\ 3 & 1 & 0\end{array}$

Secondary Sources Address Research Question One

The secondary sources of documents - from class rules to posters to activities to letters home-contribute to the interview data's language addressing research question 
one. The critical elements of success revealed by the secondary sources mirror the categories found in the "in vivo" terms from the interviews listed in Table 2 and include engaging student learning, caring for their socioemotional well-being, practicing activities and differentiated instruction, evaluating based on active learning, and building relationships with parents. In the high school, for example, the English teacher shares a vocabulary poem. Autobiographical poems decorate the walls in the English classroom. In the Special Education classroom, the teacher shares a handout on class rules including "Be polite, share, and take turns with class activities." Photographs of students on field trips and one smiling student who was recently hired at Burger King are neatly arranged on the wall next to the teacher's desk. In the mathematics classroom, handouts on balancing a checkbook and on tactile activities are collected. A poster reads, "The most important tool for success is the belief that you can succeed." The high school teachers are concerned with engaging learners, relevance to students' lives, and looking ahead through teaching life skills.

In the middle school, the social studies teacher shares handouts on finding names of locations on a map. Posters such as a large world map, pyramids and the Colosseum decorate the walls. A mission statement by the blackboard includes the wording, "All students will participate in the learning process as they strive to cultivate individual strengths, talents, and self-esteem in a supportive educational environment." The science teacher shares documents such as handouts on lab tool bingo, copies of a newspaper article on the sun's diminishing heat from which the students found seven facts, and a web page with the week's assignments. Next to the whiteboard is a poster of "Six Pillars 
of Conduct: Trustworthiness, Respect, Responsibility, Fairness, Caring, Citizenship" with examples of each. The middle school teachers, like the high school teachers, engage their students through a variety of hands-on activities and work on character and caring for the whole student.

From the intermediate school, documents such as reading comprehension exercises addressing different levels of comprehension, a graphic organizer on "Doors to Understanding: What I know, What I want to know, and What I learned," a Left Brain/Right Brain Activity, and a math word problem based on Asteroid Game scores are collected. Posters include "Give a Compliment: I know you can do it, Fantastic job, You should be proud, You made my day," and Snoopy posters saying, "Friendship picks you up when the world lets you down," and, "Friends come in all shapes and sizes." The intermediate school teachers emphasize the learning process and team work.

From the elementary school, handouts are collected on a creative spelling activity including writing words in unique writing and gluing words on a paper from letters students cut out of magazines; letters home are collected inviting parents to share "questions, concerns, or joys...with me"; and an explanation of a website designed to keep the class and parents connected is observed. Open classrooms are separated by partitions, and on the walls of one classroom is a jungle motif with monkeys and other animals including "Wild about reading." Cushions on the floor make a reading corner. The elementary school teachers are creative, caring, and focus on enjoyment in learning. In the documents and classroom atmospheres the teachers create, the elements of success are the same as those that show up in the interviews. The secondary sources 
show teachers engaging student learning and seeing that students enjoy learning.

Teachers care about the socioemotional well-being of their students as evidenced in posters, rules, and letters home. Teachers' practice and teaching techniques include hands-on activities and differentiated instruction. Teachers evaluate students through a variety of assignments, not just standardized testing. The critical elements of success that show up in the secondary sources corroborate the findings from the interview data.

\section{Research Question Two}

\section{Overall Findings Address Research Question Two}

Answering research question two, "How do educators in an elementary, an intermediate, a middle, and a high school within a single county conceptualize success?" prompts the consensus definition of "success" as caring for individual students. Again, the results of the data can be organized into pupil-based, practice-based, and policy-based language. Caring for individual students comes first and helping them to be engaged in class and enjoy lifelong learning comes second. Policy considerations come third, but they influence the pupils and the practice of teaching through the curriculum, the instruction, and the well-being of the school as a whole. The threat of restructuring the school in 2014 or earlier penalties for not making AYP under NCLB keeps principals and teacher under pressure. This pressure rests more lightly on the shoulders of those schools, subjects, and population blocks that are making AYP. In the county, the majority of the schools are making AYP. In the schools considered in this study the majority of subjects and population blocks by far are making AYP. The conceptualizing 
of success as caring for individual struggling students and challenging all students to achieve their potential occasionally clashes with standardized measures of success. Interview Data Addresses Research Question Two

Question two addresses the question of how educators conceptualize success in an elementary school, an intermediate school, a middle school, and a high school, reversing the order of how the data has been presented in previous questions and suggesting that the student grows from early grades to later grades. Looking at the four levels of schools considered allows the reader to see how educators view the growth of successful students and how to bring about that growth. At the elementary level, educators mention growth, character, being role models, compassion, and manners. In their practice, teachers of multiple subjects mention doing one's best and making a difference. As to policy, educators mention that the content standards are too broad and "bubble tests" are not a good measure of individual student growth. At the intermediate school level, educators mention the "light bulb going on," integrated learning, addressing different learning styles, helping struggling students to turn around academically. In their practice, teachers of multiple subjects mention building student confidence and again, making a difference or teacher efficacy. As to policy, educators (both teachers and administrators) do not think it fair to include Special Education students in the standardized measurements of success and hope for change in the No Child Left Behind legislation.

At the middle school level, educators mention student excitement at fun activities, individual relationships, and reaching different levels of learners as well as different learning styles. In their practice, teachers are immersed in their subject matter and want 
their students to relate academics to real life. As to policy, educators feel again that the standardized tests are not a strong measure of student success and that the content standards do not allow teachers to practice enough hands-on activities. At the high school level, educators mention the light bulb going on, individual student success, and preparing students for life, for college, or for mastery of subject matter. In their practice, teachers bring in inspirational speakers, plan differentiated instruction, and include group work in their instruction. As to policy, educators feel that testing is not the be all and end all and that the content standards could be detrimental to academic progress.

The deputy superintendent of schools mentions turning students around behaviorally and academically when he used to be a principal. In terms of teacher practice, he mentions individually relating to students (knowing what makes them tick), professional development (Marzano and APL techniques including differentiated instruction), and challenging the brightest students (a subject not directly addressed in the protocol). As to policy, he does not feel that testing measures the feel of a good school.

\section{Secondary Sources Address Research Question Two}

The secondary sources likewise show the development of the student, teacher practice, and views of policy. In the elementary school, teachers share rules, posters, tests, bell ringers, and activities concerned with the growth of the whole child, his or her learning, work ethic, and character. A list of rules says, "To be a good listener, look at the person who is speaking." A poster says, "Success: Don't just wish for it. Work for it!" A test question is phrased in an open-ended and engaging way. A bell ringer reviews 
the previous day's learning and reinforces the message that learning is an ongoing process.

In brief, the intermediate school, the middle school, and the high school documents show a trend towards more academic growth, more definition of distinct subject matter, and more concern with the students' work habits towards becoming good employees. An intermediate school letter home says, "Your child's fifth grade year is very important to me and I am excited to be a part of your child's newest educational journey." A middle school science poster says, "You never know what you can do until you try," and another shows the Periodic Table of Elements. A high school English exercise asks students to "identify whether the phrase is an adjective or an adverb prepositional phrase." Subject matter becomes more specialized in the higher grades. In the Special Education classroom, the teacher has posted pictures on her bulletin board of a smiling student who recently became employed at Burger King. The mathematics exercises that the teacher shares include reading a pie chart to compare family budgets and algebra word problems connected to family budgets. The exercise is practical and life skills oriented as well as being specialized in the subject matter of algebra.

The secondary sources, like the interviews, show caring for individual students and helping students to be engaged in class. As the teachers voiced in the interviews a desire to promote lifelong learning while they covered the diverse material of the curriculum under the state Content, Standards, and Objections, so the documents show an effort to promote the attitudes that lead to lifelong learning while increasingly addressing a higher level of academic growth. 


\section{Research Question Three}

\section{Overall Findings Address Research Question Three}

Research question three asks, "What core beliefs and values do teachers express when describing their success?" The experience of successful teachers as voiced in the interviews for this study includes making a difference, doing one's best, and making learning a joy. Teacher and student affect includes momentum and morale in the classroom. Teachers believe in teacher efficacy and in improving themselves through courses and conferences; they value growth. Community and parent involvement are essential to student success and to teacher success. Teachers believe in and value relationships with students and their families.

\section{Interview Data Addresses Research Question Three}

In terms of pupil success, teachers believe in enjoyable, engaging, and exciting classes. They value when students "beam," the "aha moment," and a successful learning environment according to the interview data. The belief in learning and the valuing of students "getting it" comes out again and again in the experience of the sample population. Teachers also believe in developing a strong work ethic; they value the development of their students into college graduates and being good employees; even as they personally work hard and continue to learn, they hope their students will give back to society through their work and become lifelong learners. Teachers also believe in developing character and social skills in school. They value compassion and friendship as well as academic progress. When policy in the form of standardized testing is consistent with developing students' academic skills, work ethic, and character, teachers 
agree that it is a valuable measure of success. When struggling students feel

overwhelmed by the difficulty of the test, when whole classes feel rushed or that they cannot learn well, or when whole schools are threatened with restructuring, teachers agree that standardized testing is inconsistent with student success. Secondary Sources Address Research Question Three

The secondary sources show teachers' values and beliefs in classroom rules, posters, letters to parents, and class assignments. Teachers value love of learning, working hard, and building character. They believe in engaging the student in learning, relating to the parents, and preparing the students to join the community through life skills. The documents show these values and beliefs in quotations such as "Come to School with a Smile and a Good Attitude" in a high school list of rules, "middle school will provide a challenging and rewarding curriculum of high expectations for all students" in a mission statement posted by the whiteboard, "parent-teacher communication is very important in your student's success in school" in an intermediate school letter home, and "Draw a picture to go with each part of the story" as a creative part of an elementary school test. Again and again, the secondary sources show that teachers believe in and value love of learning and building a character that will stand a student in good stead when he or she graduates from school. Teachers feel that they make a difference and show the teacher efficacy reported in the literature review when they influence their students to become lifelong learners. 


\section{CHAPTER VI}

\section{CONCLUSIONS}

In this study, participants view success as pupil-based, practice-based, and policybased. The educators consistently put students first. Their roles as administrators or teachers model successful practice and offer mentorship to developing educators. Their discussion of district, state, and federal policy voice some frustration and some hopes. The interview data answers the research questions as discussed in the previous chapter, shows thematic similarities and differences, relates to the literature review, and suggests implications for further research and for teacher preparation and professional development.

Success for the most part as voiced by teachers, principals, and the deputy superintendent of schools is a process of growth. That growth is characterized by joy in the instance of learning, the more long-term effort of establishing a strong work ethic, and the moving future goal of success in the community or society in which a student lives. On the other hand, educators use varied language in describing the success of students and themselves: from individual student progress and relationships to class momentum and achievement, from planning activities to spiral learning techniques, and from having good manners and character to being good employees.

Similarities and Differences Among the Research Data

Similarities and differences among the research data emerge from a consideration of axial themes. Each of the three perspectives of the teachers and their documents; the 
principals; and the deputy superintendent of schools are considered; then the emergent themes of the participants pooled are discussed.

\section{Teachers-Emergent Themes}

\section{Overall Findings Address Teachers' Emergent Themes}

Teachers' emerging themes to be discussed are the repeated patterns in the interview data and secondary sources. The teachers' experience was centered on pupils, practice, and policy. Like the principals, they valued individual relationships with students, engagement and pleasure in the classroom, and effective standardized testing. Overall similarities in how teachers describe pupils, practice, and policy include 1. similar language regarding joy in learning; individual relationships; and class momentum and morale. 2. similar language regarding getting it; engaging the students; and hands-on learning. 3. similar language regarding standardized testing not measuring success; content standards rushing the curriculum; and standardized testing not measuring thinking.

Differences in how teachers describe teaching as pupil based, practice based, and policy based include 1. different language regarding lifelong versus immediate learning; individual relationships versus individual achievement; and measuring class momentum and morale by student pleasure versus teacher "high." 2. different language regarding excitement versus achievement as the focus of learning; engagement as less or more academic, usually varying toward more academic in the higher grades; and emphasis on hands-on learning versus feeling the curriculum covers the material well enough. 3 . different language regarding seeing the standardized test as a measure of success-one 
intermediate teacher finds the math standardized test to be a good measure of individual and whole class success; the pace of the content standards is fine with some teachers and too fast for others; and, while many imply or state that the standardized test is irrelevant to student success, only one teacher uses the language of not measuring "thinking" on the standardized tests.

\section{Interview Data Addresses Teachers' Emergent Themes}

\section{Pupils and practice.}

Teachers' discussion of reaching individual students and helping them to experience joy in learning goes hand in hand with their discussion of best practice in the classroom. The high school English teacher speaks of pupils and practice in describing a program of bringing in authors and poets to her classroom. She describes reaching her pupils through the practice of inviting poets into the class. Of a successful poet the teacher says, "She talked and inspired poetry." The second participant considered, the high school Special Education teacher, says, "I achieve success with my students when I see the light bulbs go off." The third participant considered, the high school math teacher, says of her students' success, "Finally, they get it and they tell you and they're so happy with themselves...that makes you feel good and makes them feel good and that's the purpose." On the high school level, the general consensus is that success is when individual students achieve joy in learning.

The middle school social studies teacher explains that she sees success in individually relating to children. "I would measure success in the fact that my children don't only relate to me educationally, but they can come to me and say, 'My mother got 
into a fight with my aunt last night and she's in jail and I'm upset." The second middle school participant considered, the middle school science teacher, talks about pleasure in learning, "That must have been something that they enjoyed at the time and that has stuck with them." Both middle school teachers voice the wish that they had time to do more hands-on teaching with their students, finding best practice to be measured by students' excitement in learning.

In the intermediate school, the less experienced fifth grade teacher agrees with the high school and middle school teachers about pleasure in learning. Further, she uses the language "love learning all their lives." "I want them to just love learning all their lives...teachers always talk about that 'aha' moment when the light bulb goes on and it really is—there's kind of a high to it." Having just completed her second year of teaching following her student teaching for a master's degree in education, the newer teacher focuses on student-centered learning like her peers. She is full of ideas about how to accomplish student-centered learning. The more experienced fifth grade teacher says, "I see student success when the little light bulb goes on...you can just see their facial expressions." Both teachers define best practice by joy in learning.

In the elementary school, the first grade teacher sees success in terms of growth, "if they've come in here and they've grown as a child over the course of a year, then I guess I was successful." The first grade teacher is moving to be a librarian in the next year of her career and she says, "But the more satisfying part is going to be taking the library and making it more conducive to children and literature and appreciation of reading. That part I think I'll really enjoy." The third grade teacher also sees success as 
when one "see[s] growth." She defines growth as both student growth and teacher growth. She says, “Actually, I have a poster in my room that says, 'Success. Don't just wish for it. Work for it."' Pleasure in teaching and students' pleasure in learning go hand in hand. The practice of good teaching involves engagement and enjoyment. Sometimes standardized testing hinders individual relationships with learners.

\section{Policy.}

Teachers mostly find that the policy of preparing students for the standardized test to measure compliance with No Child Left Behind legislation does not help student success. Some teachers find that the requirement of every subgroup to meet Adequate Yearly Progress is not a fair measure of how the school is doing. Of the standardized tests the high school English teacher says, "Probably the hardest part of doing that would be the little isolated groups that can sometimes pull the scores down." Teachers also find that the standardized tests do not measure success accurately. The high school Special Education teacher says, "I don't really define my successes by what they get on the standardized tests." The high school math teacher finds that the standardized tests fail to measure individual improvement. Overall, in the high school, the standardized tests are not seen as a fair and accurate measure of success.

In the middle school, teachers criticize the form of the standardized tests and the way that preparing for the standardized tests changes the curriculum, making more material to cover in less time. The middle school social studies teacher says of measuring success through the standardized tests, "Do you want me to be truthful with you?" "I don't think that until we have criteria reference tests that we'll have a test that's a good 
evaluation for success as a student and success as a teacher." Like the social studies teacher, the middle school science teacher finds that the content standards that specify what will be covered on the standardized tests sometimes get in the way of love of learning. "The only thing that I would change would be doing some more activities that I think the students would enjoy instead of teaching all the [content standards]." The success teachers find in giving students a love of learning through best practice may be threatened by No Child Left Behind legislation.

In the intermediate school, the teachers are more positive about the standardized tests and see them as more closely related to student success. In her interview, the less experienced fifth grade teacher is somewhat tentative about how she would do on the standardized test, as her class has not yet taken the test, but she says, "Usually, if they are excited to learn, that will be reflected in test scores." The more experienced fifth grade teacher values the standardized test more than any other teacher interviewed as a good measure of success, saying, "Last year, all of my students that were not Special Ed students scored mastery or above on the [standardized test] — the math part of the [standardized test]—I felt that was being pretty successful." The intermediate school teachers do not say that there are too many content standards in their multiple-subject classes.

The first grade teacher says that she does feel the content standards make her curriculum a little rushed and that measuring success by test scores takes away "individuality." The third grade teacher comments on standardized tests early and often in the interview: "And I love for them to be able to give me their opinions and explain 
themselves and explain their thinking. And the standardized tests don't." She also objects to the content standards splitting Language Arts and Reading. The elementary school teachers seem to find a bit more pressure from NCLB requirements than the intermediate school teachers do.

The patterns that emerge from the interview data are similarities and agreement as to valuing students' pleasure in learning. For the most part, practice is focused on student learning and addressing different learning styles. On the other hand, some participants phrase success as the practice of relating to individual students, work ethic, or inspirational teaching styles. For the most part, teachers are concerned that preparing for the standardized tests draws time away from hands-on activities. On the other hand, the more experienced intermediate school teacher sees the standardized tests as a good measure of student success. Considering participants as a pool, in summary, the consensus is that success is when students experience the joy of learning. Beyond that, there is not a definition of success that all teachers agree upon.

\section{Secondary Sources Address Teachers' Emergent Themes}

The major themes that emerge from the secondary sources that teachers shared include work-ethic, character-building, and engaging learners. Teachers' rules and letters home explain clear behavioral expectations. Posters such as the "Six Pillars of Conduct" emphasize character-building. A number of activities, quizzes, and open-ended writing assignments engage the students and help them to enjoy learning. The middle school teachers' letter home emphasizes work ethic and explains behavioral expectations as established by a Responsible Student Program mandated by the state. In the 
intermediate school, the less experienced fifth grade teacher shows the students a poster of an autumn day and asks her students to describe what they see. Creative and vivid writing comes from this assignment. As discussed in describing how the secondary sources address the critical elements of success, research question one, both the documents collected and the posters and artifacts in the classroom reinforce the data from the interviews in focusing on student learning, socioemotional success, teachers' practice and techniques including hands-on activities and sharing, curriculum and evaluation beyond the standardized tests, and the support of parents. The themes emerging from the secondary sources corroborate the interview data.

\section{Principals—Emergent Themes}

\section{Overall Findings Address Principals' Emergent Themes}

Principals' emergent themes offer the second of the three perspectives on success. Their interview data does not parallel the critical elements of success so directly. The major themes that emerge from the school principals' experience are school environment; student attendance, graduation, and lifelong learning; and Adequate Yearly Progress and the standardized test requirements. Like teachers, the principals view parent and community involvement as an essential element of success, as central to their conceptualization of success, and as valuable towards defining a positive school environment. Further, principals envision students as primarily growing up to work and stay in their community. Like teachers, the principals view enjoyment of school and individual rapport with students as essential elements of success, as central to their conceptualization of success, and as valuable towards ensuring student attendance, 
graduation, and lifelong learning. Like teachers, principals view No Child Left Behind and standardized testing as potentially elements of success, central to their conceptualization of success, and valuable towards measuring success but as flawed.

Specifically, AYP measures and standardized tests are flawed in the experience of principals first in insisting that each population block meets AYP—especially Special Education and low SES. Second, AYP measures and standardized tests are flawed in the experience of principals in clumping students as a group rather than evaluating individual progress. Third, AYP measures and standardized tests are flawed in not being sensitive to individual learning styles—especially those of Learning Disabled students and poor test-takers. Principals' frustrations about the standardized test are stronger in the three schools that had had experience not meeting AYP. (The intermediate school made AYP in 2006-2007 but missed AYP "by one and a half students" before that.)

\section{Interview Data Addresses Principals' Themes}

\section{School environment.}

The voices and experience of principals as a pooled population show success as experienced personally, part of question two in the protocol, "How do you define success? How do you see personal success and how do you see student success?" The high school principal explains:

As a principal, I've been forced to look at how other people view success, so number one, you have to look at your test scores; you have to look at your attendance, graduation rate. All of those things are at the top of every principal's list because if you ignore them, then the state comes in and tells you you're not a good principal. Those are things you have to have immediate attention on all the time. But personally, when I look at a principal's job, is the school a reflection of the principal's personality? Is this school a place that I would like to have attended as a student? Is this a 
place that I would like to have my children attend? I'm blessed in here because I live in the school district and I want it to be that way. So when Saturday morning at the little league park rolls around, I'm there...I feel as a principal that it's important to be a part of the local community. And for the community to be the school is part of the community also. So that's important to me...It becomes difficult to push college and military and those sorts of experiences in our area because there are so many things for the students to do. They can get a quick job and earn money in construction, in service, and all kinds of things without having a college degree. We're fighting that in our area. I grew up in an area that did not have those opportunities. And if you wanted anything, you had to leave that area to go somewhere and those students that left went to college. So it's harder to sell college when students can make as much as Mom or Dad right now.

The themes of school environment and community continue in the high school principal's discussion of parental involvement.

In the middle school, the principal's discussion of school environment includes the following quotation:

Personal success-I think first thing is seeing we maintain a safe school. We had a very interesting week last week with a couple of bomb threats...Gun threats that I think were going around as a rumor as a springboard off of bomb issues. We're running all those issues down. But overall I think we're in pretty good shape for keeping safe schools. Safe schools are probably the most important thing. I've got to insure the kids' safety. So success for myself-leading teachers and students and staff members to watch out for kids and show a caring atmosphere in our school—making sure we watch out for parents' concerns and try to be as approachable as possible and as responsive as we can be...And working along with the responsibilities of parents and trying to help them to do the best they can to support their kids and yet also make sure that we're making a positive educational environment here is also important...I want to be sure that we provide a positive environment that can be supportive of each kid's opportunity for success.

The middle school principal repeatedly stresses caring for the students first, as does the high school principal, beginning with safety and school environment, including an awareness of the community and parents who work with the school. 
The intermediate school principal describes community involvement as follows:

If the community doesn't support us, we spin wheels. So I do a lot of things that help bridge that gap between school and community. I go to Little League baseball games. I have a child there, but it's a nice feeling for the kids that I'll make a big deal with them and their parents and then building that relationship - sometime I'm going to have to call on those parents and they're going to have to trust me that I want what's best for their child. So when we're at a difficult situation, making difficult decisions, in everything from discipline to Special Education placement, so the parents trust that we're doing what's right for your child. I always have that at heart. And that's important and until you've established that relationship, that can be real rocky. So it's important that from the get go we try to contact and have good relationships with our students and our parents and the community as much as possible.

The intermediate principal's attitude expresses caring for students and staff.

The elementary school principal does addresses school environment directly in answering, "How do you see personal success?" He also mentions community involvement.

Personal success, I would look at if things are going well, the environment is good, the students enjoy being in school, the staff enjoys coming to work, I think those are some of the measurements of success that we can have in a school building. Make sure the building is clean and that they're being taken care of health-wise. The parents having no qualms or fears about what happens at the school building and that they're able to come and they're able to do it and know that the staff is supportive of the efforts of the students and learning. And I talk to staff often about making a partnership. We can do only so much. They have another part that they can do that we can't do, so that both groups working together only insure success for the students.

After school environment as aided by participation from the community and in the community, the second major group of concerns voiced by principals is attendance, graduation, and lifelong learning aided by enjoyment of learning and engagement in the classroom. 
Student attendance, graduation, and lifelong learning.

The high school principal mentions the themes of attendance, graduation, and

lifelong learning using those exact "in vivo" terms:

Again, you go back to attendance, graduation rate because studies have shown that students with good attendance succeed. By succeeding that means graduating, going on to further their education whether it be a college, a university, a trade school, a technical school or in the military or specific job training. Those students who like it here, want to be here and attend here tend to succeed...The goal is for them to continue their education throughout their lives. We try to make them lifelong learners...Students that want to be here and like the class and respect the teacher are going to learn what that teacher asks them to learn. They're going to do the reading. They're going to do the homework. Many of our teachers are able to do that, to develop that rapport.

For the high school principal, success begins with the student, and student success in the form of attendance, graduation, and lifelong learning depends on that rapport that teachers establish with their classes.

The middle school principal talks about attendance, graduation, and lifelong

learning as part of what he tries to inspire his students to do. In talking about motivation,

he explains what he says to new students about life:

We say, "We want you ready. We want you prepared. We want you to be a good employee." We talk about attendance in that way. If you're not going to bother coming to school, you're toast. So we talk about school as a job. We talk about it saying, "You know, you might not be paid right now," and one of the things I say to try to motivate in the beginning of the year is that you can get essentially a thousand or two thousand dollars more in your regular salary if you work hard through every year of your school year. So I say, you know, "Take that twelve, thirteen years that you've worked in school, that's twelve thousand or twenty-four thousand dollars more in your salary. Can you use twenty-four thousand dollars more right now than what your friend did who just blew off throughout his whole school career?" And I say, "And add a little bit more college to that. That's another four thousand or eight thousand dollars on top of that. But you're going to make more than Charlie who just sat back and was a 
slug throughout his high school career or middle school career." And kids do pay a little bit of attention to facts and just to science. And hopefully we get them thinking about, "What do I want to do if I work hard now, I'm investing in my future. And that's what we're going to do."

Previously, the same principal explains success as: "So that's kind of how I would define success I guess—-being a well-rounded learner, having an enjoyable time here at middle school, yet also making sure that they're finding academic success and working their way along." In addition to showing a lot of caring for safety and school environment, the middle school principle, thus, also stresses attendance, graduation, and lifelong learning. He sees the successful teacher as enabling these successes.

As the schools serve younger populations their focus on attendance, graduation, and lifelong well rounded learners becomes more individual. The intermediate school principal talks about a specific success she had with one student.

One of the biggest successes with a student is that we had a student who did not have a positive home life, and she was one of those children that was not a discipline problem, but there was something amiss. And she had great difficulty in class and academics and I made that relationship with her in the fourth grade. I tried to. And by the fifth grade, her attendance was so bad-she had missed sixty days in third grade-and in fourth grade, it was a building year and in fifth grade, she missed a handful of days, but she opened up and talked about things because I would have lunch with her and check on her. And just knowing that someone was checking on her, she really gained some momentum, and she's been in middle school now for two years. And though she's going to be what we call one of those in the bubble students academically, but I think it was very positive for both of us because sometime you wonder do you make a difference every day. And then once they leave the school will it carry over? But that really did.

The intermediate school principal is similar to other principals in her interest in the student and the student's future. She is concerned about attendance, graduation, and 
lifelong learning as expressed in her conceptualizing success with an individual student. Individual relating enables success.

Likewise, the elementary school principal addresses the lifelong learning of the individual student by explaining the career opportunities that become available to successful students.

Working with students-I taught for eleven years-and I felt that I had several years of working with students that were successful. They have gone on and finished high school and went to college and several of them became teachers. Several of them went to the business field. And I just look at those types of learning while I was with them were important and a good foundation and an inspiration for them to continue through with their education into college and beyond.

At the elementary school, attendance and graduation rate appear to be less of an issue.

The "inspiration" of good teaching enables the future elementary student to have a successful life.

Adequate Yearly Progress (AYP) and the standardized test requirements.

The third emergent theme among principals is addressing No Child Left Behind requirements. All four principals discussed the importance of test scores towards measuring success. Two of the four schools — the high school and the middle school— did not make AYP, but two—-the intermediate school and the elementary school—did make AYP. The principals voice their experience with the standardized tests that measure AYP under NCLB legislation as follows:

The high school principal says of testing,

As a principal, I've been forced to look at how other people view success, so number one, you have to look at your test scores; you have to look at your attendance, graduation rate. All of those things are at the top of every principal's list because if you ignore them, then the state comes in 
and tells you you're not a good principal. Those are things you have to have immediate attention on all the time... They look a lot at test scores. And I expect that changing a little bit in the future because we're just getting a snapshot-in my school, we're just getting a snapshot of what four hundred students can do, and they're still eleven hundred of them out there. Four or five hundred students are being tested, and that becomes a little bit of a problem to use that data to change what the next class-we only test one class. Currently, it's tenth grade...This year we did not [make Adequate Yearly Progress] because of a cell. You have to understand the cell, socioeconomic group in language arts and readingthe English part of the exam-did not score at the-missed the target score. So we did not make AYP based on that.

The population at the high school includes a fairly high proportion of low SES students.

As measured by Free and Reduced Meals, there are "Forty percent—about as high as the rest of the state" low SES students according to the principal. As the community diversifies and becomes more urban or as the community includes more "bedroom communities," this low SES population becomes a lower percentage of the high school population.

The middle school principal sees AYP as having some good aspects but also as a frustration. He explains his experience with meeting AYP standards using the following language:

Students do not see the [standardized test] or our yearly annual measurements as that much of a measure for them. They really don't pay that much attention to it. Sometimes it gets home. Sometimes it doesn't. I'm not sure parents pay a lot of attention to those. In some cases, kids will say, "I didn't bother to do much. I just marked in whatever I felt like because I didn't feel like testing that day." And we're just going, "We have stressed to you how important it is to test well on those things, how we make some decisions for you based on how they turn out, but you're still saying you're just kind of filling them in. You're not helping us." Teachers do measure success by the [standardized test] a great deal...It has been a couple of years [that we have not made AYP]. We've bumped in and out on a couple of things. The Special Ed section is the one that has been like this every year. And we're still making progress. The scores are 
still coming up, but they're not coming up as fast as they are required.

We've made three or four percentage points gains every year. We

bumped down one year but then we still pulled back up on the others and made really substantially gains. But it's not the ten or fifteen percent that they want. And we end up going, "You know what? That stinks." We're making progress. We're in the right direction, but you don't recognize that. It's still to me a real bug-a-boo. I'll be frustrated with that for a long time.

The experience of the middle school principal also includes a positive side to his perception of the AYP requirements. "I don't think it's a bad thing to do the No Child Left Behind. I really do think we're doing a far better job teaching our Special Education students and all of our sub-groups. We're far better than we were, and we're not giving ourselves the excuse of, 'Well, they just can't learn that well.' I'm pleased about that." The standardized tests may not measure success well in this middle school, but they have some potential to help students succeed.

In the intermediate school, the principal views the AYP requirements as unfair to her Special Education students. In her own voice, she explains her experience of testing under NCLB.

Success is any time in life, in education, where there's progression, it's a success. And I think one of the things that we have to be very careful about when looking at success both personally and professionally and with students. It's not all what I can see on paper and pencil, what I can see in standardized test scores. We're just so driven by that. Our schools are measured by that Adequate Yearly Progress and it's based on those test scores. I don't judge success just on that...Each year you have a different group of children and they're not all the same and they don't all learn at the same rate. So that's very difficult to deal with. And our county's approach is always, "We know that you are doing what's good for kids." And that's important. And we stand by the high standard of professionalism. And they reiterate that constantly. And we feel secure in that. They mean that. But at the same time their level of accountability to the state and to the public_-it's a pressure to them as well because the newspaper will print which schools made AYP and which schools didn't. 
And then we always have to field questions. Parents will come in or call me. "What's going on? Why didn't you make AYP?" We had two years when we didn't make AYP and parents were concerned. They were upset. "Does my child have a good teacher?" Sometimes they don't understand this isn't a reflection on teachers. How did the children do that given day on that given test? But last year, we made AYP with flying colors. And only one parent called to congratulate us on that. So it's kind of that two edged sword...Another thing we swing on is our Special Ed population. If you have a lot of Special Ed a high level of Special Ed population, your chances of making AYP are very low because all it takes is one cell group to not master and you don't make AYP. So in essence, we worked it out one year. We missed AYP by one and a half students. And they were Special Ed students because the only area we've not made it in is Special Ed

As the length of the quotations indicate, the subject of testing is near to the hearts of the principals, especially those who have experienced not making AYP. The main flaws in the standardized tests that the high school, middle school, and intermediate school principals identified are that low SES and Special Education populations need to make AYP or the whole school "fails." The tests fail to measure individual progress. And the tests do not take into account Learning Disabled students or poor test-takers as emphasized by the middle school principal.

The elementary school principal, however, has made AYP for all his years at the elementary school. He still sees testing of students as an important theme in measuring success. He expresses his experience with the standardized test more positively.

The student success as everyone knows now, the big measure is whether you made Adequate Yearly Progress. And we have made Adequate Yearly Progress for the last several years as well as being a distinguished Title I school. So those are some of the things that we look at. One year, about three years ago, we were an exemplary school in the fact that in the [standardized test] we were $80 \%$ for reading and $80 \%$ for math. Last year's test scores, we achieved $80 \%$ for math and $77 \%$ for reading, so we missed being an exemplary school by three percentage points... We were still a distinguished Title I school. So to me those are factors that say that 
the staff are concerned and really focusing in on the learning that needs to be taking place and preparing the students for those particular areas of success. Looking at different groups of children that take the [standardized test] each year, in my mind, I don't expect it to be the same every year. I mean you're going to have some up years and some down years because of the individual students. However, I think what we're doing with Kindergarten through second grade in preparation for the [standardized test] and giving the children a good, solid foundation, we would always expect to have at least Adequate Yearly Progress.

Like some of the teachers, the elementary school principal is pleased to be making AYPs and doing well on the standardized tests, but unlike the vast majority of the educators interviewed, he does not voice frustration at the limits of the test towards measuring success.

Considered as a pooled population, principals see school environment; student attendance, graduation, and lifelong learning; and Adequate Yearly Progress and the standardized tests as the most important elements of success. These themes emerge from considering many pages of transcribed interview data, and are prominent among many other lesser themes which are also important such as caring for the students, establishing trust with both students and parents, and seeking to establish classrooms in which students are engaged and enjoying the learning process. In these themes, the principals are much like the teachers, as discussed in the findings of emergent themes of success in general. The themes that emerge from the interview data, as viewed in answering the first research question, "What are the critical elements of current educators' descriptions of their success?" are summarized in the table on pages 143-144. The consensus conceptualization of success as viewed by principals in an elementary, an intermediate, a middle school and a high school within a single county (research question two) is keeping 
students safe, happy, and learning well so that they can have productive futures within their community. The core beliefs and values of successful teachers (research question three) as viewed by the principals are putting the students first, building momentum and morale in the classroom, and being supportive peers and mentors to other faculty. In short, successful teachers make a difference in individual relationships, in engaging their classes, and in participating more widely in the school.

\section{Deputy Superintendent of Schools-Emergent Themes}

\section{Overall Findings Address Deputy Superintendent's Emergent Themes}

The deputy superintendent of schools defines success as the education and placement of teachers to ensure consistent, successful education of students. He emphasizes the importance of demanding more from the brightest students country-wide. He explains that locally there are not many jobs for college graduates although there is always a place for teachers. He believes that if the community called for more highly trained workers, the schools would produce more educated students. Like the teachers, he is concerned with teaching to different learning styles. Like three of four principals, he mentions specifically Marzano or APL techniques-part of the county-wide professional development program. He differs from teachers and principals in describing the need to demand more of the brightest students although teachers and principals agree that the brightest students had different needs from the average students. He agrees with some principals and teachers who say that many local jobs do not call for higher education. 


\section{Interview Data Addresses Deputy Superintendent's Emergent Themes}

To quote from the interview with the deputy superintendent of schools, he

explains that he sees his job as:

Making sure that our teachers are trained, [that] they're all speaking the same language. We have a lot of mobility with our students. They'll transfer from school to school. The average mobility rate in our county is like thirty-seven percent. And so it's imperative that we have a consistency in the instructional programs in our county so that when kids move from school to school to school, and teachers also, that we're not retraining or any of those things. So that's how I would measure success - that ability to say, "We have a consistent and effective position plan in place and it will allow the students to be successful and for teachers to be successful."

He goes on to describe teacher training as Marzano and APL techniques and differentiated instruction.

On the subject of demanding more from the brightest students, the deputy superintendent of schools is emphatic.

If there's one thing I wish we did better in this country is that there's not enough emphasis on effectively motivating the brightest kids. In our high schools, we have rigorous courses, the AP's and the honors classes and Calculus and advanced chemistry etcetera, but I wish we had more emphasis on taking a better look at those kids and almost demanding, demanding that they be in a more rigorous instructional program. We do that with the kids who have less ability. We basically tell them what classes they're going to be in and what level they have to be at, but we don't do it up here. And I wish we did that. I think some day our society will be criticized for saying, "Can you believe we spent so much money for the kids that had less to give back and ignored the kids that were the brightest?" Not to say that we shouldn't do a lot for our kids that have less ability; I'm not saying that at all. But our tragedy in this country is the fact that we're not putting enough emphasis on the kids that are the brightest. I feel that is a weakness in our system. 
While teachers and principals do mention that smart students learn more easily and that

more advanced classes require a higher level of expectations, they do not so strongly

emphasize the need to demand more from the brightest students.

He explains the local job market as follows:

I kind of believe in that movie, "You build it and they will come."

Sometimes, you hear the argument, you don't have a trained workforce.

Well, our students leave to go to places where there is work. If the work

was here, and I mean the technical jobs, I feel as though we are adequately

trained once they're finished with college or high school to fill those jobs.

But we won't know until those kinds of jobs are here and available to the students. But I don't believe in the fact of someone doing a survey to say, "The folks up here aren't trained to do these jobs." I just don't believe that. I feel like, if there were technical jobs to do right here, we would key up to make sure those kids could get into those jobs. And the kids that are leaving to go off to college which is approximately sixty percent of our high school graduates go to college, they can come back to do those jobs and be suitable and educated to do them...I know that any kids in education, they can find a job locally, and we really go after our homegrown kids. We do that, but this community is different. There aren't a lot of jobs that are available here for college graduates other than the normal things, the banking, insurance, those kinds of things. A lot of businesses that come in here seem to be service businesses. We're getting a new Target, a new Walmart in the other end of town, those kinds of hourly rate jobs, I'm not saying they aren't good jobs, but they're not the jobs kids go to college for.

The high school English teacher and the high school principal also mention finding jobs that do not require higher education. As the high school principal puts it, "They can get a quick job and earn money in construction, in service, and all kinds of things without having a college degree. We're fighting that in our area."

The main emphases of the answers given by the deputy superintendent of schools are: making a consistent teacher workforce, demanding more of brighter students, and preparing for the future of the students as employees or college graduates. For the most 
part, he agrees with teachers and principals on the importance of teacher education, advanced education for students, and preparing for the future, but, on the other hand, his strength of emphasizing the need to demand more of the brightest students differs from the emphases of the other participants.

\section{Pooled Population-Emergent Themes}

Participants usually define success as helping individual students with learning, socioemotional development, and life skills. Usually, in discussing the elements of success, they contrast individual student success with success on the standardized tests. Usually, in conceptualizing success, educators contrast caring relationships and excitement with learning with success on the standardized tests. They usually conceptualize personal success as helping with student success. They usually value and believe in making learning foremost enjoyable, engaging, and exciting. For the most part, participants' interview data is similar in being concerned with pupils, practice, and policy. On the other hand, there are different emphases on the axial level of which participants view which aspect of success as the most important. For the most part, teachers emphasize the moment of learning and the student. Principals emphasize the individual student and teaching methods, but in a less immediate time frame. The deputy superintendent of schools emphasizes teaching methods the most strongly. All participants are concerned with policy. For the most part, they find standardized testing a poor measure of success. On the other hand, there are positive feelings about No Child Left Behind raising standards for all students and coordinating curriculum. 


\section{Tensions in Emergent Themes}

The participants' concerns with pupils, practice, and policy raise tensions between intrinsic measures of success and extrinsic measures. While, overall, obligations to perform for standardized testing rest lightly on the shoulders of successful teachers, standardized tests do not measure the aesthetic side of teaching such as relationships of trust and caring. Strong communication between the schools and the community and the close-knit feel of the community are always relevant to education but are not directly part of NCLB reform efforts. The personal successes of teachers and administrators in fostering joy of learning can even be threatened by the demands of policy. Affect in teaching — both the teachers' joy in seeing "the lightbulb go on" or teacher efficacy and the students' enjoyment of learning through time or student affect - is intrinsic and does not come across in standardized tests. Standardized tests also fail to measure individual student progress.

Teachers and administrators feel that some of the pressure to raise test scores helps to address the learning needs of all learners and coordinated curriculum is useful in keeping students "on the same page," but the pressures of too many statewide standards and too high a "bar" threatens the successes that all participants describe. The focus on giving pupils individual attention and caring and on making practice hands-on and active may be incompatible with the focus on covering material quickly and specifically narrowing the curriculum to cater to the standardized tests.

Teaching to standards both creates tension between personal success and policy success and diminishes teachers' ability to dream of ideal teaching. There is a contradiction between the personal success of seeing students grow into lifelong learners and the policy 
success of seeing students master material for tests, unless those tests are measuring the real successes of learning. Participants question whether standardized tests are apt measures of student learning. Ambivalence as to whether mastery of math or reading is a measure of successful learning points to tension between desires to measure success by affective measures or by cognitive measures. The statewide curriculum and tests are more burdensome to some participants than to others. Some participants found that teaching to standardized tests systematically impairs creative teaching whereas others found that teaching to standardized tests rewards creative teaching.

The formality and structure of statewide curriculum and testing forms a monolith compared to the multitude of individual caring relationships described by participants. Intrinsic love of learning and teaching may or may not flourish when there is pressure to perform extrinsically. Whether seen as a high bar or a multitude of specific topics to cover, tests and standards are consistently seen as extrinsic measures of an intrinsic process. In a close-knit, familial community, reform of schools seems more threatened by NCLB than aided by its policies. Teachers may lose their joy in teaching under the pressures of making AYP or facing consequences such as losing funds in the Title I elementary school or restructuring the school if it fails to make AYP for five years. The successful participants in this study, however, have managed to create engaging lessons despite the tension between the personal and the policy sides of success. They maintain their excitement, their caring relationships, and their feelings of making a difference in the lives of individual students. 


\section{Interviews Relate to the Literature Review}

In the literature review, six ways that the literature discussed success emerged. These six headings were organized under the three main headings of quality of life, quality of teaching, and quality of educational reform - from the most proximal to the most distal. The six ways the literature discussed experiencing success included success in affect and core beliefs, success in teacher education and teaching methods, and success in community and culture. The interview data strongly relates to each of these ways of looking at success. Seven of nine teachers, three of four principals, and the deputy superintendent of schools speak in some way about pleasure in the classroom or in the school as pointing to success in teaching. A core belief in efficacy and making a difference is a pattern running through most of the teacher interviews. See table below. Most educators mention teacher education and teaching methods as essential to success. Community and culture form the backdrop to all definitions of success for the student population served. Specifically, the questions from the interviews address the themes from the literature review as shown in Table 3.

Table 3: Which Questions from the Interviews Relate to the Literature Review

$$
\text { Teachers Principals Deputy Superintendent }
$$

$\begin{array}{lccc}\text { Affect } & 2 \text { through } 9 & 2 \text { through } 9 & 2 \text { through } 5 \\ \text { Core Beliefs } & 2 \text { through } 9 & 2 \text { through } 9 & 2 \text { through } 5 \\ \text { Teacher education } & \text { mostly } 7 & \text { mostly } 7 & 2 \text { through } 5 \\ \text { Teaching methods } & 2 \text { through } 9 & 2 \text { through } 9 & 2 \text { through } 5 \\ \text { Community } & 1 \text { through } 9 & 1 \text { through } 9 & 1 \text { through } 5 \\ \text { Culture } & \text { mostly } 1 & \text { mostly } 1 & \text { mostly } 1\end{array}$


Table 4: Number of Participants Discussing Themes from Literature Review

$\begin{array}{ccc}\begin{array}{c}\text { Teachers } \\ \text { (out of nine) }\end{array} & \begin{array}{c}\text { Principals } \\ \text { (out of four) }\end{array} & \begin{array}{c}\text { Deputy Superintendent } \\ \text { (out of one) }\end{array}\end{array}$

$\begin{array}{llll}\begin{array}{l}\text { Affect- } \\ \text { pleasure in learning }\end{array} & 7 & 3 & 1 \\ \begin{array}{l}\text { Core Beliefs- } \\ \text { socioemotional success }\end{array} & 6 & 2 & 1 \\ \begin{array}{l}\text { Teacher education- } \\ \text { Marzano and APL }\end{array} & 2 & 3 & 1 \\ \begin{array}{l}\text { Teaching methods- } \\ \text { activities and group work }\end{array} & 8 & 3 & 1 \\ \begin{array}{l}\text { Community- } \\ \text { supportive }\end{array} & 8 & 4 & 1 \\ \begin{array}{l}\text { Culture- } \\ \text { describing student population }\end{array} & 9 & 4 & 1\end{array}$

In Chapter Two, the literature was searched based on the three research questions.

In the literature, six categories of success emerged, from the most proximal, affect, to the most distal, culture. In the interview data, "in vivo" language and lived experience of educators within a single school system give greater specificity to the six categories of success found in the literature review. A discussion of how the participants respond to the literature review questions proceeds category by category.

Specifically, in the first two categories, affect and core beliefs, the interview data emphasize pleasure in learning and socioemotional success of the student. The strong voices of the participants and especially the teachers say that teachers teach for the moment when the light bulb goes on and their students are excited and engaged. The participants strongly emphasize relationships with individual students, from the middle 
school social studies teacher's explaining that success is the trust that students place in a teacher so that the student can tell what is going on at home to the deputy superintendent of schools saying a good teacher knows what makes a child tick.

In looking at the third and fourth categories, teacher education and teaching methods, the county-wide program emphasizing differentiated instruction is consistent with the literature review, but it is organized in a single program more than the education and methods found in the literature review. The participants, like the examples in the literature review, emphasize hands-on learning and group work. As the literature review gave concrete examples of teaching methods, the literature was close to the experience of the participants. The participants voiced the importance of teacher education, for example the less experienced fifth grade teacher explaining her methods having recently graduated from a master's program in education, the high school English teacher explaining the worth of a writing course, and the deputy superintendent explaining the need for ongoing professional development in the form of APL and Marzano techniques.

In looking at the fifth and sixth categories, community and culture, the school system and county delineate specific strengths and challenges to living and working in the area. While the community feels familial and close-knit, the job market in the area does not call for strong education. The school system serves a sufficient number of Special Education students and low socio-economic status students to make it difficult for three of four schools to consistently meet Adequate Yearly Progress. The culture's work ethic strengthens the performance of both students and educators, but the student culture does not always call for higher education. The high school principal estimates forty-five 
percent of high school graduates in his school currently go on to college, while the school is striving for sixty or seventy percent to be able to go. Teachers like the high school English teacher help to educate students about the strengths of their culture and to help students to take pride in their culture.

For the most part, the interview data coming from a protocol based on the literature review answers the research questions with the same six categories of success as are delineated in the literature review. Each type of success, on the other hand, is given a more pungent and vivid description by interviewing live participants. Further, the interviews add richness and depth to the six categories of success by explaining the lived experience of joy in teaching and learning, the individual relationships involved in building students' socioemotional success, the particular work of professional development and planning strong teaching methods, and the strengths and weaknesses of the local community and culture.

\section{Implications for Further Research}

Further research on teachers' and other educators' conceptions of success might include studying another school system from a different community and culture to compare and contrast with the school system discussed in this study. Further research might also include a more in-depth study of the school system described. In order to arrive at a consensus definition of success to help guide the service of pupils, practice, and policy, further research might also include studying several different representative school districts. While readers of this study may conclude that joy in learning, 
differentiated instruction, and better standardized testing are needful for success in the school system described, multiple perspectives might suggest other conclusions.

Further research in comparing and contrasting the school system studied with another school system would allow the depth of detail provided while suggesting different conclusions about each element of success, conceptualization of success, and value or belief of educators. The community and culture studied include relatively low teacher state-wide teacher salaries, forty-fifth in the country. While the community is growing and diversifying, it is largely poorer than the nation as a whole and is predominantly white. A viewing of more urban or more rural school systems would put in perspective the county considered in this study.

Further research in the school system studied to allow a more in-depth look at the participants and population might include looking at more subject matters and grades from art to PE to music to theatre classes and from every grade. More participants would enrich the study by voicing more varied perspectives on success. Common ground and differences among more varied interview data and the secondary sources would reveal a broader definition of how educators view the elements of success, how they conceptualize success within a single school system, and how they value or believe in success as educators. While this study strives to find patterns and common ground within all the data collected and to relate the findings to the research questions and compare the findings with the literature, another study might work with more in-depth and broader data with which to describe success. This study is concerned with both the general question of success as a focus for where education is headed and the question of success 
as a guide to policy, but more comparative and in-depth data in the school district studied would help to answer these questions more fully.

Success as affect and core beliefs, as teaching education and methods, and as described within community and culture becomes more specific through the collection of research data from on the ground. Joy in learning, differentiated instruction, and the particular strains to a growing community describe success within the data collected. A more in-depth study might reveal different emphases as to what success means within the school system chosen. The protocol might include questions on what a successful student looks like when he or she graduates, why student success versus student improvement feels like personal success to some educators, and how success changes from lower to higher grades in school, probing more deeply for answers to the first two research questions. The protocol might include questions on how teachers and administrators value education, what beliefs give them strength to do their work, and how their feelings of efficacy lead to more success. Such protocol questions would probe the research question three on core values and beliefs more effectively.

Further research might include using the interview protocol and collection of relevant documents in different school systems to compare and contrast descriptions of success among a broader population of educators. A wider study might either turn up a voice or voices that more succinctly and vividly name what success is in the voices of educators and a wider study might also turn up a stronger argument for the universality of that named success. While a qualitative approach considers the particulars of a study and does not attempt a statistical breadth, more data on the axial level could allow 
triangulation of data from school system to school system and not just from teachers to principals to the deputy superintendent of schools. This broader population that might be studied in further research could show a different angle on what it means to be successful as an educator and as a student.

Implications for Teacher Preparation and Professional Development

There are two ways that this study has implication for teacher preparation and professional development: first, in this study successful teachers discuss their own preparation and development; second, they show how successful teachers can help developing teachers. The teachers in this study speak of instruction in student-based learning, differentiated instruction, and multiple intelligences. They also speak of how techniques such as how Marzano and APL raise test scores. Teachers also speak of the challenge of covering a quantity of material while trying to balance oral presentation of material with hands-on activities to differentiate instruction. While the content standards are based on spiral learning, some teachers such as the high school math teacher voice a desire to master one level of knowledge before progressing to the next. Successful teachers have found that Marzano and APL techniques help them to work on studentbased learning while hands-on activities and "see it, hear it, touch it" methods address multiple intelligences and provide for differentiated instruction.

Through mentoring and modeling success, the educators in this study suggest ways to improve instruction as found in the methods and mindsets reviewed in the literature and as found in the practice and attitudes expressed in the interviews and secondary sources of this study. The interview data and the documents provided as 
secondary sources do make clear that understanding student-based learning, hands-on activities, and differentiated instruction has been useful towards their success. Relating strongly to parents and students develops over time and supports successful teachers and administrators as well as defining their success. The data suggests that specific professional development and teacher preparation in the area of school family communications are potentially extremely valuable. Teaching methods and professional development likewise support and define success. Finally, as the literature suggests, community and culture support and define success. Standing out in the interview data is the "aha moment" and joy in learning, the growth and development of students into responsible members of the community, and the work of joining the instance of learning to the goal of lifelong learning.

\section{Concluding Statements}

The results section of the study finds that the critical elements of success are student-oriented, practice-oriented, and policy-oriented; that the consensus definition of success is caring for individual students; and that the beliefs and values of educators are in making a difference for every student. Relationships, joy in learning, and fair testing are enabling of success within the community and culture studied. In terms of challenges and needs_-parents are often named as the biggest barrier to success; secondly, having time to teach as well as possible; and, lastly, being able to teach well given the vast number of content standards the teachers are expected to cover. In all interviews, hope about education outweighs frustrations in the voices of successful educators. 
The study includes triangulation through multiple participants, multiple data sources (interviews and documents), multiple perspectives (teachers and administrators), and member checking. From the pooled participants' definition of success to the emergent themes of each type of perspective, patterns emerge to address the research questions and the literature review. The most central conceptualization of success is individual student learning through the engaging moment, the steady relationships, and the supportive community that occur in successful schools. 


\section{BIBLIOGRAPHY}

Achinstein, B. \& Barrett, A. (2004). (Re)framing classroom contexts: How new teachers and mentors view diverse learners and challenges of practice. Teachers College Record, 106(4).

Alton-Lee, A., Nuthall, G. \& Patrick, J. (1993). Reframing classroom research: a lesson from the private world of children. Harvard Educational Review, 63(1).

American Federation of Teachers (2007). AFT news release. Washington, DC. Retrieved on September 20, 2008, from http://www.aft.org/presscenter/releases/2007/statereleases/SalarySurvey-WV.pdf

Birmingham, N. \& Garnick, S. (1994). Teachers' voices: Reflections on the Boston University/Chelsea Public Schools partnership and its effect on the literacy initiatives. Journal of Education, 176(1).

Blackmore, J. (2004). Leading as emotional management work in high risk times: The counterintuitive impulses of performativity and passion. School Leadership Management, 24(4).

Bokhorst-Heng, W. D. (2008). School-home partnerships to nurture adolescent literacy. Middle School Journal, 39(4).

Britzman, D. P. (1991). Practice makes practice: A critical study of learning to teach. Albany, NY: State University of New York Press.

Britzman, D. P. (1999). “Thoughts awaiting thinkers”: Group psychology and educational life. International Journal of Leadership in Education, 2(4).

Britzman, D. P. (2001). Cultural myths in the making of a student teacher: Biography and social structure in teacher education. In E. Mintz, and J. T. Yun (Eds.), The 
complex world of teaching: Perspectives from theory and practice (pp. 179-192).

Cambridge, MA: Harvard Educational Review (Reprint Series No. 31).

Cramer, C. (2008). Education trends-Part 1. Child Guide Magazine Online, 1-3.

Retrieved on June 15, 2008, from

http://www.childguidemagazine.com/article_detail.asp?id=34

Davis, B. \& Sumara, D. J. (2001). Cognition, complexity, and teacher education. In E. Mintz, and J. T. Yun (Eds.), The complex world of teaching: Perspectives from theory and practice (pp. 237-254). Cambridge, MA: Harvard Educational Review (Reprint Series No. 31).

DeMoulin, D. F. \& Kolstad, R. (1999). Change in a pre-teacher education group for democratic maturity during college and graduate education. Journal of Instructional Psychology 26(3).

Department of Education (2008). School Profile. Retrieved on December 23, 2008, from http://wveis.k12.wv.us/nclb/profiles

Dewey, J. (2001). Democracy and human nature. In S. J. Goodlad (Ed.), The last best hope: A democracy reader (pp. 159-175). San Francisco: Jossey-Bass.

Dewey, J. (2001). The school and society \& The child and the curriculum. New York: Dover Publications, Inc.

Edwards, J. L.; And Others. (1996, April 8-12). Teacher efficacy and school and teacher characteristics. Paper presented at the annual meeting of the American Educational Research Association, New York, NY. 
Eggen, P. \& Kauchak, D. (1997). Motivation as a hierarchy of needs: The work of Maslow. In Educational psychology: Windows on classrooms (pp. 352-354). Upper Saddle River, NJ: Merrill, an imprint of Prentice Hall.

Federal Register (Wednesday, April 9, 2008) Vol. 73, No. 69, 19186. Retrieved on December 23, 2008, from http://www.setonresourcecenter.com/register/2008/apr/09/19186A.pdf

Feiman-Nemser, S. (1990). Conceptual orientations in teacher education. Teacher College Press. New York. Retrieved on August 29, 2005, from http://scholar.google.com/scholar?q=\%22When+Teachers+Face+Themselves\%22\& ie=UTF- $8 \& h l=e n \& b t n G=$ Search

Fenstermacher, G. D. \& Richardson, V. (2005). On making determinations of quality in teaching. Teachers College Record, 107(1).

Freire, P. (2003). Pedagogy of the oppressed. New York: Continuum.

Ferguson, R. F., Clark, R., \& Stewart, J. (2002). Closing the achievement gap in suburban and urban school communities. (Report No. NCREL-13). Naperville, IL: North Central Regional Educational Lab. (ERIC Document Reproduction Service No. ED473122)

Gilliard, J. L. \& Moore, R. A. (2007). An investigation of how culture shapes curriculum in early care and education programs on a Native American Indian reservation. Early Childhood Education Journal, 34(4).

Goodlad, J. I. (2000). Romances with schools. New York: McGraw-Hill. 
Guillaume, D. (2000). Bronx teacher's love of opera reverberates. Christian Science Monitor, 92(102).

Hargreaves, A. (2001). Emotional geographies of teaching. Teachers College Record, 103(6).

Harry, B., Sturges, K. M. \& Klingner, J. K. (2005). Mapping the process: An exemplar of process and challenge in grounded theory analysis. Educational Researcher, 34(2).

Henry, J. J. (1999). Challenges for teachers attempting to integrate mathematics innovation. Journal of Research on Computing in Education, 31(3).

Holliday, C. O. (2005). The human connection. The Clearing House, 79(1).

Hu, W. (2008, November 11). School district tries to lure Asian parents. The New York Times, p. A1.

Jansen, J. D. (2005). Race, reconciliation, and the emotions of deanship. Harvard Educational Review, 75(3).

Jersild, A. T. (1955). When teachers face themselves. New York: Teachers College Press.

Johnson, D. (1999). Designing research projects students (and teachers) love. Multimedia Schools, 6(5).

Kent, A. M. (2004). Improving teacher quality through professional development. Education, 124(3).

Kilbourn, B. (2006). The qualitative doctoral dissertation proposal. Teachers College Record, 108(4)

Kozol, J. (1991). Savage inequalities. New York: Harper Perennial. 
Kuhn, A. L. (2005). Decision-making in the use of instructional technology by novice and experienced public school teachers. Dissertation, West Virginia University. Retrieved on June 24, 2006, from $\underline{\text { https://eidr.wvu.edu/etd/documentdata.eTD?documentid=4586 }}$

Lorenz, J. R (2000). A study of early childhood preservice teachers' locus of control and self concept as compared to their approach to discipline. Unpublished master's thesis. The Graduate College, University of Wisconsin-Stout.

Love, A. \& Kruger, A. C. (2005). Teacher beliefs and student achievement in urban schools serving African American students. The Journal of Educational Research, 99(2).

Mathers, J. K. \& King, R. A. (2001, April 10-14). Teachers' perceptions of accountability. Paper presented at the annual meeting of the American Educational Research Association, Seattle, WA.

McArdle, K. \& Coutts, N. (2003). A strong core of qualities—a model of the professional educator that moves beyond reflection. Studies in Continuing Education, 25(2).

Meier, D. (2002). In schools we trust: Creating communities of learning in an era of testing and standardization. Boston: Beacon Press.

Mitchener, C. P. \& Field, K. (1998). Identity and boundary tensions when educators and mental health professionals collaborate: Between wish and reality. Child and Adolescent Social Work Journal, 15(6).

Nodding, N. (2003) Happiness and education. New York: Cambridge University Press.

Norton, N. E. L. \& Bentley, C. C. (2006). Making the connection: Extending cultural responsive teaching through home(land) pedagogies. Feminist Teacher, 17(1). 
Ouimette, M. Y., Feldman, J., \& Tung, R. (2006). Collaborating for high school student success: A case study of parent engagement at Boston Arts Academy. School Community Journal, 16(2).

Patton, M. Q. (2002) Qualitative research \& evaluation methods: Third edition. Thousand Oaks, CA: Sage Publications.

Pfeifer, R. S. \& Polek, M. (2007). Creating a climate of trust. Principal Leadership, $8(1)$

Powell, K. C. (2004). Developmental psychology in adolescent girls: Conflict and identity issues. Education 125(1).

Public School Review (2008). Public School Profile. Retrieved on December 23, 2008, from http://www.publicschoolreview.com

Rancifer, J. L. (1993, November). Correcting impaired student self-concepts: An instructional leadership strategy for teachers and principals. Paper presented at the meeting of the Annual Meeting of the Mid-South Educational Research Association, New Orleans, LA.

Rebora, A. (2008). Making a difference: Carol Ann Tomlinson explains how differentiated instruction works and why we need it now. Teacher Magazine 2(1).

Rieg, S. A. \& Marcoline, J. F. (2008, February 20-23). Relationship building: The first "R" for principals. Paper presented at the Eastern Educational Research Association Conference, Hilton Head, SC.

Ross, J. A. (1995). Strategies for enhancing teachers' beliefs in their effectiveness: Research on a school improvement hypothesis. Teachers College Record 97(2). 
Rothstein-Fisch, C., Trumbull, E., Isaac, C., Daley, C. \& Perez, A. I. (2003). When "helping someone else" is the right answer: Bridging cultures in assessment. Journal of Latinos and Education, 2(3).

Sanders, M., \& Lewis, K. (2005). Building bridges toward excellence: Community involvement in high schools. High School Journal, 88(3), 1-9.

Shechtman, Z. (2002). Validation of the Democratic Teacher Belief Scale (DTBS). Assessment in Education, 9(3).

School Matters: A Service of Standard \& Poor's (2008). Retrieved on December 23, 2008, from http://www.schoolmatters.com

Sipe, P. (2004). Newjack: Teaching in a failing middle school. Harvard Educational Review, 74(3), 330-339.

Smith, M. S. (1998, March). Using an anthropological lens to study the enabling factors in successful collaboration. Paper presented at the Annual National Conference on Creating the Quality School, Washington, DC.

Sobel, A. \& Kugler, E. G. (2007). Building partnerships with immigrant parents. Educational Leadership, 64(6).

Stainton, R. \& Bangs, J. (2003). From pioneers to champions. Education Review, 16(2).

Starnes, B. A. (2005, February). On the H-bomb, the queen of hearts, and a tormented self. Phi Delta Kappan.

Stoner, J. B., Bock, S. J., Thompson, J. R., Angell, M. E., Heyl, B. S., \& Crowley, P. (2005). Welcome to our world: Parent perceptions of interactions between parents 
and young children with ASD and educational professionals. Focus on Autism and Other Developmental Disabilities, 20(1).

Stuart, J. (1949). The thread that runs so true: A mountain school teacher tells his story. New York: Touchstone.

Stumbo, C. (2001). Beyond the classroom. In E. Mintz, and J. T. Yun (Eds.), The complex world of teaching: Perspectives from theory and practice (pp. 169-178). Cambridge, MA: Harvard Educational Review (Reprint Series No. 31).

U.S. Census Bureau: State and County QuickFacts (July 25, 2008). Retrieved on December 12, 2008, from http://quickfacts.census.gov/qfd/states/54/54003.html

Wood, J. M. (2000). The virtues of our virtual community. Instructor, 110(1). 
Appendix A: Teacher Interview Protocol and Letter

\section{Interview protocol. Forty minutes.}

1. Could you describe your students, school, and community?

2. As a teacher, how do you define success? How do you see personal success and how do you see student success?

3. Describe a time when you have experienced success - with an individual student; with a class; and as a professional, faculty member.

4. How does student success compare with teacher success?

5. How do you see others defining success—-students, other faculty, principal and other administrators, parents and community, school district, and state?

6. How do you make decisions about what to teach in your curriculum?

7. How do you make decisions about how to teach in terms of instructional methods?

8. If you could teach however you chose, would you teach differently?

9. As you work to succeed, what is supportive and what forms barriers to your success? 
Katherine Cox

681 Carlyle Rd.

Martinsburg, WV 25404

March 25, 2007

\section{Dear Teacher,}

I am conducting a study, "Success in the Voices of Educators," in partial fulfillment of the requirements for a doctoral degree in Curriculum and Instruction from West Virginia University. The purpose of the study is to hear teacher's conceptions of success in an era of testing and to compare their conceptions with those of principals and the deputy

superintendent of schools within a single school district. The subject's response will be kept anonymous and descriptions of the interview findings will maintain confidentiality. In case a description of a participant renders the participant identifiable to colleagues, the study includes "member checking," asking participants to review descriptions of themselves and edit the descriptions. The interviews will be audiotaped and transcribed. The audiotapes will be destroyed following completion of the study. The findings of the study will protect confidentiality.

In keeping with Internal Review Board requirements at West Virginia University, not every question needs to be answered by the subject. The subject's job will not be affected by refusal to participate. Participation is voluntary. I look forward to our interview and thank you in advance for your time.

Sincerely,

Katherine Cox 
Appendix B: Principal Interview Protocol and Letter

\section{Interview protocol. Forty minutes.}

1. Describe your students, school, and community.

2. As a principal, how do you define "success"? How do you see personal success and how do you see student success?

3. Describe a time when you have experienced success-with an individual student; with a class; and as an advisor to faculty members.

4. How does student success compare with teacher success?

5. How do you see others defining success-students, other faculty, principal and other administrators, parents and community, school district, and state? Has your conception of success changed?

6. How do teachers at your school make decisions about what to teach in your curriculum?

7. How do teachers at your school make decisions about how to teach in terms of instructional methods? (Prompt with examples if necessary, e.g. group work, hands-on work, research in community, field trips, school spirit-games, assemblies, artwork...non-curriculum qualities of a good teacher, include community building as a possible quality if the principal does not mention it.)

8. If the teachers at your school could teach however they chose, would they make any changes in curriculum or in instructional methods?

9. As you work to succeed, what is supportive and what forms barriers to your success? 
Katherine Cox

681 Carlyle Rd.

Martinsburg, WV 25404

March 25, 2007

\section{Dear Principal,}

I am conducting a study, "Success in the Voices of Educators," in partial fulfillment of the requirements for a doctoral degree in Curriculum and Instruction from West Virginia University. The purpose of the study is to hear teacher's conceptions of success in an era of testing and to compare their conceptions with those of principals and the deputy

superintendent of schools within a single school district. The subject's response will be kept anonymous and descriptions of the interview findings will maintain confidentiality. In case a description of a participant renders the participant identifiable to colleagues, the study includes "member checking," asking participants to review descriptions of themselves and edit the descriptions. The interviews will be audiotaped and transcribed. The audiotapes will be destroyed following completion of the study. The findings of the study will protect confidentiality.

In keeping with Internal Review Board requirements at West Virginia University, not every question needs to be answered by the subject. The subject's job will not be affected by refusal to participate. Participation is voluntary. I look forward to our interview and thank you in advance for your time.

Sincerely,

Katherine Cox 
Appendix C: Deputy Superintendent Interview Protocols and Letter

\section{Interview protocol. Introductory Interview. Twenty minutes.}

1. Describe your students, school, and community.

2. As a superintendent, how do you define "success"? How do you see personal success and how do you see student success?

3. Describe a time when you have experienced success-with an individual student; as an advisor to faculty members; with a program or with a school.

5. How does student success compare with teacher success?

5. What does a successful teacher look like? 


\section{Katherine Cox}

681 Carlyle Rd.

Martinsburg, WV 25404

March 25, 2007

Dear Deputy Superintendent of schools,

I am conducting a study, "Success in the Voices of Educators," in partial fulfillment of the requirements for a doctoral degree in Curriculum and Instruction from West Virginia University. The purpose of the study is to hear teacher's conceptions of success in an era of testing and to compare their conceptions with those of principals and the deputy superintendent of schools within a single school district. The subject's response will be kept anonymous and descriptions of the interview findings will maintain confidentiality. In case a description of a participant renders the participant identifiable to colleagues, the study includes "member checking," asking participants to review descriptions of themselves and edit the descriptions. The interviews will be audiotaped and transcribed. The audiotapes will be destroyed following completion of the study. The findings of the study will protect confidentiality.

In keeping with Internal Review Board requirements at West Virginia University, not every question needs to be answered by the subject. The subject's job will not be affected by refusal to participate. Participation is voluntary. I look forward to our interview and thank you in advance for your time.

Sincerely,

Katherine Cox 


\section{Appendix D: County Demographics}

The population in the county studied has grown by $28.5 \%$ from April 1, 2000 to July 1, 2006 (U.S. Census Bureau, 2008) as compared with 0.6\% growth in the state overall. In 2000 , there were 236.5 persons per square mile in the county as opposed to 75.1 persons per square mile in the state. As of 2006, the population was 97,534. The median household income was $\$ 45,390$ in 2004 , as compared with $\$ 33,993$ median household income in the state overall. The racial composition of the county in 2006 was $92.0 \%$ White, $5.8 \%$ African American, 2.7\% Hispanic or Latino, 0.7\% Asian, and 0.2\% Native American. $1.2 \%$ of persons reported two or more races. The percent of adults with at least a high school diploma was $91.0 \%$ in 2006 and the percent of adults with at least a bachelor's diploma was $20.1 \%$ (School Matters, 2008). Current teachers' salaries in the area average about $\$ 30,000$ for starting teachers and $\$ 45,000$ overall, according to the deputy superintendent of schools. In 2004-2005, in the Mid-Atlantic state as a whole, average teacher salary was $\$ 26,704$ for starting teachers and $\$ 38,404$ overall, according to the American Federation of Teachers (2007). The state average teacher salary ranked $44^{\text {th }}$ in the nation in 2004-2005. 


\author{
Katherine Eddy Cox \\ 681 Carlyle Rd. \\ Martinsburg, WV 25404 \\ e-mail: coxke2007@aol.com \\ telephone: (304) 274-2515
}

\title{
EDUCATION:
}

West Virginia University, Shepherdstown campus, WV

2002 to 2009

Doctor of Education with a major in Curriculum and Instruction and a minor in English. Wrote dissertation on "success" in an era of testing, as defined by interviews with teachers, principals, and the deputy superintendent of schools of a single school district in a Mid-Atlantic state. (4.0 GPA)

San Francisco State University, San Francisco, CA

1993 to 1994

Credentialed in English, grades five to twelve. (4.0 GPA and 99\% on NTE.)

University of Virginia, Charlottesville, VA

1990 to 1992

M.A. in English Literature. Studied medieval, Renaissance, Neo-classical and Romantic periods, and postmodernist theory. (3.6 GPA.)

Harvard University, Cambridge, MA

1982 to 1987

B.A. Cum Laude in Honors English. Won John Harvard Scholarship for academic achievement. Rowed Varsity Lightweight Crew, twice National Champions. Sang in a twelve-woman a capella group, the Radcliffe Pitches.

\section{TEACHING EXPERIENCE:}

\section{University, College, and International Baccalaureate}

West Virginia University, Morgantown, WV

Fall 2005

Education lecturer. Co-taught media portion of graduate level course on Cultural Diversity in the Classroom. Led and evaluated on-line discussion of media events and multiculturalism. Responsible for twenty-five student "media logs" weekly.

Hagerstown Community College, Hagerstown, MD

Fall 2002

English lecturer. Taught three writing classes to beginning Freshmen.

Shepherd College, Shepherdstown, WV

2001 to 2002

English lecturer. Taught literature and composition, and great ideas and composition.

International School Eerde, Ommen, The Netherlands

1997 to 1998

English teacher. Taught English and World Literature to students between the ages of sixteen and twenty, English A and B levels in International Baccalaureate 1 and 2. 


\section{English and Elementary}

Berkeley County Schools, Berkeley County, WV

Spring 2002 to 2009

K-12 Substitute teacher. Teaching all subjects, all ages, part-time.

Berkeley Springs High School, Berkeley Springs, WV

2000 to 2001

English teacher. Taught World Literature and American Literature in preparation for the Stanford 9 tests. Also taught journalism, yearbook, and creative writing.

International School of Amsterdam, Amsterdam, The Netherlands $\quad$ Spring 1996 Assistant pre-kindergarten teacher. Substitute taught throughout the lower school. Worked closely with students on language arts, math, and science.

Everett Middle School, San Francisco, CA

Fall 1993

English teacher. Student taught seventh grade to inner city students, including many ELL students.

Wallenberg Traditional High School, San Francisco, CA

Fall 1993

English teacher. Student taught eleventh grade American Literature.

"The Great Success School" and Castilleja School, Menlo Park, CA

1992 to 1993

ELL teacher. Taught American Literature, grammar, and composition in a Korean-

American school, grades seven to eleven. Dormitory counselor at an all girls' school.

Menlo School, Menlo Park, CA

1992 to 1993

Assistant to the Academic Dean and substitute teacher. Screened applicants for teaching positions, wrote minutes for Department Head meetings, and substitute taught in an independent high school in SF suburb.

Potomac School, McLean, VA

1989 to 1990

Middle School teaching intern. Taught all subjects, grades four to six. Participated in "Teachers New to Teaching" mentoring program. Coached seventh and eighth grade girls" "A" soccer team.

Potomac School, McLean, VA

Summers 1985 and 1986

Assistant Science Camp and Art Camp teacher. Worked with Science Campers, grades one through three, and with Art Campers, grades four through six, at independent school in DC suburb. 


\section{WRITING:}

Pedagogy and Theatre of the Oppressed, Minneapolis-St. Paul, MN

May 2007

Presenter. Will lead discussion of paper on "Voice and Indigenous Culture: Paulo Freire's 'Critical Consciousness' and 'Dialogue' and the Culturally Diverse Classroom," followed by an exercise in poetry writing and appreciation to exemplify pedagogy inclusive of indigenous cultures.

Pedagogy and Theatre of the Oppressed, Chapel Hill, NC

May 2006

Presenter. Led discussion of paper on "Teaching Paulo Freire to Teachers," connecting specific classroom techniques and assignments, in a hypothetical syllabus, to Freire's humanizing theories of social equity and justice.

Stockholm, Sweden, and Martinsburg, WV

1994 to 2000

Writer. As an expatriate spouse without a work permit, wrote a novel Rayshawnda's Wine; began every chapter with a poem. Wrote dissertation proposal for a $\mathrm{PhD}$ on Jacques Derrida, Michelle Foucault, and the effects of postmodernism on the canon. Studied Derrida and Foucault at length. Completed Rayshawnda's Wine in 2000. Published a poem, "Herstory," in the International Society of Poets 2004 collection.

Office of Technology Assessment, Washington, DC

1988 to 1989

Research Assistant to U.S. Congress. Researched and wrote background papers for report on rural health care. Summarized federal funding for rural health care and compared rural and urban health care. Edited parts of the final draft on quality of care. See publications:

- U.S. Congress, Office of Technology Assessment. Health care in rural America. OTA-H-434. Washington, DC: U.S. Government Printing Office, 1990.

- U.S. Congress, Office of Technology Assessment. The quality of medical care: Information for consumers. OTA-H-386. Washington, DC: U.S. Government Printing Office, June 1988.

Crowell and Moring, Washington, DC

1987 to 1988

Paralegal. Edited briefs regarding asbestos litigation. 